Portland State University

PDXScholar

Summer 8-1-2016

\title{
Information Literacy in the First Year of Higher Education: Faculty Expectations and Student Practices
}

Meredith Esther Michaud

Portland State University

Follow this and additional works at: https://pdxscholar.library.pdx.edu/open_access_etds

Part of the Educational Leadership Commons, Higher Education Commons, and the Information Literacy Commons

Let us know how access to this document benefits you.

\section{Recommended Citation}

Michaud, Meredith Esther, "Information Literacy in the First Year of Higher Education: Faculty Expectations and Student Practices" (2016). Dissertations and Theses. Paper 3079.

https://doi.org/10.15760/etd.3074

This Dissertation is brought to you for free and open access. It has been accepted for inclusion in Dissertations and Theses by an authorized administrator of PDXScholar. Please contact us if we can make this document more accessible: pdxscholar@pdx.edu. 
Information Literacy in the First Year of Higher Education:

Faculty Expectations and Student Practices

by

Meredith Esther Michaud

A dissertation submitted in partial fulfillment of the requirements for the degree of

Doctor of Education

in

Educational Leadership: Curriculum and Instruction

Dissertation Committee:

Micki M. Caskey, Chair

Dannelle Stevens

Susan Lenski

Lindsey Wilkinson

Portland State University

2016 
(C) 2016 Meredith Esther Michaud 


\begin{abstract}
Information literacy is widely acknowledged as important for student success in higher education. Information literacy is the ability to sort through a large amount of available information, decide what is useful and believable, and apply it in an effective and ethical way. Faculty members have expectations regarding information literacy for students in the first year of college, while students have information literacy practices that may or may not match those expectations. In my study, I examined the alignment of faculty member information literacy expectations and student information literacy practices, focusing on freshman students and faculty members who teach freshman students in a required general education course at a public university in the northwestern United States. Using an exploratory sequential mixed methods research design, I began my study with qualitative interviews of students and faculty members, used data from the interviews to develop a survey instrument, conducted a pilot study with the survey instrument, and used the survey instrument to administer an online quantitative survey to 106 students and 10 faculty members. The survey consisted of 42 items pertaining to student practices and faculty expectations as identified by student and faculty member interview participants. Survey data showed the percentage of faculty members expecting a practice was generally higher than the percentage of students carrying out that practice. Overall, the study findings revealed a gap between faculty expectations and student practices.
\end{abstract}




\section{Table of Contents}

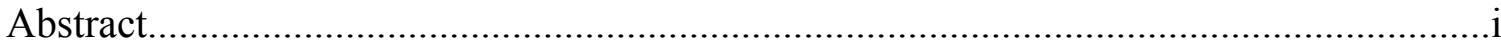

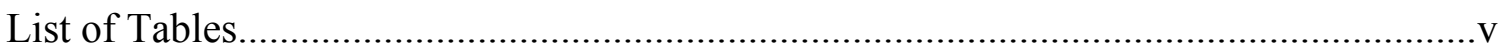

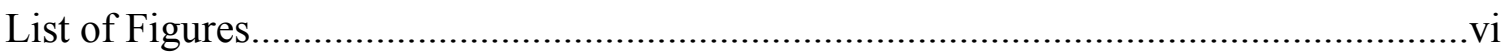

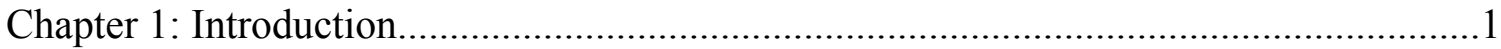

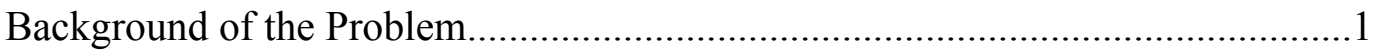

Statement of the Research Problem......................................................................5

Significance of the Research Problem...............................................................5

Presentation of Methods and Research Questions................................................

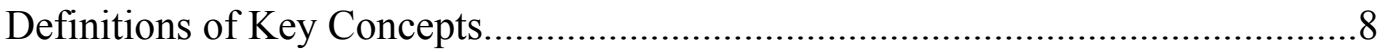

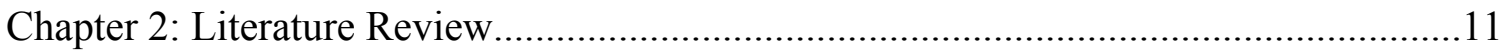

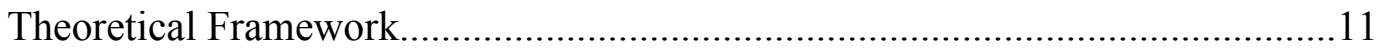

Review of the Research Literature.................................................................14

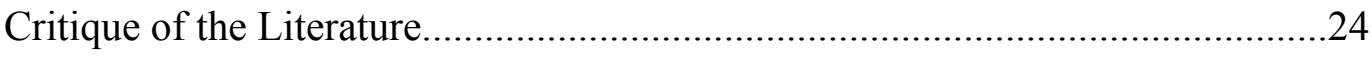

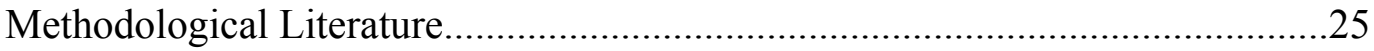

Summary of the Research Literature and Application to the Study....................28

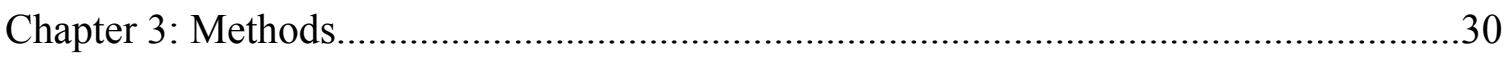

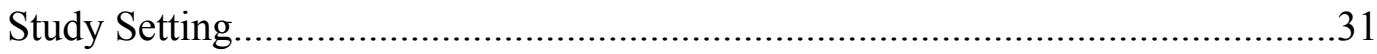

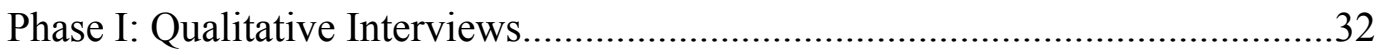

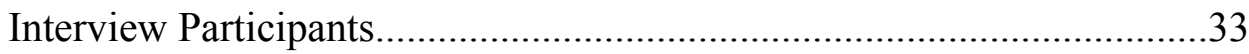

Phase 2: Quantitative Instrument Development..............................................34

Data Collection and Analysis: Qualitative Interviews............................34

Survey Instrument Development.....................................................35

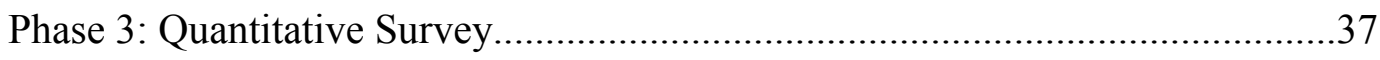

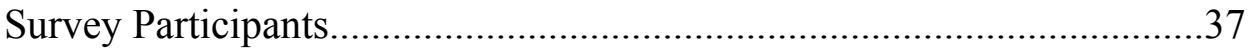

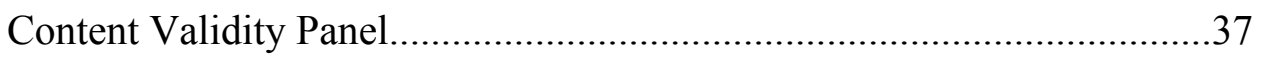

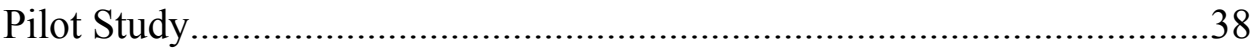

Data Collection and Analysis: Quantitative Survey...............................39

Research and Dissertation Timeline.............................................................40

Role of the Researcher............................................................................. 41

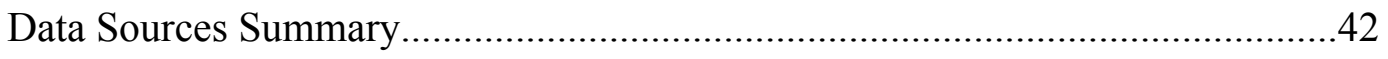

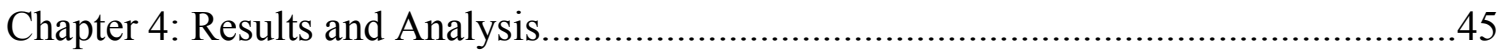

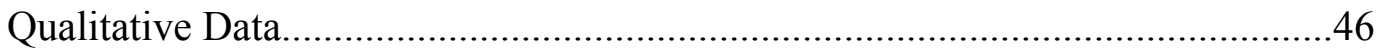


Interview Data Analysis and Results...............................................46

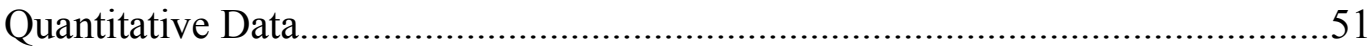

Survey Data Analysis and Results....................................................51

Student Results: Demographics and Content Items................................52

Student Results: Open-Ended Question..................................................64

Student Results: Differences Based on Demographics............................64

Faculty Results: Demographics and Content Items...............................69

Faculty Results: Open-Ended Question...............................................77

Faculty Results: Differences Based on Demographics............................78

Comparing Student and Faculty Responses.......................................... 78

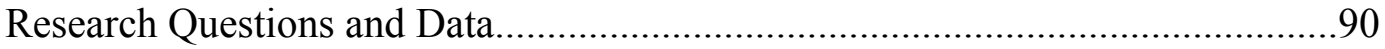

Student Practices and Faculty Expectations.........................................90

Alignment and Differences of Student Practices and Faculty

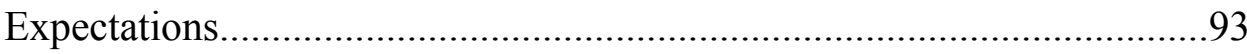

Survey Reliability...................................................................... 96

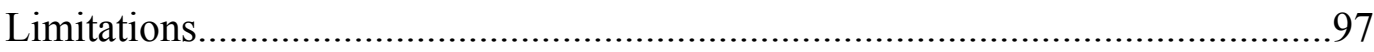

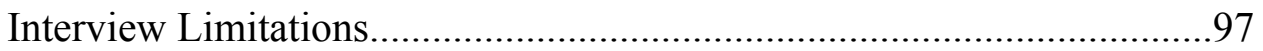

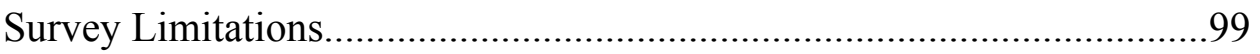

Chapter 5: Discussion and Recommendations.................................................... 101

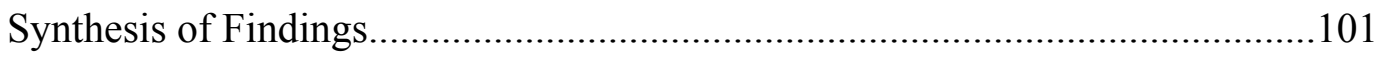

Student Demographic Differences....................................................108

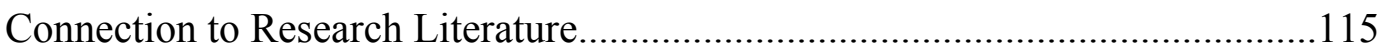

Theoretical Framework..................................................................117

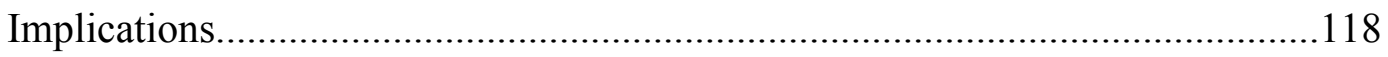

Overall Recommendations for Practice..................................................... 125

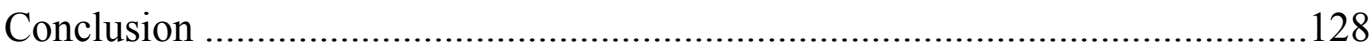

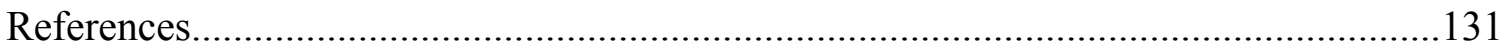

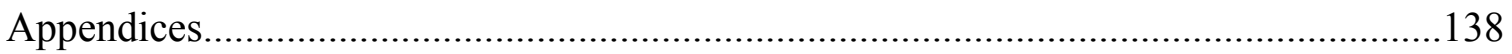

Appendix A: Interview Protocol: Students.....................................................138

Appendix B: Interview Protocol: Faculty Members........................................139

Appendix C: Student Survey Instrument.......................................................140

Appendix D: Faculty Survey Instrument........................................................144

Appendix E: Student Percentage Agreement to Content Questions Including Somewhat Agree, Agree, and Strongly Agree...............................................147 
Appendix F: Faculty Percentage Agreement to Content Questions Including Somewhat Agree, Agree, and Strongly Agree...............................................151 Appendix G: Comparison of Student and Faculty Member Responses with Levels of Agreement Calculated with Somewhat Agree, Agree, and Strongly Agree...155 


\section{List of Tables}

Table 1 Research and Dissertation Timeline 40

Table 2 Research Questions and Data Sources

Table 3 Demographics of Survey Participants Compared to Demographics of Total Population of Students Enrolled in Freshman General Education Courses......................54

Table 4 Additional Demographics of Survey Participants.

Table 5 Survey Items with Statistically Significant Differences Based on Use of a Home

Language Other than English

Table 6 Survey Items with Statistically Significant Differences Based on Student First

Generation Status.

Table 7 Demographics of Faculty Survey Participants and Population of General

Education Faculty Teaching Freshman Courses. .70

Table 8 Percentage of Students Who Agreed Compared to Percentage of Faculty Members Who Agreed to Statements about Their Practices (Students) and Expectations (Faculty Members) Regarding Finding Information....

Table 9 Percentage of Students Who Agreed Compared to Percentage of Faculty Members Who Agreed to Statements about Their Practices (Students) and Expectations (Faculty Members) Regarding Evaluating Information.

Table 10 Percentage of Students Who Agreed Compared to Percentage of Faculty Members Who Agreed to Statements about Their Practices (Students) and Expectations (Faculty Members) Regarding Using Information.... .86

Table 11 Percentage of Students Who Agreed Compared to Percentage of Faculty Members Who Agreed to Statements about Their Practices (Students) and Expectations (Faculty Members) Regarding Basic Skills.

Table 12 Percentage of Students Who Agreed Compared to Percentage of Faculty Members Who Agreed to Statements about Their Practices (Students) and Expectations (Faculty Members) Regarding Attitudes.

Table 13 Percentage of Students Who Agreed Compared to Percentage of Faculty Members Who Agreed to Statements about Their Practices (Students) and Expectations (Faculty Members) Regarding Citation.

Table 14 Freshman Student Academic Practices from Interview Data............................91 Table 15 Faculty Member Expectations for Freshman Students from Interview Data.....91

Table 16 Difference in Student and Faculty Agreement to Survey Items.........................93

Table 17 Thematic Category with Number of Items and Cronbach's $\alpha$ Reliability Statistic. 


\section{List of Figures}

Figure 1 Percentage of students who agreed with statements about their academic practices regarding finding information.

Figure 2 Percentage of students who agreed with statements about their academic practices regarding finding information (reverse structure items)

Figure 3 Percentage of students who agreed with statements about their academic practices regarding evaluating information.

Figure 4 Percentage of students who agreed with statements about their academic practices regarding using information.....

Figure 5 Percentage of students who agreed that they used APA, MLA, or another citation style, and percentage of students who agreed to any of these three content items.

Figure 6 Percentage of students who agreed with statements about their academic practices regarding basic skills.

Figure 7 Percentage of students who agreed with statements about their academic practices regarding attitudes.

Figure 8 Percentage of faculty members who agreed with statements about their expectations for students regarding finding information.

Figure 9 Percentage of faculty members who agreed with statements about their

expectations for students regarding finding information.

Figure 10 Percentage of faculty members who agreed with statements about their expectations for students regarding evaluating information.

Figure 11 Percentage of faculty members who agreed with statements about their expectations for students regarding using information.

Figure 12 Percentage of faculty members who agreed that they expected their students to use APA, MLA, or another citation style, and percentage of faculty members who agreed to any one of these three content items....

Figure 13 Percentage of faculty members who agreed with statements about their expectations for students regarding basic skills.

Figure 14 Percentage of faculty members who agreed with statements about their expectations for students regarding attitudes. 


\section{Chapter 1: Introduction}

In the past six years, I have assumed multiple roles within academia at two higher education institutions. I have been a student, student mentor, adjunct faculty member, and academic support professional. Having these roles, concurrently and overlapping, has given me an interesting perspective on higher education. Most importantly, it has offered me the opportunity to look at educational issues from more than one lens.

One educational issue that I have noticed is a certain amount of frustration expressed, by both faculty members and students, towards the actions and expectations of the other. I have often heard students share statements such as: "I don't know what the heck my teacher wants me to do here" and from teachers: "I just don't get what my students are thinking." Often student and faculty complaints have been on the topics of conducting research, finding sources, critically evaluating them, and using them appropriately in academic work, practices that fall into the category of information literacy.

This study is a response to my observations, and broadly, an attempt to answer the questions that I have heard posed by students and faculty members. When it comes to information literacy, what do teachers want? What are students doing? Most importantly, how do the answers to these two questions align or differ?

\section{Background of the Problem}

In past eras, the challenge was accessing information. Books had to be ordered, articles hunted down in library stacks or microfiche machines. Although these methods of finding information still exist, it is increasingly common to access information on the 
Internet. Many journal articles are available online and students have free access through their school's subscription. Online books are also increasingly available. Along with journals and books, other sources of information are readily available on the Internet, such as commercial, private, and government websites. Wikis and other group written information sources are also commonly accessible. How is one to sort through all these sources of information, and decide what to use, and how to use it?

In recent decades, many scholars have referred to information literacy when answering questions about dealing with information. For example, Cameron, Wise, and Lottridge (2007) described information literacy as the ability to "conduct an efficient search for information, think critically about the value of a particular piece of information, select sources that are high in quality, and then use the information to accomplish a purpose" (p. 229). In contrast to past eras when the challenge was accessing information, in most developed countries it is becoming increasingly easy to access large amounts of information. The challenge has become selecting information to use, and knowing how to use it.

The American Library Association (ALA) discussed the importance of information literacy in their seminal report. The report pointed out "most people have become dependent on others for their information" (ALA, 1989, para. 6), a situation in which they can be taken advantage of, or simply not have all the information that would allow them to make the best decision for themselves. According to the ALA, information literacy is necessary for individuals to be informed and empowered in current society. It is "central to the practice of democracy" (para. 15). DeMars, Cameron, and Erwin (2003) 
concurred, "A foundation in information literacy equips college graduates with skills essential for self-directed learning, sound decision-making, and active citizenship" (p. 253). The importance of information literacy both in college and out of college has been widely acknowledged in the literature (e. g., Bowles-Terry, 2012; Cameron et al., 2007; DeMars, Cameron, \& Erwin, 2003; Samson, 2010).

Though there is general agreement about the importance of information literacy, there are different views about what information literacy is or should be. Views may differ among scholars and librarians, tutors and academic professionals, faculty members and students. Whether ideas about information literacy are articulated or tacit, they may lead to different practices for students, and to different expectations for faculty members. The difference in faculty members' expectations and students' practices is the focus of this study. Although other people, such as librarians and peers, are involved in each student's education, faculty members are some of students' first contacts in the university setting, and their actions and beliefs have an impact on student success. Students' ability to understand faculty members' expectations impacts their experience of the university and their grades, making the student-faculty relationship an important one to examine.

When it comes to information literacy, my personal observations have led me to think that there may be a misalignment between what faculty members expect, and what students actually do. In addition, some scholars (Avdic \& Eklund, 2010; Ganley, Gilbert, \& Rosario, 2013; Leckie, 1996) have indicated that there may be a difference between faculty and student understandings of information literacy. 
With regard to information literacy, students may have a very different understanding from their instructors. In addition, they may have different information literacy practices than those that their instructors expect. Further, a difference does not necessarily indicate a deficiency. It is possible that student information literacy practices are well adapted to their information environments and are more appropriate than practices that faculty members expect.

Researchers have explored the relationship between faculty member expectations and student academic performance. Schilling and Schilling (1999) wrote about the effect of faculty expectations on student performance. They described an "expectation gap" (p. 5), or a notable difference between faculty expectations of students, and students' expectations of themselves, in regards to academic performance. Additional scholars examined the difference between student expectations and student practice. For example, Lammers, Kiesler, Curren, Cours and Connett (2005) compared faculty member expectations and student expectations for academic work. While Lammers et al.'s study does not specifically mention information literacy; it does indicate that there may be a misalignment between what faculty members expect and what students do with regard to academic work in general.

Another strong area of research literature looked at information literacy from the library science perspective. To begin with, the most seminal works on information literacy, including definitions and standards (ALA, 1989; Association of College and Research Libraries, 2000) have come from library organizations. In addition, many seminal works on information literacy are written from a library science perspective (e.g. 
Breivik \& Gee, 1989). Many scholars look at the interactions between librarians and faculty members (e.g. Smith \& Dailey, 2013) and librarians/library and students (e.g. Maughan, 2001). Although these interactions are important, I have chosen in my study and in my review of the research literature to focus on the faculty member-student interaction, rather than the library science perspective, because I am interested in exploring a phenomenon concerning faculty members and students.

\section{Statement of the Research Problem}

My experiences and my review of the literature revealed a possible misalignment between faculty expectations and student practices in information literacy. However, my own experiences and the existing literature were not strong enough to confirm the existence of this misalignment, and although some research literature supported the idea that there was a problem, it was too little to be conclusive. My study sought to answer the question about whether or not a misalignment existed between faculty expectations and student practices, and to explore the relationship between faculty expectations and student practices.

\section{Significance of the Research Problem}

Information literacy has been acknowledged as being important not only for success in college, but also beyond. Bruce (2004) expounded on the importance of information literacy for students and for society as a whole, stating, "IL is generally seen as pivotal to the pursuit of lifelong learning, and central to achieving both personal empowerment and economic development" (p. 8). In the United States and many other wealthy countries, people have access to large amounts of information not only in school, 
but after they leave. Although university may be the last place that students are asked to cite their sources or to find credible information for a letter grade, the need to be able to find credible information, to know where it came from, and to be able to apply it will likely be required professionally or personally in the future. While I was not able to find empirical research on the link between information literacy and positive outcomes throughout life, it is not a stretch of the imagination to think about the ways in which knowing how to find, evaluate, and use information can be valuable in personal and professional settings, such as finding credible information to back a work proposal, or deciding whether or not to take a new medication for a medical condition. For either of these scenarios, and many others, being able to successfully use the wealth of information that we have access to is imperative. College is not the only opportunity to learn information literacy, but it is a good opportunity, and faculty members should feel positive about supporting students' development of a mindset and skillset that they will be able to use for years to come.

Understanding the ways in which faculty and student views on information literacy concur and diverge can be useful for both parties. Access to information, and the nature of information available, have evolved rapidly over the past few decades, and faculty and students may have developed their understanding of information literacy at different time points in this evolutionary line. Furthermore, information literacy may be a part of what Smith (2004) referred to as "hidden curriculum," which is "the unwritten and unspoken rules of how to successfully navigate through the nebulous academic culture of higher education, which is essential for academic success" (p. 48). If students 
do not receive these tacit instructions on how to find information and use it in the way their instructors expect, their grades may suffer. In addition, it is possible that hidden curriculum about information literacy is more accessible to students from some backgrounds and cultures than others, leading to a lack of equity in academic success.

For students, a clear understanding of what faculty members expect them to know and do can help them to succeed in class. A number of academic expectations are not written in syllabi, or openly stated by faculty (Karp \& Bork, 2014). For example, Karp and Bork (2014) examined the role of the community college student and stated, "individuals filling the community college student role must understand when to use a given resource, as well as how to access the resource" (p. 16). It is not a stretch to imagine that knowing when and how to access resources could be a challenge for many college students, and that additional expectations for information literacy may be included in the expected role for college students.

Faculty may expect that students know and will apply specific information literacy skills, and students may not be aware of these expectations. Likewise, faculty may not be aware of how their students approach information, and which information literacy skills they usually apply. Faculty can use this knowledge to improve communication with students regarding their expectations, as well as instructional strategies and practice.

\section{Presentation of Methods and Research Questions}

In my study, I used an exploratory sequential mixed methods design (Creswell,

2014). In this mixed methods approach, also referred to as QUAL $\rightarrow$ QUANT, an initial 
qualitative method is followed by a quantitative method. My study began with interviews of faculty members. The goal of the interview phase was to explore faculty information literacy expectations and student information literacy practices, and to collect data to use for survey instrument development. In the second phase of the study, I used interview data from the first phase to create a quantitative survey instrument. In the third phase, I administered the quantitative survey instrument to freshman students and faculty members who taught freshman students at a public university in the northwestern United States. The goal of the third phase was to compare faculty expectations and student practices and to examine where they aligned and differed. I used the following research questions to guide my study:

1. What information literacy practices do faculty members expect freshman students to use?

2. What information literacy practices do freshman students use?

3. How do faculty members' information literacy expectations and students' information literacy practices align?

4. How do faculty members' information literacy expectations and students' information literacy practices differ?

\section{Definitions of Key Concepts}

Central to my study is the concept of information literacy. Information literacy is the ability "to recognize when information is needed and have the ability to locate, evaluate, and use effectively the needed information" (ALA, 1989, para. 3). The ALA further described information literate people as "those who have learned how to learn. 
They know how to learn because they know how knowledge is organized, how to find information, and how to use information in such a way that others can learn from them" (para. 3). Although the ALA definition has been critiqued and expanded on by several authors (e.g., Hillard, 2009; McDonough, 2014; Townsend, Brunetti, \& Hofer, 2011), it is still widely used and built upon in research literature.

A related concept discussed in literature and by student participants is that of critical thinking. Critical thinking as a concept has similarities to information literacy, in that it can be applied to dealing with information. Indeed, Deitering and Jameson (2008) emphasized the importance of critical thinking in higher education and its application to work in the library when they stated, "Students who seem unlikely, or worse, unwilling to engage in critical reflection about their beliefs and opinions are a source of frustration to librarians and writing instructors alike" (p. 58). Critical thinking is related to information literacy, and may even be considered to be necessary for information literacy. However, a dictionary definition of critical thinking calls it "disciplined thinking that is clear, rational, open-minded, and informed by evidence." While critical thinking is needed in order to be able to evaluate information, critical thinking does not encompass the entire definition of information literacy.

Another key aspect of my study is its focus on higher education students. Higher education refers to education that occurs after secondary school/high school. It can include college or university. According to Encyclopedia Brittanica (2015), “A university differs from a college in that it is usually larger, has a broader curriculum, and offers graduate and professional degrees in addition to undergraduate degrees" (para. 1). 
Although my study takes place at a university, some of the literature refers to college students rather than university students. Students are defined broadly as people who take courses or classes, either in a formal or informal setting, and can be of any age or demographic group. My study focuses on university students, who are people attending courses at a university, although my review of the research literature also mentions students at other institutions. More specifically, my study focuses on freshman students, who are students with 45 or less college credits, usually in their first year of studies (although there may be some exceptions to the first year, for example students who took time off during their first year and returned to college later).

Faculty members are another key group in my study. In this study, faculty members refer to people employed at a higher education institution to teach students. Faculty members can be full-time or part-time. They may have different designations within the institution, such as tenured faculty, fixed-term faculty, or adjunct faculty. Faculty members assess students during a course and issue a final grade at the end.

Through its theoretical framework, my study also touches on the concept of culture. Culture refers to the vast body of information learned from other humans, beginning at birth, and continuing for one's whole life. Barrett (1984) defined culture as "the body of learned beliefs, traditions, and guides for behavior that are shared among members of any human society" (p. 54). Culture includes beliefs about oneself, most aspects of one's surroundings, and the nature of the world. It also includes instructions on how to operate within the world and interact with others. The ways in which people interact with written and digital media are included in cultural knowledge. 


\section{Chapter 2: Literature Review}

The purpose of my study was to explore the alignment between faculty member expectations of information literacy and student information literacy practices. To give a context and guide the study, I used the theoretical framework of sociocultural theory. Next, I reviewed the research literature including the concept of information literacy, faculty expectations, and student practices.

\section{Theoretical Framework}

My study focused on the information literacy of higher education students, specifically freshmen. The purpose of this study was to examine the alignment of freshman students and faculty members in their views, expectations, and use of information literacy. To recognize the importance of the sociocultural context of information literacy, I used the theoretical framework of sociocultural theory.

Sociocultural theory is an interdisciplinary theory that posits that culture is central to human development and learning (Vygotsky, 1978). I contend that sociocultural theory is an appropriate framework for looking at information literacy because the ways in which humans create, find, use, and evaluate information are a part of culture. Psychologist Lev Vygotsky (1978), the seminal author of sociocultural theory, applied the theory to learning. Vygotsky wrote that the use of speech and tools (both aspects of culture) are central to psychological development.

One part of sociocultural theory that is useful in education is Vygotsky's (1978) "zone of proximal development" (p. 84). According to Vygotsky, the zone of proximal development describes activities that a learner is unable to do alone, but can do with the 
help of someone more experienced. I suggest that the practices of information literacy could be seen as being in the zone of proximal development because higher education students may be able to do them with the help of the instructor, or another experienced guide.

At the root of sociocultural theory is the concept of culture. Limberg, Sundin and Talja (2013) emphasized that information literacy is specific to particular cultures:

The term information literacy captures abilities of significance in contemporary society. The concept refers to purposeful information practices in a society characterized by almost limitless access to information and where information practices in digital environments shape and constitute important elements in most people's lives in our part of the world. (p. 95)

Limberg et al. drew attention to the fact that the need for information literacy is caused by the large amount of information that is available, which can be seen as the sociocultural context.

In sociocultural theory, learning takes place within a social context. Information literacy, too, is learned through social interactions, whether virtual or in person. Understanding more about these social interactions can help inform information literacy practice. For example, understanding the ways in which faculty member and student views on information literacy align, or differ, can help individuals from both of these groups carry out their tasks of teaching and learning more effectively. For students, knowing what their faculty members expect can help them to work more efficiently and have better results. Likewise, for faculty members, knowing their students' actual 
practices around information literacy can help them design activities to build on those practices.

The zone of proximal development (Vygotsky, 1978) is a part of sociocultural theory applicable to information literacy, particularly on the part of faculty. Although this might not always be the case, if students are in the role of the learner, and faculty members are in the role of the experienced guide, then faculty members are operating within the zone of proximal development. Therefore, it is important that faculty members understand students' current knowledge and practices to design activities that are within their zone of proximal development and to guide them in learning information literacy practices that are new to them.

When it comes to the zone of proximal development and learning information literacy, one might assume that faculty members are the experienced guide and students the learners. However, as I mentioned earlier, this may not be the case. In fact, students may be more experienced at certain information literacy practices than their instructors. Likewise, students may be more experienced at working with different kinds of media than their instructors. While there is a widespread assumption that younger people are more adept at working with digital media and social media, this may not apply to each situation. Furthermore, students are not always younger than faculty; they may be older or around the same age. Therefore, casting faculty in the role of guide and student in the role of learner in the zone of proximal development may not always be appropriate.

Most people have had the experience of helping learners or being helped at some point in their lives. To assist someone to learn something, it is important to understand 
what she or he currently knows and can do. Regardless of which role is assumed by a faculty member and a student, this study has the goal of increasing understanding about what the learner currently knows and can do.

\section{Review of the Research Literature}

In my review of the research literature, I begin with the concept of information literacy. The term information literacy came into use in the 1970s. Zurkowski (1974) is generally credited for the first documented use of the term information literacy. He wrote about the term in a proposal for the National Commission on Libraries and Information Science (NCLIS). Zurkowski stated, "People trained in the application of information resources to their work can be called information literates. They have learned techniques and skills for utilizing the wide range of information tools as well as primary sources in molding information solutions to their problems" (p. 6). He distinguished those who were information literate from those who were not, cautioning:

The individuals in the remaining portion of the population, while literate in the sense that they can read and write, do not have a measure for the value of information, do not have an ability to mold information to their needs, and realistically must be considered to be information illiterates. (p. 6)

In addition to introducing the term information literacy, Zurkowski also introduced the concept of needing skills to deal with the information that was available, which was, and still is, rapidly increasing due to advancements in technology. He stated, "In our age of information overabundance, being information literate means being able to find what is known or knowable on any subject" (p. 23). It is worth noting that, since Zurkowski 
raised these concerns, the amount of information available has grown substantially, and continues to grow.

Since Zurkowski's 1974 report, a substantial amount of scholarly work has been dedicated to the concept of responding to the large amount of information that is available to the general public, both in and out of an academic setting. It is outside of the scope of my dissertation to review all of these works. However, it is worth noting that not all scholars have used the same terminology to address this concept, throughout the past several decades. For example, Dubicki (2013) found that faculty did not always use the term information literacy "to describe the skills associated with the ACRL IL standards" (p. 103), referring to standards by the Association of College and Research Libraries (ACRL). Dubicki reported that $57 \%$ of respondents used the term research skills to describe the concept of information literacy, while others used "information technology, computer literacy, critical thinking, literature review, library research, and bibliographic instruction" (p. 103). A reader interested in the concept of information literacy may find it referred to with these terms throughout past and current literature. Information literacy is widely acknowledged as important by many scholars (e.g. Bowles-Terry, 2012; Cameron et al., 2007; DeMars et al., 2003; Samson, 2010). DeMars et al. (2003) presented information literacy as an important set of skills for college and for life, writing, "Finding, accessing, and determining the credibility of information are skills most of us would deem necessary for the college educated person, if not the average citizen, to possess today" (p. 253). Pushing the boundary of information literacy 
out even further than college and life, Britz (2004) discussed information poverty within a global and social justice perspective. He defined information poverty as: that situation in which individuals and communities, within a given context, do not have the requisite skills, abilities or material means to obtain efficient access to information, interpret it and apply it appropriately. It is further characterized by a lack of essential information and a poorly developed information infrastructure. (p. 194)

This underlines the importance of information literacy not just to help students get an A on their research papers, for example, but also to enable people to make use of information in their lives in general.

Information literacy is widely acknowledged as important for college and life success, though a lack of empirical evidence links information literacy skills directly to measurements of student success. However, studies that do not directly measure these two variables may still be informative. Wong and Cmor (2011) compared attendance of library instruction and GPA in sample groups totaling 8701 students at Hong Kong Baptist University. They found a correlation between higher attendance of library workshops and higher student GPA; however, this correlation was only in effect if students were offered a sufficient number of library instruction sessions. Of their results, Wong and Cmor summarized,

One or two discrete library workshops offered within a program have very little impact on overall student success as measured by final GPA. Three or four library workshops offered within a program are more likely to result in a positive 
association with GPA, with approximately half the programs offering this number of workshops showing a positive association with GPA. (p. 472)

In another investigation with similar results, Bowles-Terry (2012) conducted a mixed methods study of information literacy and student success. She looked at the GPA of 4489 graduating seniors to see if there were differences based on the level of library instruction that students had. Bowles-Terry found "a statistically significant relationship between students' GPA at graduation and upper-division library instruction" (p. 88). Because library instruction includes information literacy instruction, these studies may hint at a possible relationship between information literacy and student success, though more research focusing directly on information literacy is needed.

While Bowles-Terry (2012) looked at students' experience in the later years of college, students may face more challenges earlier in their college experience. Most people would agree that the first year of college is a time when students face many new expectations, including expectations about how they will find, evaluate, and use information. Researchers addressed information literacy expectations and practices in first-year college students. For example, Donham (2014) suggested that students face information literacy expectations during their first year of college. In her study, Donham examined readiness for college in first-year students. She looked at faculty members' expectations and assumptions regarding what first-year students know and can do. Her analyses of 41 instructor assignments from 15 higher education institutions indicated that faculty embedded expectations for students in their assignments, including expectations 
for writing and information-seeking behavior. Donham's findings reinforce the idea that faculty expect students to have information literacy skills in their first year of college.

In addition to looking at student information literacy in the first year of college, a review of the last year of secondary school may provide insight about students' skills. Smith, Given, Julien, Ouellette and DeLong (2013) investigated the transition between high school and college with regard to information literacy skills. They assessed 103 twelfth grade students using the James Madison University Information Literacy Test (Wise, Cameron, Yang, Davis, \& Russell, 2009). Smith et al. (2013) found that student results "demonstrated very poor information literacy skills" (p. 90). The students in the study scored an average of $50.7 \%$ on the assessment. When rated in terms of proficiency "none of the participants ( $\mathrm{N}=103)$ achieved advanced IL and only $20(19 \%)$ demonstrated proficient IL skill, leaving 83 (81\%) non-proficient participants" (p. 90). Smith et al. concluded, "The information literacy skills of high school students are insufficient, as evidenced by the Information Literacy Test results" (p. 94). Furthermore, they noted that students' "lack of proficiency with these tools when they are about to graduate suggests that students entering post-secondary education are not familiar or able to effectively use these tools either" (p. 95). Although some students may study or gain information literacy skills elsewhere in the interim between high school and college, it is reasonable to assume that many students enter the first year of college with about the same level of information literacy they had when they left high school.

Smith (2013) also drew attention to insufficient information literacy instruction at the secondary level. She wrote, 
INFORMATION LITERACY

Educators spend approximately 12 years with students before they graduate. Teachers have ample opportunities to provide embedded and meaningful IL instruction. However, IL instruction occurs neither consistently nor effectively. Students graduating with low or inconsistent IL proficiency enter academic, professional, and personal environments where advanced IL skills are beneficial. (p. 221)

This suspected deficit in instruction does not mean that teachers think information literacy is unimportant. Smith (2013) interviewed eight secondary school teachers, exploring their understanding of the concept of information literacy, and their perceptions of their students' skills. Participants thought that information literacy was important for their students. Smith reported:

All participants felt that IL skills were valuable for students, and all described factors that influenced their ability to offer IL instruction. There was an assumption that students would acquire IL skills as they needed them with the prevalent assumption that having a personal motivation for acquiring IL skills was a mediating factor. (p. 219)

In other words, participants thought that students would learn information literacy skills if they wanted to. This belief could be associated with less instruction on the part of teachers. As Smith asserted, "The findings suggest that teachers, presuming that students, driven by need, will eventually acquire these skills, are not taking ownership of this knowledge and imparting it onto students" (p. 220). This attitude may contribute to lower information literacy levels when students enter their first year of college. 
Other researchers echoed the idea that students will learn information literacy on their own. McGuiness (2006) studied how faculty members and librarians work together to develop information literacy. One of the themes that McGuiness identified in her study was "the pervasiveness of the belief that the extent to which students develop as information literate individuals depends almost entirely on personal interest, individual motivation, and innate ability, rather than the quality and format of the available instructional opportunities" (p. 577). In other words, faculty considered students to be responsible for their own development of information literacy. In addition, among the faculty interviewed, McGuiness identified a "sink-or-swim" mentality and an: assumption that no formal structure is necessary to encourage ILD among students-it is seen as a natural, almost intuitive process, whereby students will somehow work it out for themselves through encountering and resolving information problems through the course of their education. (p. 578) McGuiness suggested that faculty have specific information literacy expectations for students, and that they assume that students will meet those expectations on their own. Weiner (2014), who studied faculty expectations of information literacy and faculty teaching practices of information literacy, illustrated specific expectations regarding information literacy. She surveyed 299 faculty members at Purdue University regarding how their students learned about information literacy practices in five categories: defining a topic, finding resources, evaluating resources, synthesizing information, and avoiding plagiarism. Most faculty members surveyed provided instruction on information literacy practices; however, a significant percentage of faculty 
members expected students to know information literacy practices before the course ( $12 \%$ for defining topics; $43 \%$ for finding resources; $46 \%$ for avoiding plagiarism).

How are students living up to faculty expectations? Asher and Duke (2010) conducted ethnographic research with first-year college students. They found that students do not have a firm grasp on basic information literacy skills. Asher and Duke wrote, "Although students appear to be 'getting by' and finding sources, the results of this study indicate a lack of overall understanding of information literacy concepts and how to successfully apply them in their research" (p. 8). Their findings may indicate a lack of students' ability to fulfill expectations regarding information literacy.

Similarly, Gross and Latham (2012) expressed concern about students' information literacy. Based on the concern that students "tend to believe that they have above-average IL skills, when, in fact, an objective test of their ability indicates that they are below proficient in terms of their actual skills" (p. 574), Gross and Latham studied 578 first-year students at two community colleges. They compared the students' estimations of their scores on an information literacy skills assessment and their actual scores on the assessment, finding that students' estimations were on average much higher than their actual scores. In their study, Gross and Latham used the James Madison University Information Literacy Test (Cameron, Wise, \& Lottridge, 2007). Gross and Latham considered scoring less than $65 \%$ on the information literacy test belowproficient, $65 \%$ to $90 \%$ proficient, and above $90 \%$ advanced. Most students in Gross and Latham's study scored at the below-proficient level $(95.1 \%$ at one school; $80.34 \%$ at the other school), with the remaining students scoring at the proficient level. None of the 
students achieved advanced scores. This study provides an example of student deficiency in regards to information literacy skills, a deficiency that students may not be aware of, because those in the study tended to overestimate their actual skill level.

In another study that provided an example of students' lack of information literacy skills, Head (2008) explored information literacy in upper-division students majoring in humanities and social sciences. She held informal discussion groups with 13 students and surveyed 178 students at Saint Mary's College of California (SMC). In addition, she analyzed 30 research assignment handouts. Among many other findings reported in the article, Head concluded:

This study did find students lacking in information literacy competencies, especially as detailed in the ACRL standards for higher education. In particular, students in this study reported that they struggled to: (1) determine the nature and extent of information needed, and (2) evaluate information and its sources critically to incorporate selected information into their knowledge base and value system. (p. 436)

Head's study provided a student perspective on information literacy, and it is worth noting that students in the study were aware that they faced challenges with information literacy skills. In another stage of the same study, Head analyzed assignment handouts from faculty, and found that many of them did not express detailed instructions. Although the study did not examine whether faculty expressed expectations orally in class, the lack of detailed instructions for research assignments that this study found demonstrates a lack of written communication of faculty expectations for students. 
Based on the literature on faculty expectations and student practices, I think it is reasonable to ask whether or not there is a misalignment between the two. Leckie (1996) described the difference in faculty and undergraduate approaches to research, and suggested a possible lack of understanding of students by faculty. "Faculty members, no matter how concerned they are about their students, have not been undergraduates for a long time. Simply because of the passage of time, they have often forgotten what their own undergraduate experience was like" (p. 203). Due to this distance, Leckie predicted, "There is likely to be a large disjuncture between the expectations of the faculty member as the expert researcher, and the capabilities of the undergraduate as the novice researcher" (p. 203). Essentially, faculty members have advanced research skills and forget that students often do not, which could lead to a mismatch between faculty expectations and student practices.

In another study proposing that students and faculty may not completely understand one another, Avdic and Eklund (2010) examined faculty perceptions and student experience with research databases at Orëbro University in Sweden. Their goal was to compare student experience and faculty beliefs about student experience (p. 225). Based on their survey of 92 students and nine teachers, Avdic and Eklund concluded that among their participants that "there is a significant difference between the teachers' and the students' understanding of how students experience the use of the reference databases" (p. 232). Although the use of research databases is only one information literacy practice, Avdic and Eklund found a gap between faculty and student 
understandings that may exist in other populations and when looking at other information literacy practices.

Ganley, Gilbert, and Rosario (2013) also compared faculty and student understandings in an online survey that "identified how students perceived challenges with regard to research and IL, identified students' self-reported behaviours when engaging in information research and assessed students' knowledge of basic reference information, keyword use and understanding of important criteria for evaluation of online reference sites" (p. 83). When it came to the comparison of IL challenges, faculty saw many skills as more challenging than students. For example, $39.5 \%$ of students said that narrowing down topics was most often or always challenging, while $69.2 \%$ of faculty said that this skill was most often or always challenging. In another example, $25.9 \%$ of students said that determining credibility of resources was most often or always challenging, while $60.8 \%$ of faculty said that this skill was most often or always challenging. One interesting aspect of this study is that faculty saw information literacy skills as more challenging than students, indicating that students and faculty do not share the same understandings regarding many information literacy skills.

\section{Critique of the Research Literature}

As I mentioned earlier, one major weaknesses of the research literature about information literacy is the lack of empirical evidence linking it to student success. Although the link between information literacy and student success would be logistically complex to pursue through systematic research, it would be a worthwhile endeavor to 
take on, because it would strengthen the work of other researchers investigating information literacy.

In addition, the research literature overall explored faculty expectations and student practices regarding information literacy separately, looking at faculty expectations in some studies, and student practices in others. Some studies compared different aspects of faculty and student experience; for example, Avdic and Eklund's (2010) comparison of the problems that students experience when using databases and the problems that professors believe the students experience. In addition, Ganley et al. (2013) compared student and faculty understandings of information literacy. However, I did not find any studies that focused on comparing information literacy faculty expectations and information literacy student practices. I argue that this comparison could be an important addition to the body of research literature on information literacy.

\section{Methodological Literature}

To explore these possible differences between faculty member expectations and student practices I used a mixed methods exploratory design to conduct interviews and surveys. Creswell (2014) defined mixed methods research as:

An approach to inquiry involving collecting both quantitative and qualitative data, integrating the two forms of data, and using distinct designs that may involve philosophical assumptions and theoretical frameworks. The core assumption of this form of inquiry is that the combination of qualitative and quantitative approaches provides a more complete understanding of a research problem than either approach alone. (p. 4) 
In the case of this study, I used the qualitative method of interviewing and the quantitative method of surveying in combination to answer the research questions.

The qualitative data collection method to be used, interviewing, is essentially asking people questions. Vogt, Gardner, and Haeffele (2012) described the method as one with a long tradition. They stated, "Asking questions of others and paying attention to their answers is probably nearly as ancient as the invention of language" (p. 31). Despite the long tradition behind it, Vogt et al. emphasized the preparation involved in conducting an interview as a part of scholarly research, and the importance of having an intentional design. In addition, Vogt et al. provided guidance about selecting participants to interview, and on following ethical guidelines while using this data collection method.

Kvale (2007) noted that interviewing has a long history, dating back to ancient Greece. He emphasized the need to have a systematic approach to interviewing. Kvale presented an in-depth, systematic process for doing interview research, consisting of seven stages: (a) thematizing, (b) designing, (c) interviewing, (d) transcribing, (e) analyzing, (f) verifying, and (g) reporting. Kvale provided details about each of these seven stages that were useful for having a thoughtful and well-planned approach to interviewing.

Surveying, the quantitative method that I used, is similar to interviewing in that it involves asking people questions. However, surveying generally aims to ask more people less questions than does interviewing. Rea and Parker (2014) stated, "Survey research involves soliciting self-reported verbal information from people about themselves. The ultimate goal of sample survey research is to allow researchers to generalize about a large 
population by studying only a small portion of that population" (p. 4). While interviews attempt to capture the experience of one particular person or a small group of people, surveying is concerned with understanding the experience of a population, and doing so by asking questions of a sample of that population.

My study was guided by the pragmatic approach (Morgan, 2007), which focuses on the practical use of research methods and seeks to acknowledge what researchers actually do during the research process. Three primary concepts undergird the pragmatic approach: abduction, intersubjectivity, and transferability. Morgan (2007) pointed out that while students are taught that induction and deduction are two distinct ways of going about research, actual research, whether academic or a part of daily life must use both of these methods alternately. He referred to this process as abduction, which "moves back and forth between induction and deduction-first converting observations into theories and then assessing those theories through action" (p. 71). Based on personal observations and reading, I theorized the existence of a misalignment between faculty expectations and student practices and proposed to take action by studying the matter further. Data collected in my study has the potential to lead to a new set of ideas to be assessed by action.

Pragmatism's second concept, intersubjectivity, refers to a rejection of complete subjectivity or objectivity (Morgan, 2007). Instead, "any practicing researcher has to work back and forth between various frames of reference" (p. 71). While my study aspired to objectivity in some ways, such as in the intentional and disciplined application of research methods and research protocols, it was also subjective, because my personal 
experiences and perspectives were present throughout the study. Finally, the third concept in pragmatism, transferability, refers to the "pragmatic focus on what people can do with the knowledge they produce and not on abstract arguments about the possibility or impossibility of generalizability" (p. 72). While my research project may not be generalizable to all faculty members and students on all college campuses, some of my research findings may be useful to faculty members and students or may inspire ideas for improving practice.

\section{Summary of the Research Literature and Application to the Study}

My review of research literature began with sociocultural theory (Vygotsky, 1978 ) as a theoretical framework for my study. I suggested that sociocultural theory would support my study because the theory positions learning within a social context, and my study investigates that social context. Next, I reviewed the report that is credited with the first appearance of the term information literacy in the 1970s (Zurkowski, 1974) and research literature that supported the importance of information literacy (Bowles-Terry, 2012; Britz, 2004; Cameron et al., 2007; DeMars et al., 2003; Samson, 2010). After noting the lack of empirical studies connecting student success to information literacy, I reviewed some studies that indicated a possible connection (Bowles-Terry, 2012; Wong \& Cmor, 2011).

My review of the research literature centered on faculty members' information literacy expectations and student information literacy practices. I referred to studies of students in secondary school that demonstrated that at this level, students did not have the skills to meet those faculty expectations (Smith, 2013; Smith et al., 2013). I suggested 
that most students' information literacy levels entering college would be about the same as they were in their last year of secondary school. I also reviewed literature regarding student information literacy practices (Asher \& Duke, 2010; Bowles-Terry, 2012; Gross \& Latham, 2012; Wong \& Cmor, 2011) and literature regarding faculty expectations about information literacy (Donham, 2014; McGuiness, 2006; Weiner, 2014). Overall, the literature indicated a potential misalignment between student practices and faculty expectations when it comes to information literacy. I describe my plan for studying this possible misalignment in Chapter 3. 


\section{Chapter 3: Methods}

The purpose of this study was to examine the alignment of higher education students' information literacy practices and faculty members' information literacy expectations. To examine the alignment, I used a mixed methods design. Creswell (2014) defined a mixed methods design as the "integration of qualitative and quantitative research and data" (p. 14). In my view, quantitative and qualitative methods tell two different kinds of stories: qualitative tells about individuals and their personal experiences, while quantitative tells a story about trends in populations. I contend that a phenomenon can be understood more fully when considering both how the phenomenon affects populations and how it affects individuals within the populations. To this end, I used both quantitative and qualitative methods to gain a fuller understanding of how student information literacy practices and faculty information literacy expectations compared.

Specifically, I used an exploratory sequential mixed methods design, in which "the researcher first begins by exploring with qualitative data and analysis, and then uses the findings in a second quantitative phase" (Creswell, 2014, p. 226). In this study, I followed the exploratory mixed methods design by conducting qualitative interviews, analyzing the interview data, and using the results to build a quantitative survey, administering the survey, and analyzing the survey results. This exploratory mixed methods design is sometimes referred to as a QUAL $\rightarrow$ QUAN design, because the first step of the design is a qualitative data collection and analysis method, followed by a quantitative data collection and analysis method. In my study, one of the main purposes 
of the qualitative method was to gather data to construct a survey to use with the subsequent quantitative method. I used the following research questions to guide my study:

1. What information literacy practices do faculty members expect freshman students to use?

2. What information literacy practices do freshman students use?

3. How do faculty members' information literacy expectations and students' information literacy practices align?

4. How do faculty members' information literacy expectations and students' information literacy practices differ?

I pursued these questions in three phases, which I explain in the subsequent sections.

\section{Study Setting}

I conducted my study at a public university located in the northwest United States. My study focused on freshman students (i.e., undergraduates with less than 45 credits) and faculty members teaching freshman students. I obtained permission to invite students and faculty members from the general education department at the university. In this university, most freshmen are required to take courses through the general education department in which I conducted my study, with the exception of transfer students and a small number of students who participate in general education through a separate department. In the general education department in which I conducted my study, freshman-required courses run through the entire academic year, and are interdisciplinary 
and organized around a theme. Additional goals of these yearlong freshman courses are to encourage critical thinking and lifelong learning.

\section{Phase I: Qualitative Interviews}

In the qualitative phase, I conducted interviews with six freshman students and six faculty members who taught freshman students. I used purposive sampling to select the participants. In purposive sampling, potential participants are selected from a pool of participants from the population that is the focus of research (Vogt et al., 2012). For my study, the two target populations were freshman college students, and faculty members who teach freshman students. I recruited student and faculty member participants from a general education department at the university. I sent an email invitation to faculty members who teach freshmen in the general education department and to freshman students who take courses in the general education department, asking the students and faculty members to participate in interviews. Six members of each population consented to participate in the interviews. I conducted all 12 interviews by phone and audio recorded the interviews digitally using my cell phone. I conducted all of the interviews at my home office. The time of the day for each interview varied in response to the participants' and my schedules. The interview protocol for students and faculty members can be found in Appendices A and B.

One of the goals of the interviews was to elicit information from students and faculty partners about their expectations and practices around information literacy. Information literacy has been defined thoroughly, and its standards have been described at length and in detail by the ACRL (2000). The intention of the interviews was to hear 
which practices and expectations were mentioned by students and faculty members, rather than to ask about each standard as detailed by the ACRL. To guide students and faculty members towards the field of information literacy, I shared the ALA (1989) definition with participants in each interview. However, my intention was to find out what topics came to mind for students and faculty members, with the hope that hearing the ALA definition would bring to the forefront of my study those information literacy practices and expectations that were most frequently a part of daily practices for students and faculty members.

\section{Interview Participants}

Six students and six faculty members participated in the interview phase of my study. I asked the student participants whether they were 18 years or older, because I needed to provide students under 18 with an additional consent form for a parent or guardian. All of the student participants were at least 18 or older and were freshmen at the university. I did not ask student participants for additional demographic information such as age or gender. All of the faculty member participants taught freshman students at the university. As with the students, I did not ask faculty member participants to provide any demographic information. I chose not to ask any interview participants for demographic information. Instead, my focus for the interviews was to gain information about student practices and faculty expectations related to information literacy. 


\section{Phase 2: Quantitative Instrument Development}

In the second phase of the study, I analyzed the interview data. I used the results of the qualitative interview data to develop the quantitative survey instrument for use in the final phase of the study.

\section{Data Collection and Analysis: Qualitative Interviews}

My data collection process and analysis process overlapped, as I began to transcribe and analyze the first few interviews before completing all 12 interviews. For my data analysis, I followed Creswell's (2014) recommended guidelines, transcribing the interviews, reading the interview transcripts, and then coding the data.

I also followed Creswell's (2014) recommended guidelines when coding my interview data. According to Creswell, codes can be developed in three ways: (a) by designating the codes in advance, (b) by developing codes directly from the data, or (c) by a combination of these two methods. He stated, "The traditional approach in the social sciences is to allow the codes to emerge during the data analysis" (p. 199), which I determined to mean that the researcher identifies the codes from the data. Using this traditional approach to coding, I started developing codes while reading and transcribing the participants' interview responses. During the transcription process, I gained a general understanding of the data and wrote memos to myself after transcription was complete. After transcribing each interview, I read the transcription, this time making notes of themes in the margins, and underlining phrases and sentences that seemed particularly meaningful or illustrative of a theme. Then, I made a list of all of the themes I had noted, and refined them into a list of codes, combining categories where appropriate and 
creating new codes when a more precise category was necessary. Next, I read the transcribed interviews again and coded them according to the list of codes. I created a single code list for both the student and faculty member interviews, rather than designating separate codes for each group of participant interviews.

\section{Survey Instrument Development}

After the interviews were completed, transcribed, and coded, I used the list of codes to develop survey items. I developed 42 survey items as statements that had a parallel form for faculty members and students (e.g., I go to the university library/I expect my students to go to the university library), so that it would be possible to compare student and faculty responses to these items when I analyzed the survey. For these 42 content items, I used a Likert-scale structure. Likert-scale items generally have the format of a statement, followed by a scale of responses, such as always, often, sometimes, rarely, never (Vogt et al., 2012). For these 42 survey content items, I had six possible responses: strongly agree, agree, somewhat agree, somewhat disagree, disagree, and strongly disagree. I also included one open-ended question about whether students had any additional comments about their academic practices. The corresponding item on the faculty member survey was about whether faculty members had anything else to add about their expectations for students.

In addition, I included demographic items in the student and faculty survey instruments. The purpose of the demographic items was to make it possible to compare responses to demographic items with the 42 content items to see if there were significant differences in responses to the content items based on demographic characteristics. I 
included 12 demographic items for students. All 12 student demographic items were multiple-choice, and five of these demographic items had an option for students to enter a short text response to explain either a "yes" or "other" choice. I included 11 multiplechoice demographic items for faculty members, six of which had options for short text responses. A full copy of the student survey instrument can be found in Appendix C, and the full survey instrument for faculty members can be found in Appendix D.

Next, I constructed two separate surveys for students and faculty members using Qualtrics, an online survey platform. The landing page for each survey was an informed consent form, in which participants had to confirm that they had read the form, and had to give their consent before continuing to any further items in the study.

Alignment with ACRL standards. After coding the interviews, I had a list of 42 content items for my survey. I mapped these items to the ACRL information literacy standards (2000) and found that my content items directly addressed a few items from each of the five ACRL standards. I noted that in their interviews students or faculty members did not articulate many of the subtopics of the ACRL standards. On the other hand, students and faculty members expressed practices and expectations that were not addressed by the ACRL standards. I decided to use all student practices and faculty expectations that were articulated by interview participants, regardless of whether or not they were covered by the ACRL standards. I made this decision to acknowledge the importance of the participants' experience. Without necessarily knowing or reading about the standards of information literacy (although I did read them the definition), participants brought up subjects that they felt were important to disclose. Therefore, in 
my opinion, including all of these items in my research would make it the most useful to other students and faculty members.

\section{Phase 3: Quantitative Survey}

For the quantitative phase of the mixed methods study, I used a cross-sectional survey design, administering an online survey through Qualtrics. My purposes for a cross-sectional design were to have as many participants as possible, and to capture a picture of their expectations and practices at one point in time.

\section{Survey Participants}

I conducted the quantitative part of my study at the same northwest public university that was the setting for the qualitative part of my study. For the surveys, I invited students enrolled in courses in a general education department, and faculty members who taught in that department. I recruited two groups of participants: freshman students, and faculty members who taught freshman students. I recruited both groups through the general education department. For students, I recruited from those who were registered in a required freshman general education course. Because a small number of sophomores, juniors, and seniors take these freshman-required education courses, I also filtered out sophomores, juniors, and seniors before sending out email invitations for the survey. For faculty members, I recruited faculty members who taught freshmen in the general education department.

\section{Content Validity Panel}

I wanted to ensure that my survey was investigating what I intended to investigate, or in other words, had validity. Validity in a survey instrument refers to 
"how well it measures what it sets out to measure" (Litwin, 1995, p. 33). I chose to examine specifically content validity, which Litwin (1995) defined as "a subjective measure of how appropriate the items seem to a set of reviewers who have some knowledge of the subject matter" (p. 35). To examine content validity, I assembled a panel of four academic professionals and faculty members who had expertise in information literacy, in working with undergraduate students, or in both of these fields. I sent my survey instruments to the content validity panel for review, and incorporated some minor changes to the survey instrument based on their feedback.

\section{Pilot Study}

As an additional preparation for the implementation of the survey, I conducted a pilot study. In order to not draw away potential participants from my full study, I recruited faculty members who taught required courses for sophomores in the same general education department where I conducted qualitative and quantitative phases of my survey. Two faculty members who taught sophomore students consented to take part in the study by taking the faculty member survey themselves, and by providing the link to the student survey to the students in their courses and asking the students to take part in the pilot study. I conducted the pilot survey in October 2015. Forty-nine students took the student survey, and two faculty members took the faculty member survey. I asked students and faculty members for additional comments about the content and demographics. While students and faculty members made a few comments, none of these comments identified major concerns with the survey instrument. 
INFORMATION LITERACY

\section{Data Collection and Analysis: Quantitative Survey}

Through the university general education department, I obtained lists of freshman students attending required freshman courses, and faculty members who taught freshman students. I sent an email invitation to students and faculty members on these lists. The email invitation included a short description of my study and the link to the survey. I sent the first email invitation to 1487 students and 40 faculty members on November 17 , 2015. I sent a follow-up reminder email to the same lists of students and faculty members on December 1, 2015. I closed the survey to data collection on December 9, 2015, after it had been open for approximately three weeks.

As an incentive to complete the survey, I offered five $\$ 10$ gift certificates to a local bookstore. After submitting the survey, participants were directed to another, separate online survey where they could enter their email addresses if they desired to be entered into the drawing for a gift certificate. I numbered the responses to the separate online gift certificate survey, and then used an online random number generator to select five participants to receive the gift certificate, and emailed the winning participants the link to the electronic certificate.

My data set included responses from 106 students and 10 faculty members, after I eliminated surveys without any data. Two of the students identified as sophomores; however, because I filtered all potential participants to make sure that they classified as freshmen by credit hours before sending out the email invitations, I decided to include data from these two students in the analysis. 
I conducted two main types of analyses: frequency tables; and contingency tables, using IBM's Statistical Package for the Social Sciences (SPSS). I describe these analyses and results in Chapter 4.

\section{Research and Dissertation Timeline}

From the first stage of proposal defense to the final stage of dissertation defense, my study took place between March 2015 and June 2016. An outline of the steps and the months and years in which they were completed is shown in Table 1.

Table 1

Research and Dissertation Timeline

\begin{tabular}{lll}
\hline Phase & Date & Action \\
\hline Proposal & March 2015 & Defend dissertation proposal \\
& March 2015 & Submit IRB proposal \\
April 2015 & Receive IRB approval \\
Research Phase 1 & April-May 2015 & $\begin{array}{l}\text { Send email invitations for } \\
\text { interviews }\end{array}$ \\
& May-August 2015 & Conduct interviews \\
Research Phase 2 & June-October 2015 & Transcribe interviews \\
& & Analyze interview data \\
& & Develop survey instrument \\
Research Phase 3 & November 2015 & Send emails with link to \\
& survey \\
& November-December 2015 & Collect survey data \\
& January-April 2015 & Analyze survey data \\
& January-May 2016 & Write dissertation \\
& June 2016 & Defend dissertation \\
\hline
\end{tabular}




\section{Role of the Researcher}

I introduced my study in the first chapter by describing my overlapping roles within academia that led me to become interested in the alignment of faculty expectations and student practices in information literacy. However, it is important to acknowledge that I am not an undergraduate student, and my multiple roles have generally involved teaching and assisting students with information literacy skills. Therefore, I have more experience that helps me to understand the faculty member experience, rather than the student experience. I tried to keep my imbalance towards understanding of the faculty member experience in mind throughout all the stages of my study.

In the interview phase of the study, I saw my role as a researcher as creating meaning with the participants, not just from the participants' words. Kvale (2007) emphasized the exchange between research and participant in research interviews. He wrote, "The research interview is an inter-view where knowledge is constructed in the inter-action between the interviewer and the interviewee" (p. 1). Kvale's statement draws attention to the active part that the researcher plays in an interview- not merely asking questions and recording the responses, but taking part in a conversation with the participant. In my student and faculty member interviews, I engaged in conversation with the participants, in addition to asking questions and having the participant answer those questions. For example, one of the student participants was curious about my graduate program, and I engaged in some conversation about the program with him after our interview was finished. 
It is important to be aware that the conversation between interviewer and participants has power dynamics that may not be present in a day-to-day conversation. Kvale (2007) stated that in an interview

A conversation has a structure and purpose determined by one party-the interviewer. It is a professional interaction, which goes beyond the spontaneous exchange of views as in everyday conversation and becomes a careful questioning and listening approach with the purpose of obtaining thoroughly tested knowledge. (p. 7)

In other words, in an interview, the researcher controls the conversation. I believe that there is an element of choice in how closely they control it, and this could be a delicate balance. In my interviews, I controlled the conversation by asking participants a list of questions from my interview protocol. However, when participants offered additional information that was outside the scope of the question, I tried to find out more about their thoughts, rather than immediately steering the participants back to the interview protocol. My goal was to encourage participants to express what they thought was important, regarding academic practices (for freshman students) and expectations (for faculty members), even if the conversation sometimes went outside my own expectations for what directions participants' answers might take, or what topics might be covered.

\section{Data Sources Summary}

In Table 2, I show my plan to answer the research questions for my study, using my two data sources: qualitative interviews and quantitative surveys. 
INFORMATION LITERACY

Table 2

Research Questions and Data Sources

Research Question Data Source

1. What information literacy practices do faculty members Interviews and Surveys expect freshman students to use?

2. What information literacy practices do freshman Interviews and Surveys students use?

3. How do faculty members' information literacy Surveys expectations and students' information literacy practices align?

4. How do faculty members' information literacy Surveys expectations and students' information literacy practices differ?

To answer Research Question 1 (What information literacy practices do faculty members expect freshman students to use?) and Research Question 2 (What information literacy practices do freshman students use?) I used data from the qualitative interviews of freshman students and faculty members and data from the quantitative surveys of freshman students and faculty members. To answer Research Questions 3 and 4 (How do faculty members' information literacy expectations and students' information literacy practices align/differ?) I primarily used survey data from the surveys of freshman students and faculty members. Again, one of the strengths of mixed methods research is that it draws on multiple sources of data, using both numbers and words to understand the phenomenon it investigates. It was my intention to use both qualitative interviews and a quantitative survey to give me a fuller picture of information literacy practices among students and information literacy expectations among faculty members than I might have if I used only one of these methods. In addition to using the qualitative interviews as a 
data source, one of my main reasons for collecting data through interviews was to develop a survey instrument that contained student practices and faculty expectations, as expressed by student and faculty member participants.

In the following chapter, I share the results of my data analysis for the qualitative interviews and the quantitative survey, and discuss how data from both sources helps to answer my research questions. 


\section{Chapter 4: Results and Analysis}

The research problem addressed by my study is whether alignment exists between faculty information literacy expectations and student information literacy practices in freshman college students. To find out more about my research problem, I conducted an exploratory sequential mixed methods study (Creswell, 2014). The exploratory sequential mixed methods involved a qualitative phase, in which I conducted phone interviews of students and faculty members, then a development phase in which I used interview data to construct a survey instrument for students and faculty members, followed by a quantitative phase, in which I administered an online survey to students and faculty members.

The following four research questions guided my study:

1. What information literacy practices do faculty members expect freshman students to use?

2. What information literacy practices do freshman students use?

3. How do faculty members' information literacy expectations and students' information literacy practices align?

4. How do faculty members' information literacy expectations and students' information literacy practices differ?

In this chapter, I share the data analysis and results of the study, and explain how the results help to answer the research questions. First, I write about the qualitative data, which was obtained through interviews, and its analysis and results. Second, I report the quantitative data, obtained through an online survey, and its analysis and results. 


\section{Qualitative Data}

Following the exploratory sequential mixed methods model (Creswell, 2014), I first collected qualitative data through interviews. The purpose of collecting qualitative data was twofold. First, it allowed me to hear about the experiences of individual students and faculty members on the topic of information literacy. Second, and most importantly for my study, the qualitative interviews allowed me to gather data about student practices and faculty member expectations, data which I used to create a survey instrument for the quantitative phase of the study.

\section{Interview Data Analysis and Results}

I interviewed 12 participants by phone during spring quarter and summer quarter 2015. Of these participants, six were faculty members, and six were students. The phone interviews ranged in length from 10 minutes to 30 minutes, approximately. I digitally audio recorded and transcribed each interview. After transcribing was complete, I read each interview and identified thematic codes related to information literacy practices and expectations. I compiled a list of student practices and a list of faculty expectations, using data from all 12 interviews to make a code list. In other words, data from student interviews contributed to the list of faculty expectations, and vice versa. I used the lists of information literacy practices and expectations to create my survey instrument, a process that has been detailed in the previous chapter.

In addition to coding the interviews, I read through them to identify quotes and phrases that were particularly meaningful because they illustrated student practices or faculty expectations, or because they expressed a student or faculty member perspective 
or experience that I thought would be useful for stakeholders (i.e. students, faculty members, academic professionals) to hear about. I will first share the prominent ideas and themes from the student interviews, followed by the faculty interviews.

Student interviews. I interviewed six freshman students. All freshman student participants were 18 years or older. I did not ask interview participants for additional demographic details such as gender or race/ethnicity. Although my time talking with the students was limited to 10-20 minutes, it was my impression that all of the students I interviewed seemed to have intermediate to advanced research and information literacy skills, and to be familiar with many concepts of information literacy, including searching for information, evaluating information, and citing information sources. Overall, these freshman students reported that they used a wide range of sources, from Internet sites like Google and Wikipedia, to university databases, to asking experts in the field. Students talked about where they found information for use in their academic work. Three students mentioned Google Scholar specifically as a place where they started their information searches, while one said that she went directly to the larger web (i.e., Google). One student said that she used the databases available through the university library website, while two others said they did not understand or were not sufficiently instructed on how to use those websites.

In addition, the freshman students talked about how they determined credibility. One student said that she looked up authors to find out more about them, saying "I just like to look at who the publisher is, and the authors, and make sure that they're as credible as possible." In addition, two students expressed that they were not able to trust 
Wikipedia. As one stated, "if it's Wikipedia, probably not the best thing to use in your research paper." Students also talked about how they used information, in terms of documenting sources, with four of the students saying that they used MLA (Modern Language Association) citation style. However, when it came to using sources, one student said that she was not entirely clear about what plagiarism was, and wished that there were more instruction about how to avoid it, saying that she wanted to know "more of how to cite resources, because sometimes there are gray areas, because I didn't know it would be plagiarizing..." Another student stated that she would like more instruction on how to do research, and how to find information when a topic was difficult to research. She would prefer that instructors taught basic skills, even if some students already knew those skills. She stated, “In college...when I don't know something, I feel embarrassed to ask, or to even ask another student, because I think that they're smarter than me.” In other words, this student had concerns about disclosing areas of academic weakness.

One interesting point that a student brought up was an observation that students came into college lacking passion for academic work, and merely did what they thought their instructors wanted. She said, "A lot of the time...my experience is, in newly entered college students, that most kids are just trying to appease their professors," thus expressing concern in the attitude towards academics that she observed in her peers.

With regard to applying information literacy outside of college, one of the students expressed:

I feel like what we're doing here isn't just a way of knowing how to write papers for your job, I feel like it's how you can connect ideas, as far as science, and 
medical fields, and other current politics that are going on, and connecting them, and understanding what's true, what's not true. Because if you're believing everything that's coming in, with a lot of information that's coming through a web page, right now you're going to suffer, because you're hindered by this gullibility that you have.

I interpreted this statement as acknowledgement of the importance of information literacy for life in general, outside of college.

Faculty interviews. Of the six faculty members I interviewed, three noted that they did not have expectations for students who were just entering their courses because they recognized that there would be a wide range of backgrounds and previous preparation. As one stated, "You really have to start from the beginning, because most of them have never written a research paper...as hard as it is to believe, many of them tell me they've never read a book before." Two of these faculty members talked about No Child Left Behind and a focus on standardized testing as a reason that students were arriving in college with less information literacy preparation than they could have, stating that this lack of preparation was a result of not having librarians in high school. One of the faculty members talked about the need to be clear between expectations in high school and expectations in college, and another mentioned the different expectations for research and writing in high school as opposed to college. Four of the faculty member participants mentioned the problem of students going to Wikipedia as a go-to or scholarly source, with one of the faculty members observing that when their students need 
information “Oh, it's Wikipedia right away,” expressing concern that students use Wikipedia for their assignments rather than a scholarly source, as required.

One interesting observation made by a faculty member was that although her students had experience with technology that did not necessarily mean that they could use it well. She stated, "It's true that students are comfortable with technology, but that doesn't mean that they're using it as effectively as they could...I don't know that those skills are transferring as much to their information literacy." Another faculty member was surprised that students were familiar with technology, but did not apply that familiarity to their work.

All of the faculty members brought up the fact that they worked with the library to help students develop research skills, and emphasized the importance of working with a librarian or having library sessions for their students. A faculty member stated, "One of my tasks is to...say hey, this is the library, this is what it does, this is why you shouldn't think it's creepy or be afraid of it." Another said, "In all of my classes, I usually have library sessions where I work with a librarian, and they have my assignment," explaining how the librarian tailored the session to the course assignment.

Faculty members also referenced persistence and tenacity. One of the faculty members spoke of their expectation that students go beyond just the first page of search results. Speaking about persistence, another faculty member said, "One of the hardest things to teach...you just got to keep going. And you may never find the perfect thing, but then you have to let what you found take you in whatever direction it's taking you," referring to the messy, non-linear process of doing research and the mindset of 
persistency that is necessary to carry it out. Additionally, two of the faculty members mentioned the attribute of curiosity, with one of the faculty members saying that she encourages her students to tap into it, and the other saying that she tries to "light up" curiosity in her students, a practice that she described as difficult.

In addition to these themes and ideas, faculty members and students also expressed a number of faculty expectations and student practices throughout the interviews. As I described in the previous chapter, I used these themes and ideas to develop codes for the student and faculty member survey instruments that I used in the quantitative phase of the study.

\section{Quantitative Data}

I surveyed students and faculty members using an online survey to collect quantitative data. I developed the survey instrument based on the results of my qualitative interviews. To summarize the development process, after student and faculty interviews were completed, I transcribed the interviews, and coded their content, as described in the previous chapter, using the final list of codes to create the survey instrument.

\section{Survey Data Analysis and Results}

To understand the survey analysis and results, it may be helpful to know that my survey instrument consisted of two corresponding surveys: one for faculty and one for students. Each of these surveys had 43 content items related to information literacy practices and expectations. The first 42 of the 43 content items asked participants to use

a Likert scale (strongly agree, agree, somewhat agree, somewhat disagree, disagree, 
strongly disagree) to indicate their level of agreement with given statements. The last question was an open-ended question asking students for additional comments on their academic practices, and faculty members for additional comments on their expectations for students. The content items on the student survey and faculty survey were in parallel forms, so that student and faculty responses could be compared. In addition, the student survey had 12 demographic items, and the faculty survey had 11 demographic items. The full version of both survey instruments can be found in Appendices C and D.

I used IBM's Statistical Package for the Social Sciences (SPSS) to analyze the survey data. First, I produced frequency tables, which show the number and percentage of students and faculty members who chose each response, and compared the student and faculty member responses to their corresponding content items. Second, I produced contingency tables, which compare categorical variables, to see if there were any associations between student demographic items and student content item responses. I detail these analyses in the following section. I share the student analyses and results, followed by the faculty analyses and results, and I then compare student and faculty results.

\section{Student Results: Demographics and Content Items}

In this section, I describe the student participants' demographic characteristics, comparing the student participants to the population of all freshman students enrolled in the general education department. Then, I share tables that show the percentage of student agreement to the content items (the 42 questions about student practices). 
Student demographics. The sample of 106 student survey participants differed in several ways from the entire population of freshman students enrolled in the general education program. The latest data available for the entire population of freshman students enrolled in the general education program at the time of writing was from fall 2014 (personal email correspondence from general education department staff member). For the sake of comparison, it is important to note that while the student survey population was all freshmen, the entire population of students enrolled in freshman general education was $94 \%$ freshmen, and $6 \%$ sophomores, juniors, and seniors. However, the entire population of students enrolled in required freshman general education courses was still the closest available comparison group to the group of student participants. Table 3 shows the demographics that were available to be compared between my group of student survey participants and the entire group of students enrolled in freshman general education classes.

With regard to gender, $71.7 \%$ of survey participants identified as female, $25.5 \%$ as male, and $2.8 \%$ as other, compared to the 2014 total population, of which $44 \%$ identified as male, $55 \%$ identified as female, and $1 \%$ did not identify a gender. Therefore, female students were heavily overrepresented in the sample.

When it came to race/ethnicity, among survey participants $14.2 \%$ identified as Asian/Pacific Islander, $1.9 \%$ as Black/African American, $14.2 \%$ as Hispanic/Latino, $64.2 \%$ as White/Caucasian, $4.7 \%$ as Multiple Ethnicities, and $0.9 \%$ as other. Among the total population, $10 \%$ identified as Asian, $1 \%$ as Pacific Islander, $3.8 \%$ as Black, $16 \%$ as Hispanic/Latino, $1.8 \%$ as Native American, $8.5 \%$ as Multiple Ethnicities, $50 \%$ as White, 
and 3\% as unknown. Regarding race/ethnicity, Asian, Pacific Islander and White/Caucasian students were overrepresented in the sample, while Black/African American, Hispanic/Latino, Native American, and Multiple Ethnicities students were underrepresented. International students made up $1.9 \%$ of the survey population and $5.9 \%$ of the total population, so were underrepresented in the survey population.

Finally, among survey participants, $93.4 \%$ were 19 or younger and $6.6 \%$ were 20 or older, while among the total population, $87 \%$ were 19 or younger and $13 \%$ were 20 or older. In this sense, the survey population was overrepresented by younger participants when compared to the total population. However, because the total population of students taking freshman-required courses also included some sophomores, juniors, and seniors, it would make sense that the percentage of students older than 19 in the total population would be higher than that of the survey participants, which was limited to freshmen only.

Table 3

Demographics of Survey Participants Compared to Demographics of Total Population of Students Enrolled in Freshman General Education Courses

\begin{tabular}{|c|c|c|}
\hline Demographic & $\begin{array}{l}\text { Survey Participants (fall 2015) } \\
n=106\end{array}$ & $\begin{array}{l}\text { Students enrolled in freshman } \\
\text { general education classes (fall } \\
\text { 2014) } N=1345\end{array}$ \\
\hline Gender & $\begin{array}{l}25.5 \% \text { male, } 71.7 \% \text { female, } \\
2.8 \% \text { other }\end{array}$ & $\begin{array}{l}44 \% \text { male, } 55 \% \text { female, } 1 \% \text { did } \\
\text { not report a gender }\end{array}$ \\
\hline Race/Ethnicity & $\begin{array}{l}\text { Asian/Pacific Islander: } 14.2 \% \\
\text { Black/African American: } 1.9 \% \\
\text { Hispanic/Latino: } 14.2 \% \\
\text { Native American/American } \\
\text { Indian: } 0 \% \\
\text { White/Caucasian: } 64.2 \%\end{array}$ & $\begin{array}{l}\text { Asian: } 10 \% \\
\text { Pacific Islander: } 1 \% \\
\text { Black: } 3.8 \% \\
\text { Hispanic/Latino: } 16 \% \\
\text { Native American: } 1.8 \% \\
\text { Multiple Ethnicities: } 8.5 \%\end{array}$ \\
\hline
\end{tabular}




\begin{tabular}{lll} 
& $\begin{array}{l}\text { Multiple Ethnicities: } 4.7 \% \\
\text { Other: } 0.9 \%\end{array}$ & White: $50 \%$ \\
& & Unknown: $3 \%$ \\
$\begin{array}{l}\text { International } \\
\text { Student Status }\end{array}$ & $\begin{array}{l}\text { International Students: } 1.9 \% \\
\text { Age }\end{array}$ & International Students: $5.9 \%$ \\
& 19 or younger: $93.4 \%$ & 19 or younger: $87 \%$ \\
\hline
\end{tabular}

In addition to the survey participant demographics that could be compared with the total population demographics, I collected additional demographics from the survey participants, which are summarized in Table 4.

Table 4

Additional Demographics of Survey Participants

\begin{tabular}{ll}
\hline Demographic & Survey Participants (fall 2015) $n=106$ \\
\hline $\begin{array}{l}\text { First Generation } \\
n=105\end{array}$ & First generation: $44.8 \%$ \\
& \\
$\begin{array}{l}\text { Home Language } \\
n=106\end{array}$ & Family uses a language other than English at home: $24.5 \%$ \\
Urban/Rural Current & In open country (not on a farm): $0.9 \%$ \\
$n=106$ & On a farm: $0 \%$ \\
& In a small town under $50,000: 8.5 \%$ \\
& In a city or town $50,000-250,000: 15.1 \%$ \\
& In a suburb near a large city: $14.2 \%$ \\
& In a large city over $250,000: 58.5 \%$ \\
& Other: $2.8 \%$ \\
& In open country (not on a farm): $2.8 \%$ \\
Orban/Rural Past & On a farm: $0.9 \%$ \\
$n=106$ & In a small town under $50,000: 27.4 \%$ \\
& In a city or town $50,000-250,000: 20.8 \%$ \\
& In a suburb near a large city: $25.5 \%$ \\
& In a large city over $250,000: 20.8 \%$ \\
& Other: $1.9 \%$ \\
& \\
$n=104$ & Less than $\$ 25,000: 29.8 \%$ \\
& $\$ 25,000-49,999: 20.2 \%$ \\
& $\$ 50,000-74,999: 12.5 \%$ \\
& $\$ 75,000-99,999: 14.4 \%$ \\
\hline &
\end{tabular}


$\$ 100,000-149,999: 16.3 \%$

$\$ 150,000$ or more: $6.7 \%$

Student content items. I categorized 37 of the 42 Likert-scale content items into five thematic categories: find, evaluate, use, basic skills, and attitudes. Because I structured the remaining five survey content items differently, I analyzed these five items in two additional categories: find reverse structure items and citation items. For all 42 Likert-scale survey items, I asked students to choose whether they strongly agreed, agreed, somewhat agreed, somewhat disagreed, disagreed, or strongly disagreed to statements about their academic practices. In Figures 1-14, I calculated the levels of agreement by combining the agree and strongly agree response categories. Somewhat agree was not included in the level of agreement because I did not consider it to be sufficient agreement with the statements. However, I include a calculation of the level of agreement including somewhat agree in Appendix E.

Find. In content items about their academic practices that related to the category of finding information, $72.7 \%$ of students agreed that they found credible sources for their papers, $71.7 \%$ of students agreed that they used the appropriate keywords for a topic when searching in an online database or search engine, and $62.2 \%$ of students agreed that they found scholarly, academic, and/or peer-reviewed sources for their class assignments and papers. Regarding finding information to answer a research question, $55.6 \%$ of students agreed that they could recognize the relevant journals, books, and databases to answer their research question. When it came to university library online resources, $53.8 \%$ of students agreed that they located journal articles through the university library 
website, $52.4 \%$ of students agreed that they used the university library website to do research, and $51.9 \%$ agreed that they located electronic books through the university library website. Almost half of students, $48.1 \%$, agreed that they asked librarians at university for assistance and $46.2 \%$ agreed that they could locate physical books in the university library. Finally, $44.3 \%$ of students said that they used Google Scholar to find scholarly or academic sources, $31.1 \%$ of students agreed that they went to the university library to do research, and $21.7 \%$ of students agreed that they could locate hard-copy journals in the library. Figure 1 offers a visual display of the level of agreement to student survey content items in the category of finding information. 


\section{Find}

Find credible sources for papers

Use the appropriate keywords for a topic when searching in an online database or search engine Find scholarly, academic, and/or peer-reviewed sources for class assignments and papers

Recognize the relevant journals, books, and databases to answer a research question

Locate journal articles through the university library website

Use the university library website to do research

Locate electronic books through the university library website

Ask librarians at the university library for assistance

Locate physical books in the university library building

Use Google Scholar to find scholarly or academic sources

Go to the university library building to do research

Locate hard-copy journals in the university library building

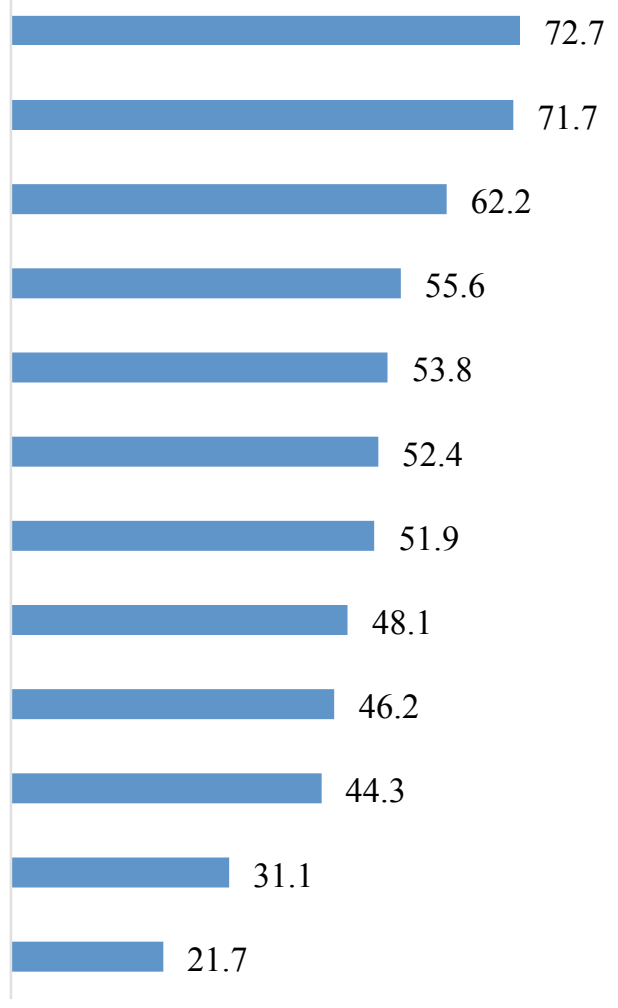

$\begin{array}{lllllllllll}0 & 10 & 20 & 30 & 40 & 50 & 60 & 70 & 80 & 90 & 100\end{array}$

Figure 1. Percentage of students who agreed with statements about their academic practices regarding finding information.

Find reverse structure. Under the category of finding information, my survey included three content items that were reversed for students and faculty members. In other words, the statements were positive for students, and negative for faculty members (e.g., I use Wikipedia as a scholarly or academic source vs. I expect my students to NOT use Wikipedia as a scholarly or academic source). Due to the reverse structure of these items, their results are shown separately from the other find category content items and are displayed in Figure 2. 
Regarding finding sources, $63.2 \%$ of students said that they found sources for their class assignments and papers on websites that ended with .com or .org. In addition, $36.8 \%$ of students said that when they conducted web or database searches, they generally just looked at the first page of results. Finally, $8.5 \%$ of students agreed that they used Wikipedia as a scholarly or academic source.

\section{Find reverse structure}

Find sources for class assignments and papers on websites that end with .com or .org When conducting web or database searches, just look at the first page of results Use Wikipedia as a scholarly or academic source

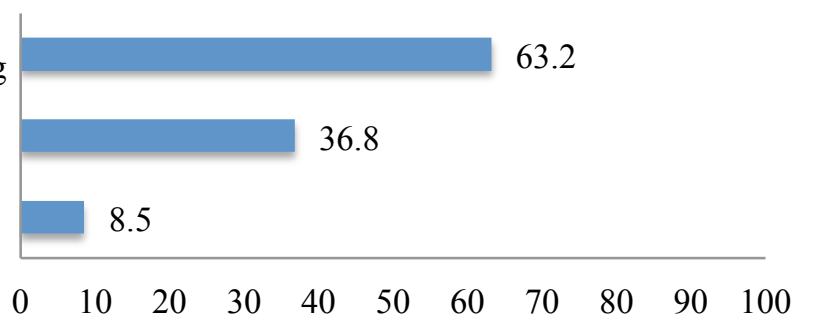

Figure 2. Percentage of students who agreed with statements about their academic practices regarding finding information (reverse structure items).

Evaluate. When it came to content items regarding their academic practices around evaluating information, $72.4 \%$ of students agreed that they could identify a credible source, and $72.4 \%$ of students agreed that they thought critically about information that they read in books, articles, or other sources. In addition, $71.7 \%$ of students agreed that they took the context of a source into account when determining its credibility and appropriateness, $64.1 \%$ of students agreed that they could tell the difference between academic and popular sources, and $61.6 \%$ of students agreed that they questioned what they read on the Internet. When it came to identifying sources, $54.7 \%$ of students agreed that they could identify a primary source and a secondary source.

Finally, $42.9 \%$ of students agreed that they questioned their own beliefs when they found 
new information that contradicted those beliefs. Figure 3 shows the percentage of students agreeing with survey content items regarding evaluating information.

\section{Evaluate}

Be able to identify a credible source

Think critically about information that they (students) read in books, articles, or other sources Take the context of a source into account when determining its credibility and appropriateness

Be able to tell the difference between popular and academic sources

Question what they (students) read on the Internet

Be able to identify a primary source and a secondary source

Question their (students') beliefs when they find new information that contradicts those beliefs

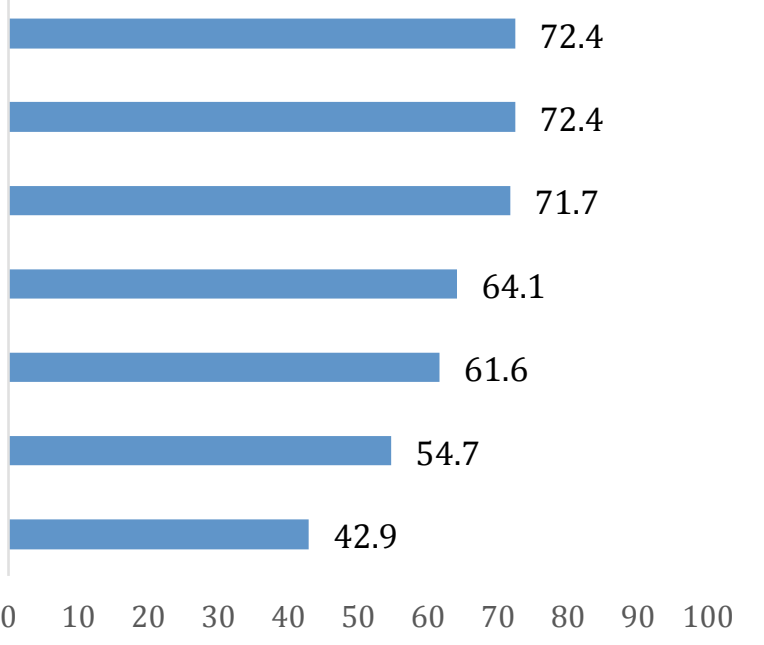

Figure 3. Percentage of students who agreed with statements about their academic practices regarding evaluating information.

Use. Responding to content items about their academic practices when it came to using information, a strong majority of students, $92.5 \%$, agreed that they gave credit to authors when they used their work. With regard to plagiarism, $88.7 \%$ of students agreed that they did not plagiarize or use sources unethically. In other strong demonstrations of agreement, $86.7 \%$ of students agreed that they used facts and/or evidence to back up claims that they made in their class assignments or papers, $79.1 \%$ agreed that they could write a thesis statement, $70.8 \%$ agreed that they used scholarly, academic, and/or peerreviewed sources for their class assignments and papers, and $67 \%$ of students agreed that they used the language of their field. In addition, $57.6 \%$ of students agreed that they 
picked topics they were interested in for their papers and $49.5 \%$ agreed that they could write an annotated bibliography. Only $18.9 \%$ of students agreed that when writing a paper, they entered into a conversation with experts in the field of their topic, and $17.9 \%$ agreed that they used a reference management tool. A visual representation of students' agreement with statements regarding using information can be seen in Figure 4.

\section{Use}

When using other people's work in class assignments or papers, give credit to the author When working on class assignments or papers, NOT plagiarize or use sources unethically Use facts and/or evidence to back up claims in class assignments or papers

Be able to write a thesis statement

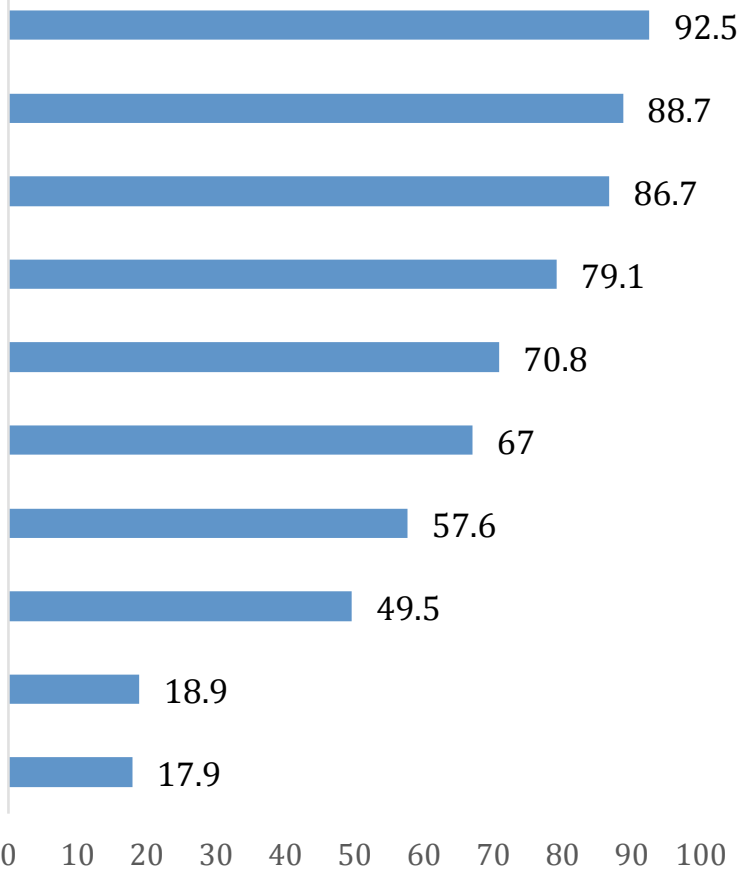

Use scholarly, academic, and/or peer-reviewed sources for class assignments or papers

In research and class work, use the language of the student's field

Pick topics that they (students) are interested in for their papers

Be able to write an annotated bibliography

When writing a paper, enter into a conversation with experts in the field of the topic

Use a reference management tool

$\begin{array}{llllllllll}0 & 20 & 30 & 40 & 50 & 60 & 70 & 80 & 90 & 100\end{array}$

Figure 4. Percentage of students who agreed with statements about their academic practices regarding using information.

Citation. I analyzed three content items about citation styles under the category of using information separately, because the content items inquired into students' use of specific citation styles, and students or their faculty partners might have had specific preferences or instructions for which citation style needed to be used. A large majority of 
student participants, $75.5 \%$, agreed that they used MLA in their class assignments or papers, while 23.6\% agreed that they used APA (American Psychological Association), and $11.4 \%$ agreed that they used another citation style. Overall, $85.8 \%$ of students agreed to one of the three content items, indicating that they used APA, MLA or another citation style. The level of student agreement to content items regarding citation style can be seen in Figure 5.

\section{Citation}

Use MLA citation style in class assignments or papers

Use APA citation style in class assignments or papers

Use a citation style other than APA or MLA

Use APA, MLA, or another citation style

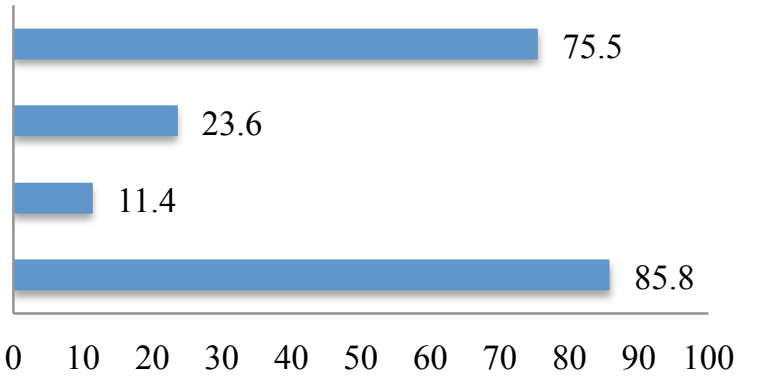

Figure 5. Percentage of students who agreed that they used APA, MLA, or another citation style, and percentage of students who agreed to any of these three content items.

Basic skills. In response to content items about their academic practices regarding basic skills, $90.5 \%$ of students agreed that they displayed basic writing skills, $90.5 \%$ of students agreed that they displayed basic comprehension skills, and $90.4 \%$ of students agreed that they displayed basic search skills, as shown in Figure 6. 


\section{Basic skills}

Display basic writing skills

Display basic comprehension skills

Display basic search skills

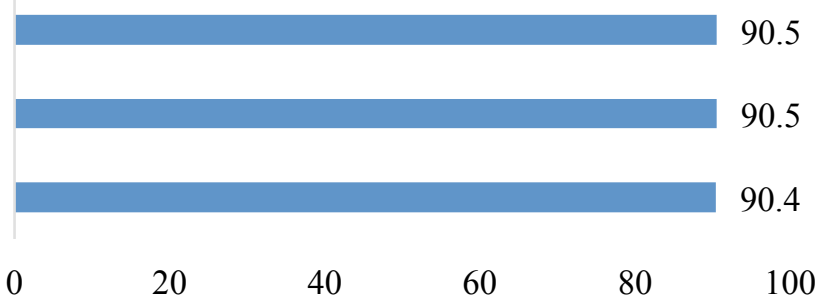

0

40

60

100

Figure 6. Percentage of students who agreed with statements about their academic practices regarding basic skills.

Attitudes. When asked about their attitudes, $84.6 \%$ of students agreed that they displayed curiosity, $81.1 \%$ agreed that they displayed persistence, $67.9 \%$ agreed that they displayed motivation, and $46.6 \%$ agreed that they got out of their comfort zones. Figure 7 displays the level of student agreement with content items regarding attitudes.

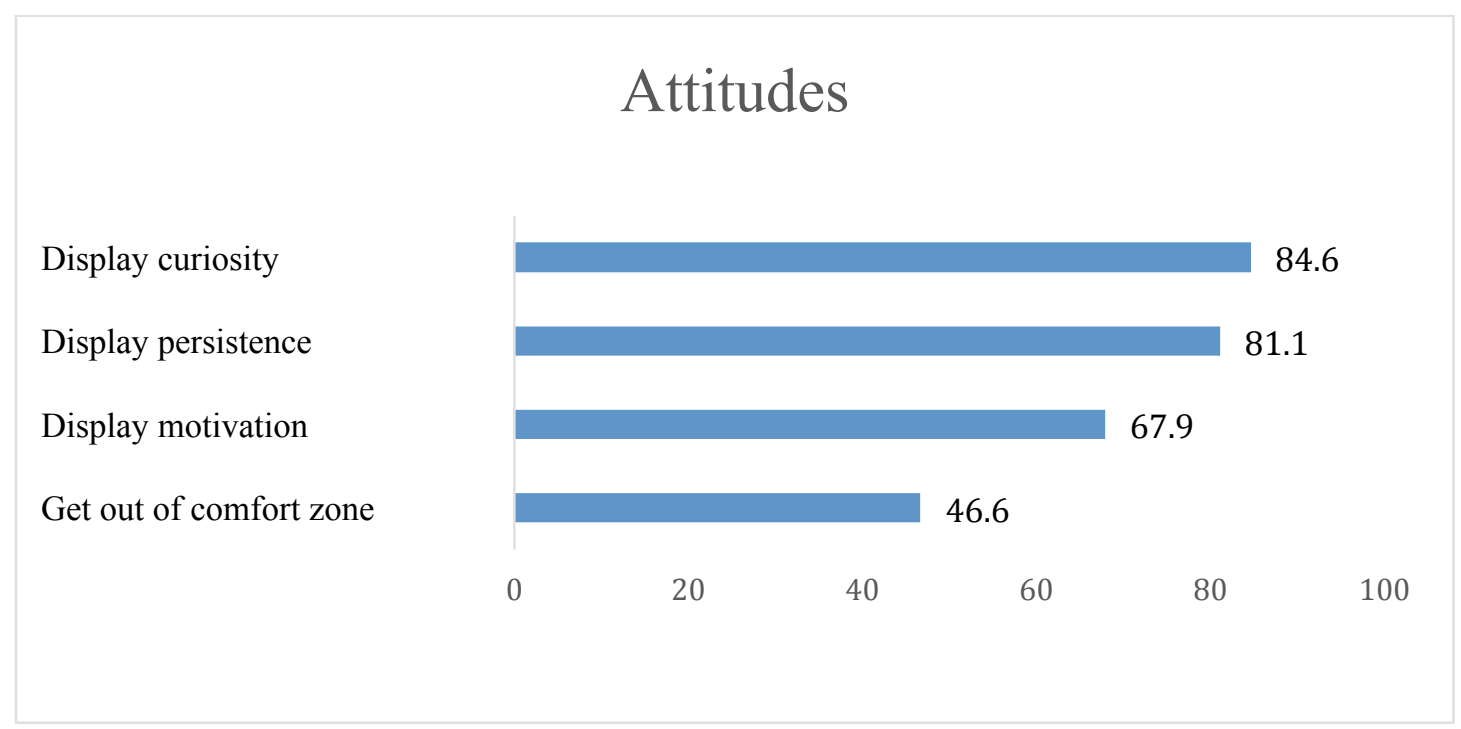

Figure 7. Percentage of students who agreed with statements about their academic practices regarding attitudes. 


\section{Student Results: Open-Ended Question}

I asked students one open-ended question in the survey: Do you have any additional comments about your academic practices? Of all student participants, 33 responded to this question. Of those 33 responses, 16 were some variation of no. Students mentioned several other themes related to the topic. One student mentioned a desire to do better with regard to her academic practices. Three students expressed enjoyment in academics: of learning, writing, or attending the university. Four students expressed confidence in their academic abilities. One participant expressed both enjoyment and confidence when they said "I love learning, and reading and writing are some of my stronger skills." Three participants described some part of their research process, with one saying "When conducting research I take everything down on paper and outline my essay before even typing it out on the computer. Also, after taking notes on various sources I go through and highlight important points and ideas." Two students disclosed their perfectionism or high goals when it came to academics, while another shared their difficulty in finding sources. Finally, one participant said that they had "always been extremely motivated." Overall, these comments echoed themes expressed during the qualitative interviews.

\section{Student Results: Differences Based on Demographics}

Based on student answers to demographic items, I examined nine demographic variables to see if there were meaningful differences in responses to content items across the variables. The nine demographic variables included age, gender, home language, international student status, racial/ethnic background, urban/rural current residence, 
urban/rural upbringing, income, and first generation status. To find statistically significant differences based on demographic variables, I produced contingency tables with Chi-Square analyses. Contingency tables compare one categorical variable to another categorical variable to see if there is a relationship between two variables, while Chi-Square determines the probability that the relationship is caused by chance. A $p$ value of under 0.05 indicates that there is a low likelihood that the relationship is caused by chance (Field, 2013).

Of these nine variables, gender and international student status did not have any survey items with statistically significant differences, while the seven remaining variables did show some survey items with statistically significant differences. Of these seven variables, five of them (age, race/ethnicity, urban/rural current residence, urban rural upbringing, and income) contained multiple categories with small numbers of participants (between 1 and 3). Therefore, the contingency tables with these five variables did not show meaningful results that contributed to my research questions, or to an understanding of demographic differences in student responses.

Two of the demographic categories showed meaningful differences in results: home language and first generation. Taking into account whether students spoke a language other than English at home, eight survey items showed meaningful statistically significant results. In addition, looking at whether or not students were first generation, or in other words did not have either of their parents/primary guardians complete a 4-year degree, resulted in three survey items with statistically significant results. 
Home language. With regard to home language, I found that eight survey items were statistically significant for the demographic question: "Does your family use a language other than English at home?" including (a) I use Wikipedia as a scholarly or academic source; (b) when searching in an online database or search engine, I can use the appropriate keywords for my topic; (c) I can identify a credible source; (d) I question my beliefs when I find new information that contradicts those beliefs; (e) I can write a thesis statement; (f) I display basic writing skills; (g) I display basic comprehension skills; and (h) I display basic search skills. The percent agreement for these survey items for students who speak a home language other than English and students who speak English as a home language are displayed in Table 5.

Students who used a language other than English at home were more likely to agree or strongly agree that they used Wikipedia as a scholarly or academic source (19.2\%) compared to students did not use a language other than English at home (of whom $5.1 \%$ said they used Wikipedia). When it came to searching in an online database or search engine, $76.9 \%$ of students who used a language other than English at home agreed or strongly agreed that they could use the appropriate keywords for their topic, compared to $70 \%$ of students who did not use a language other than English at home. Out of all students who used a language other than English at home, $42.3 \%$ agreed or strongly agreed that they could identify a credible source, while $82.2 \%$ of students who did not use a language other than English at home agreed or strongly agreed that they could identify a credible source. When it came to students questioning their beliefs when they found new information that contradicted those beliefs, $15.4 \%$ of students who used a 
language other than English at home agreed or strongly agreed that they did so, while $51.9 \%$ of students who did not use a language other than English at home agreed or strongly agreed. Of all students who used a language other than English at home, 57.7\% agreed or strongly agreed that they could write a thesis statement, compared to $86.1 \%$ of other students. Regarding basic skills, $76.9 \%$ of students who spoke a language other than English at home agreed or strongly agreed that they displayed basic writing skills, compared to $95.1 \%$ of students who did not speak a language other than English at home. In addition, $80.8 \%$ of students who spoke a language other than English at home agreed or strongly agreed that they displayed basic comprehension skills compared to $93.8 \%$ of other students, and $77 \%$ of students who spoke a language other than English at home agreed or strongly agreed that they displayed basic search skills, compared to $94.8 \%$ of students who did not speak a language other than English at home.

Table 5

Survey Items with Statistically Significant Differences Based on Use of a Home Language Other than English*

\begin{tabular}{llll}
\hline Survey Item & $\begin{array}{l}\text { Percent agreement for } \\
\text { students using a } \\
\text { home language other } \\
\text { than English }(n=26)\end{array}$ & $\begin{array}{l}\text { Percent agreement for } \\
\text { students using a home } \\
\text { language of English } \\
(n=80)\end{array}$ & $p$-value \\
\hline $\begin{array}{l}\text { I use Wikipedia as a } \\
\text { scholarly or academic } \\
\text { source }\end{array}$ & 19.2 & 5.1 & .024 \\
$\begin{array}{l}\text { When searching in an online } \\
\text { database or search engine, I } \\
\text { can use the appropriate } \\
\text { keywords for my topic }\end{array}$ & 76.9 & 70 & .019 \\
$\begin{array}{l}\text { I can identify a credible } \\
\text { cand }\end{array}$ & 42.3 & 82.2 & .001
\end{tabular}


source

I question my beliefs when I 15.4

51.9

.021

find new information that

contradicts those beliefs

I can write a thesis

86.1

.046

statement

I display basic writing skills

76.9

95.1

.011

I display basic

80.8

93.8

.015

comprehension skills

I display basic search skills

77

94.8

.012

*Percent of agreement includes students agreeing or strongly agreeing to survey item

First generation. Three survey items had a statistically significant response based on the first generation variable. I developed the first generation variable from students' responses to demographic items asking about the level of education completed by their mother or primary female guardian and their father or primary male guardian. If a student's response to both demographic items was less than a 4-year degree, I identified the student as first generation. The three survey items with a statistically significant difference based on first generation status are displayed in Table 6.

First generation student participants were more likely to agree that they asked librarians at the university library for assistance (61.7\%) compared to students who were not first generation (38\%). Regarding questioning beliefs, $28.3 \%$ of first generation students agreed that they questioned their beliefs when they found new information that contradicted those beliefs, while $55.2 \%$ of students who were not first generation agreed with this statement. Finally, $21.2 \%$ of first generation students agreed that they used a 
citation style other than APA or MLA in their class assignments or papers, while $3.4 \%$ of students who were not first generation agreed with this statement.

Table 6

Survey Items with Statistically Significant Differences Based on Student First Generation Status*

\begin{tabular}{llll}
\hline Survey Item & $\begin{array}{l}\text { Percent agreement } \\
\text { for first generation } \\
\text { students }(n=47)\end{array}$ & $\begin{array}{l}\text { Percent agreement for } \\
\text { students who were not } \\
\text { first generation }(n=58)\end{array}$ & $p$-value \\
\hline $\begin{array}{l}\text { I ask librarians at the } \\
\text { university library for } \\
\text { assistance }\end{array}$ & 61.7 & 38 & .047 \\
$\begin{array}{l}\text { I question my beliefs when I } \\
\text { find new information that } \\
\text { contradicts those beliefs }\end{array}$ & 28.3 & 55.2 & .009 \\
$\begin{array}{l}\text { I use a citation style other } \\
\text { than APA or MLA in my } \\
\text { class assignments or papers }\end{array}$ & 21.2 & & .035 \\
\hline *Percent agreement includes students agreeing or strongly agreeing to survey item
\end{tabular}

\section{Faculty Results: Demographics and Content Items}

In the following section, I share demographic information about the faculty member participants, comparing them to the population of faculty members teaching freshman-required classes in the general education program. Then, I share the results of faculty member participant responses to the survey content items.

Faculty demographics. I asked the 10 faculty member participants about their age, gender, race/ethnicity, home language, urban/rural residency, total household income, educational background, and the number of courses they were teaching. Faculty member participants identified as $70 \%$ female and $30 \%$ male, while the entire population 
of faculty members teaching freshman-required courses in the general education department identified as $52.2 \%$ female and $47.8 \%$ male, meaning that females were overrepresented in the sample. The average age of survey participants was 48 , and their age range was 36-64. The average age and age range of the freshman-teaching faculty member population was not available. Table 7 compares the gender of survey participants and the total population of faculty members teaching freshmen in 2014, and shows the average age and age range of faculty member survey participants. When I began to look at the remaining demographic variables, it became apparent that the identity of individual faculty participants could become known if I shared the remaining demographic variables, due to the small number of faculty member participants.

Therefore, I did not disclose the remaining demographic variables.

Table 7

Demographics of Faculty Survey Participants and Population of General Education Faculty Teaching Freshman Courses

\begin{tabular}{lll}
\hline Demographic & $\begin{array}{l}\text { Faculty Survey Participants } \\
\text { (Fall 2015) } n=10\end{array}$ & $\begin{array}{l}\text { Faculty Population Teaching } \\
\text { Freshmen (Fall 2014) } n=46\end{array}$ \\
\hline Gender & $70 \%$ Female, 30\% Male & $52.2 \%$ Female, 47.8\% Male \\
Average Age & 48 & \\
Age Range & $36-64$ & \\
\end{tabular}

Faculty content items. As I did for students, I calculated the faculty member level of agreement by combining agree and strongly agree into one category. I share the results of the 42 survey content items in the following section. As a reminder, I grouped 
survey content items into five categories: find, evaluate, use, basic skills, and attitudes. In addition, I analyzed two categories separately: find reverse structure and citation.

Find. When responding to content items about their expectations for students finding information, $100 \%$ of faculty members agreed that they expected their students to a) find credible sources for their papers and b) locate journal articles through the university library website. In addition, $90 \%$ of faculty members agreed that they expected their students to be able to locate physical books in the library building, $90 \%$ agreed that they expected their students to be able to use the appropriate keywords for their topic, $90 \%$ agreed that they expected students to ask librarians at the university for assistance, and $90 \%$ agreed that they expected their students to find scholarly, academic and/or peer-reviewed sources to use in their class assignments and papers. Regarding the university library website, $90 \%$ of faculty members agreed that they expected their students to locate electronic books through the university library website, and $90 \%$ agreed that they expected their students to use the university library website to do research. In response to additional items on finding information, $80 \%$ of faculty members agreed that they expected their students to use Google Scholar to find scholarly or academic sources, and $80 \%$ of faculty members agreed that they expected their students to go to the university library. Finally, $70 \%$ of faculty members agreed that they expected their students to recognize the relevant journals, books, and databases to answer a research question, and $40 \%$ agreed that they expected their students to be able to locate hard-copy journals in the library. The percentage of faculty member participants agreeing with content items regarding finding information is displayed in Figure 8. 


\section{Find}

Find credible sources for papers

Locate journal articles through the university library website

Locate physical books in the university library building

Use the appropriate keywords for a topic when searching in an online database or search engine Ask librarians at the university library for assistance

Find scholarly, academic, and/or peer-reviewed sources for class assignments and papers

Locate electronic books through the university library website

Use the university library website to do research

Use Google Scholar to find scholarly or academic sources

Go to the university library building to do research

Recognize the relevant journals, books, and databases to answer a research question Locate hard-copy journals in the university library building

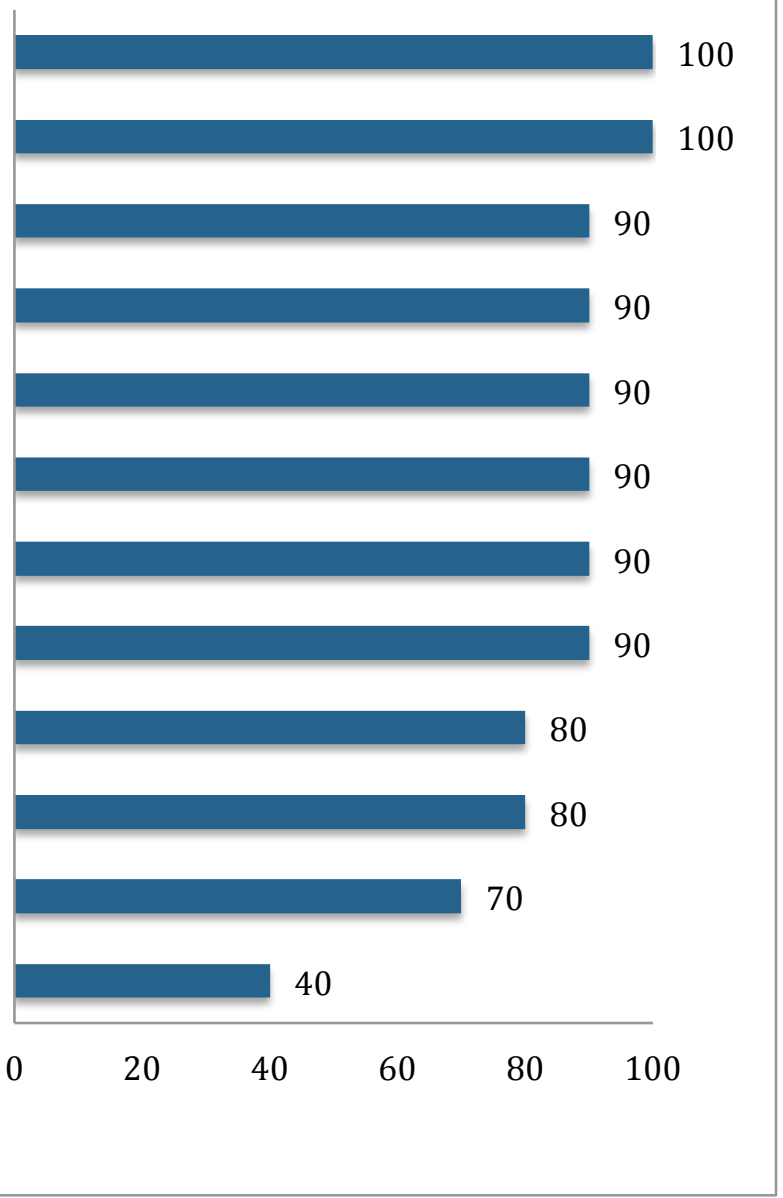

Figure 8. Percentage of faculty members who agreed with statements about their expectations for students regarding finding information.

Find reverse structure. Under the category of finding information, I included three content items that were reversed for students and faculty members. Due to their reverse structure, I did not include these items in the find category, but instead analyzed them separately, and the results are shown in Figure 9. Regarding searching for information, $80 \%$ of faculty members agreed that they expected their students to go 
beyond the first page of web or database search results, $70 \%$ of faculty members agreed that they expected their students to not use Wikipedia as a scholarly or academic source, and $40 \%$ of faculty members said that they expected their students to not find sources for their class assignments or papers on websites that end with .com or .org.

\section{Find reverse structure}

Go beyond the first page of web or database search results

NOT use Wikipedia as a scholarly or academic source

NOT find sources for class assignments and papers on websites that end with .com or .org

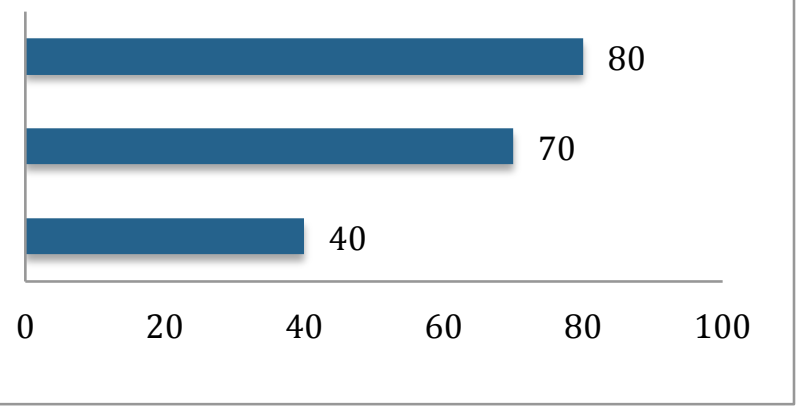

Figure 9. Percentage of faculty members who agreed with statements about their expectations for students regarding finding information.

Evaluate. In response to content items about their expectations for students when it came to evaluating information, $100 \%$ of faculty members agreed that they expected their students to be able to identify a credible source, $100 \%$ agreed that they expected their students to be able to tell the difference between popular and academic sources, and $100 \%$ of faculty members agreed that they expected students to take the context of a source into account when evaluating its credibility and appropriateness. In addition, $100 \%$ of faculty members agreed that they expected their students to think critically about information that they read in books, articles, or other sources, and $100 \%$ agreed that they expected their students to question what they read on the Internet. Finally, $80 \%$ of faculty members agreed that they expected their students to question their own beliefs 
when they found new information that contradicted those beliefs, and $60 \%$ of faculty members agreed that they expected their students to be able to identify a primary source and a secondary source. These results can be seen in Figure 10.

\section{Evaluate}

Be able to identify a credible source

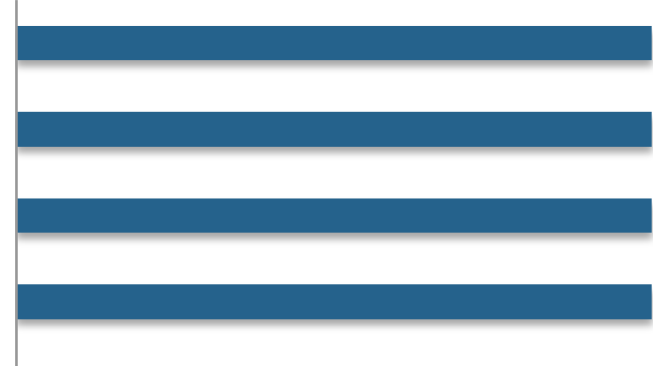

Be able to tell the difference between popular and academic sources

Take the context of a source into account when evaluating its credibility and appropriateness Think critically about information that they (students) read in books, articles, or other sources Question what they (students) read on the Internet

Question their (students') beliefs when they find new information that contradicts those beliefs Be able to identify a primary source and a secondary source

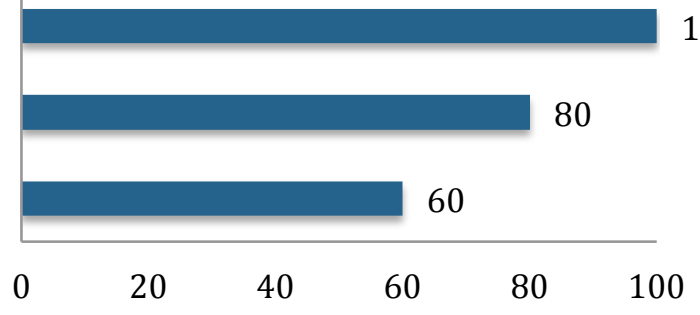

Figure 10. Percentage of faculty members who agreed with statements about their expectations for students regarding evaluating information.

Use. Responding to content items about their expectations for students around using information, $100 \%$ of faculty members agreed that they expected their students to (a) use facts and/or evidence to back up claims that they made in their class assignments or papers, (b) give credit to authors when they used their work, and (c) not plagiarize or use sources unethically. In addition, $90 \%$ of faculty members agreed that they expected their students to use scholarly, academic, and/or peer-reviewed sources for their class assignments or papers and $90 \%$ agreed that they expected their students to pick topics that they were interested in for their papers. In addition, $80 \%$ agreed that they expected 
their students to be able to write a thesis statement, $80 \%$ agreed that they expected their students to be able to write an annotated bibliography, and $70 \%$ agreed that they expected their students to enter into a conversation with experts in their field when writing a paper. Far fewer, only $20 \%$ of faculty members, agreed that they expected their students to use the language of their field, and no faculty members, or $0 \%$, agreed that they expected students to use a reference management tool. The percentage of agreement to statements regarding using information can be seen in Figure 11.

\section{Use}

Use facts and/or evidence to back up claims in class assignments or papers

When using other people's work in class assignments or papers, give credit to the author

When working on class assignments or papers, NOT plagiarize or use sources unethically

Use scholarly, academic, and/or peer-reviewed sources for class assignments or papers

Pick topics that they (students) are interested in for their papers

Be able to write a thesis statement

Be able to write an annotated bibliography

When writing a paper, enter into a conversation with experts in the field of the topic

In research and classwork, use the language of the students' field

Use a reference management tool

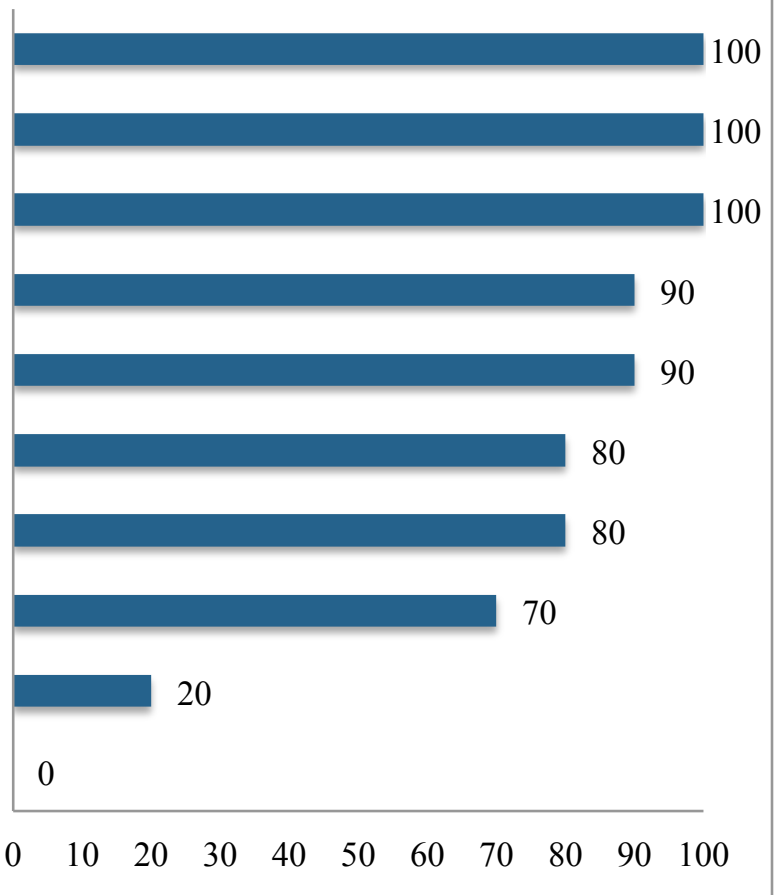

Figure 11. Percentage of faculty members who agreed with statements about their expectations for students regarding using information.

Citation. Under the category of using information, I asked three questions about citation styles, which are shown in Figure 12. I asked if faculty members expected their students to use APA, MLA or another citation style. One half $(50 \%)$ of faculty member 
participants agreed that they expected their students to use APA in their class assignments and papers, and one half $(50 \%)$ agreed that they expected their students to use MLA, while $20 \%$ agreed that they expected their students to use a citation style other than APA or MLA. Overall, $80 \%$ of faculty members agreed that they expected their students to use APA, MLA, or another citation style.

\section{Citation}

Use APA citation style in class assignments or papers

Use MLA citation style in class assignments or papers

Use a citation style other than APA or MLA

Use APA, MLA, or another citation style

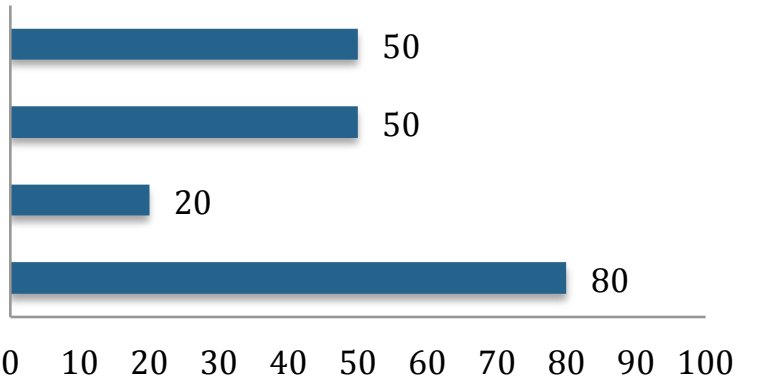

Figure 12. Percentage of faculty members who agreed that they expected their students to use APA, MLA, or another citation style, and percentage of faculty members who agreed to any one of these three content items.

Basic skills. In response to content items about expectations that faculty had for students' basic skills, $100 \%$ of faculty members agreed that they expected their students to display basic writing skills and basic comprehension skills, and $90 \%$ agreed that they expected their students to display basic search skills, as shown in Figure 13.

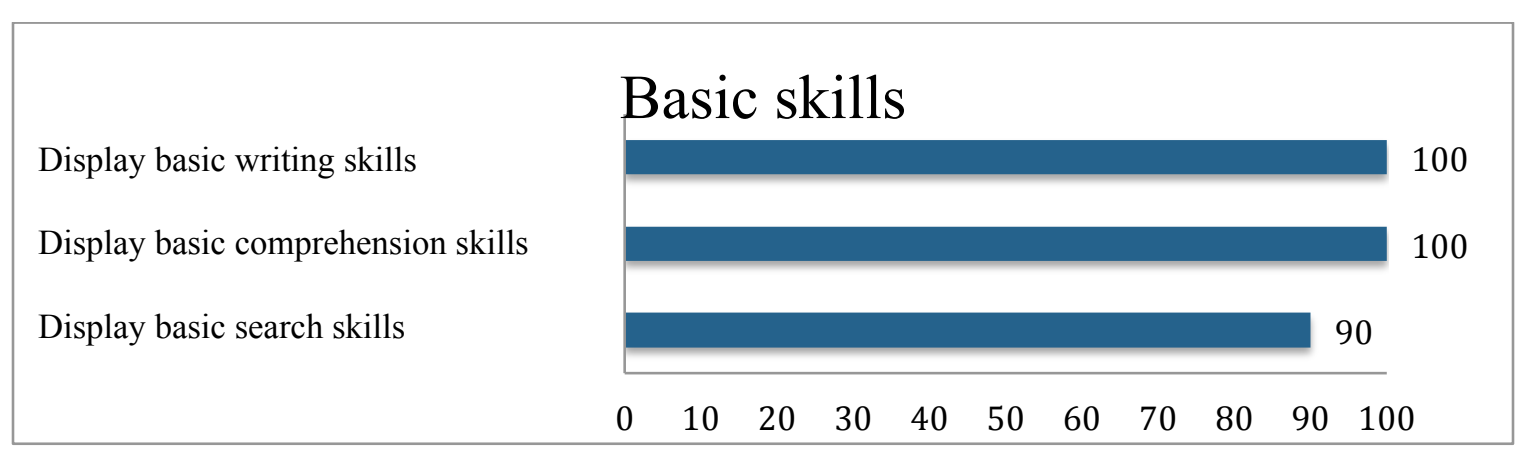


Figure 13. Percentage of faculty members who agreed with statements about their expectations for students regarding basic skills.

Attitudes. In response to content items about their expectations for students' attitudes, $100 \%$ of faculty members agreed that they expected their students to display curiosity and persistence, $88.9 \%$ agreed that they expected their students to display motivation and $88.9 \%$ also agreed that they expected students to get out of their comfort zones. Faculty agreement to content items regarding attitudes can be seen in Figure 14.

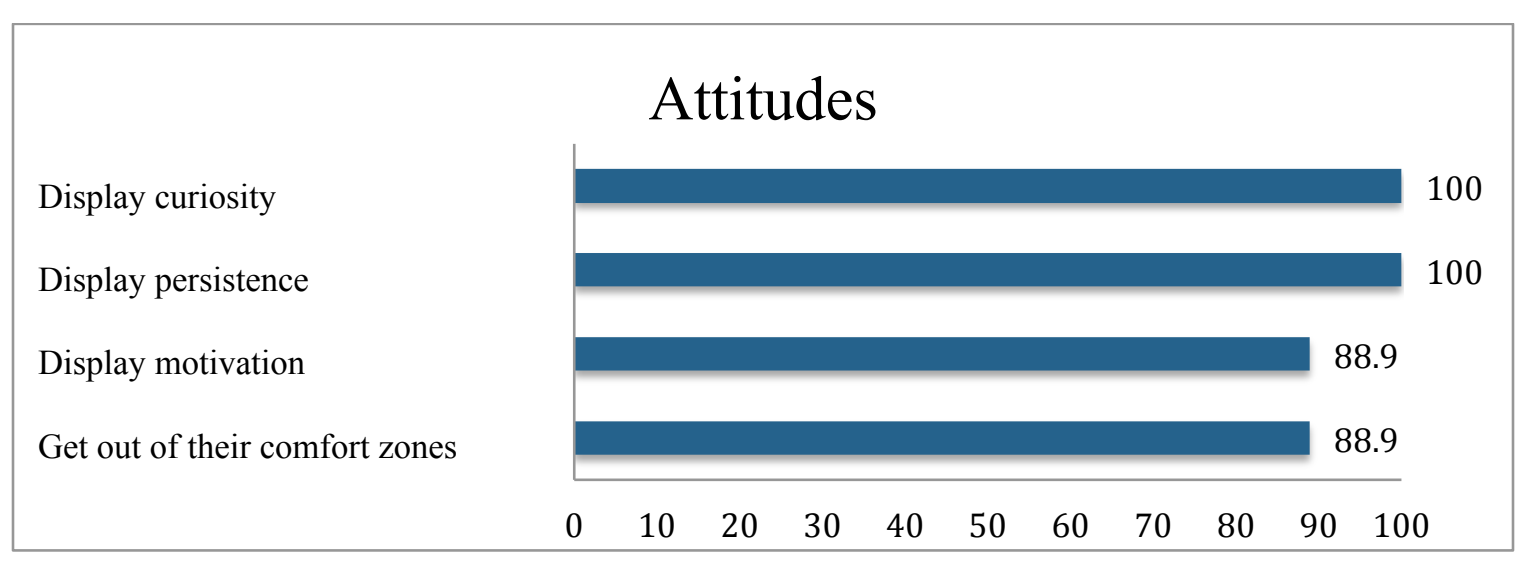

Figure 14. Percentage of faculty members who agreed with statements about their expectations for students regarding attitudes.

\section{Faculty Results: Open-Ended Question}

I asked faculty member participants one open-ended question on the survey: Do you have anything else to add about your expectations for students? Of 10 participants, six responded to this question. Two faculty members commented that students needed to learn many of the skills mentioned during their freshman year. One faculty member stated that they did not expect students to already have many of the information literacy skills, but to learn the skills during their first year, while another similarly stated, "There is a big gap with freshmen between what I expect or hope they will be able to do, and 
what it is that they are often prepared to do. A big part of the first year is socializing students into academic expectations." Two faculty members gave details on specific sources that they introduced their students to (e.g., The Economist), and one faculty member emphasized that they encouraged the use of different types of sources depending on students' purpose and context. Overall, the faculty member comments echoed themes that were present in the qualitative interviews.

\section{Faculty Results: Differences Based on Demographics}

As I noted previously, only 10 faculty members completed the faculty survey. Therefore, the number of faculty members within each demographic group was even smaller. Due to the low number of participants, contingency tables comparing survey demographic items and survey content items did not include meaningful results or contribute to an understanding of my research problem.

\section{Comparing Student and Faculty Responses}

Because one of the major objectives of my study was to compare faculty member expectations and student practices, and see how they aligned and differed, I produced frequency tables that showed faculty member and student responses to their parallel content items. As I did with student and faculty results earlier, I combined the strongly agree and agree categories to indicate agreement.

As I mentioned earlier, three of the survey items were reversed for students and faculty members, with a positive statement for students and a negative statement for faculty members (e.g., I use Wikipedia as a scholarly or academic source; I expect my students NOT to use Wikipedia as a scholarly or academic source). To compare these 
items for students and faculty members, I reversed the responses for students (e.g., strongly disagree $=$ strongly agree, disagree $=$ agree $).$ I chose to reverse the item responses for students because for these items, the students' agreement with the answers showed a lower level of information literacy practices.

In the following tables, I have displayed comparisons of the percentage of students who agreed to each of the statements about a specific practice to the percentage of faculty members who agreed to a statement about their expectation of that practice. I determined the level of agreement by combining the strongly agree and agree responses. Levels of agreement that include the category somewhat agree are presented in Appendix G. In the following sections, I present tables for categories of find, evaluate, use, basic skills, attitudes, and citation.

Find. Under the find category, the practices and expectations about finding information, $80 \%$ of faculty members agreed that they expected students to go to the university library, while $31.1 \%$ of students agreed that they went to the university library. Ninety percent of faculty members agreed that they expected students to be able to find physical books in the library building, compared to $46.2 \%$ of students who agreed that they could find physical books in the library building. Also regarding searching in the library building, $40 \%$ of faculty members agreed that they expected students to be able to locate hard-copy journals in the library building, while $21.7 \%$ of students agreed that they could locate journals in this location. With regard to asking librarians at the university for assistance, $90 \%$ of faculty members agreed that they expected students to ask for assistance, compared to $48.1 \%$ of students who agreed that they did so. On the subject of 
the library website, $90 \%$ of faculty members agreed that they expected students to use the university library website to do research, while $52.4 \%$ of students agreed that they used the university library website to do research. Similarly, $90 \%$ of faculty members agreed that they expected students to be able to locate electronic books through the university library website, compared to $51.9 \%$ of students who agreed that they located electronic books in this manner. Another difference was that $100 \%$ of faculty members agreed that they expected students to locate journal articles through the university library website, while $53.8 \%$ of students agreed that they did so. Likewise, $100 \%$ of faculty members agreed that they expected students to be able to find credible sources for their papers, compared to $72.7 \%$ of students who agreed that they could find credible sources. Regarding websites ending with .com or .org, $40 \%$ of faculty members agreed that they expected their students not to use these websites for sources, while $6.6 \%$ of students agreed that they did not use websites ending in .com or .org for sources. In a close match, $70 \%$ of faculty members agreed that they expected their students to not use Wikipedia as a scholarly or academic source, compared to $69.8 \%$ of students who agreed that they did not use Wikipedia in this manner. With regard to Google Scholar, $80 \%$ of faculty members agreed that they expected their students to use Google Scholar to find scholarly or academic sources, while $44.3 \%$ of students agreed that they used Google Scholar. In response to another item about sources, $90 \%$ of faculty members agreed that they expected students to find scholarly, academic, and/or peer-reviewed sources for their class assignments and papers, compared to $62.2 \%$ of students who agreed that they found these sources. Similarly, $70 \%$ of faculty members expected students to recognize the 
relevant journals, books, and databases to answer a research question, while $55.6 \%$ of students agreed that they could recognize the relevant journals, books, and databases to answer a research question. In addition, $80 \%$ of faculty members agreed that they expected their students to go beyond the first page of web or database results, while only $18.9 \%$ of students agreed that they did so. Finally, $90 \%$ of faculty members agreed that they expected their students to use the appropriate keywords for their topic, compared to $71.7 \%$ of students who agreed that they used the appropriate keywords. All of the survey item comparisons in the category of finding information can be seen in Table 8 .

Six of the 15 survey items in the find category had statistically significant differences with a $p$-value of less than 0.05 , including: (a) go to the university library building to do research; (b) be able to locate physical books in the library building; (c) ask librarians at university library for assistance; (d) use the university library website to do research; (e) NOT find sources for class assignments or papers on websites that end with .com or .org; and (f) go beyond the first page of web or database results.

Table 8

Percentage of Students Who Agreed Compared to Percentage of Faculty Members Who Agreed to Statements about Their Practices (Students) and Expectations (Faculty Members) Regarding Finding Information

\begin{tabular}{llll}
\hline $\begin{array}{l}\text { Survey Item (Student Practice/Faculty } \\
\text { Expectation) }\end{array}$ & $\begin{array}{l}\text { Student } \\
\text { Percent } \\
\text { Agreement }\end{array}$ & $\begin{array}{l}\text { Faculty } \\
\text { Percent } \\
\text { Agreement }\end{array}$ & $\begin{array}{l}p \text {-value } \\
\text { (*indicat } \\
\text { statistica } \\
\text { signific } \\
\text { at the }>0 \\
\text { level). }\end{array}$ \\
\hline $\begin{array}{l}\text { Go to the university library building to } \\
\text { do research }\end{array}$ & 31.1 & 80 & $.008^{*}$ \\
$\begin{array}{l}\text { Locate physical books in the university } \\
\text { nof }\end{array}$ & 46.2 & 90 & $.022^{*}$
\end{tabular}


library building

Locate hard-copy journals in the

Ask librarians at the university library

for assistance (in person or via chat,

email, text, or phone)

Use the university library website to do

research.

Locate electronic books through the

NOT find sources for class assignments

Find scholarly, academic, and/or peer- 
Evaluate. When it came to survey items in the category of evaluating information, $100 \%$ of faculty members agreed that they expected their students to be able to identify a credible source, while to $72.4 \%$ of students agreed that they could identify a credible source. Similarly, $100 \%$ of faculty members agreed that they expected their students to question what they read on the Internet, compared to $61.6 \%$ of students who agreed that they questioned what they read on the Internet. Regarding the practice of students questioning their own beliefs when they found information that contradicted those beliefs, $80 \%$ of faculty members agreed that they expected students to do so, while $42.9 \%$ of students agreed that they did so. In addition, $100 \%$ of faculty members agreed that they expected their students to think critically about information that they read in books, articles, or other sources compared to $72.4 \%$ of students who agreed that they did so. In the same way, $100 \%$ of faculty members agreed that they expected students to take the context of a source into account when determining its credibility and appropriateness, while $71.7 \%$ of students agreed that they did so. Concerning academic sources, $100 \%$ of faculty members agreed that they expected students to be able to tell the difference between popular and academic sources, while $64.1 \%$ of students agreed that they could do so. Finally, $60 \%$ of faculty members agreed that they expected students to be able to identify a primary source and a secondary source, compared to $54.7 \%$ of students who agreed that they could do so. Two of these survey items showed a statistically significant difference between student and faculty results: (a) question what they (students) read on the Internet and (b) think critically about information that they (students) read in books, 
articles, or other sources. All student-faculty comparisons regarding evaluating information can be seen in Table 9.

Table 9

Percentage of Students Who Agreed Compared to Percentage of Faculty Members Who Agreed to Statements about Their Practices (Students) and Expectations (Faculty Members) Regarding Evaluating Information

\begin{tabular}{llll}
\hline $\begin{array}{l}\text { Survey Item (Student Practice/Faculty } \\
\text { Expectation) }\end{array}$ & $\begin{array}{l}\text { Student } \\
\text { Percent Agreement }\end{array}$ & $\begin{array}{l}\text { Faculty } \\
\text { Percent } \\
\text { Agreement }\end{array}$ & $\begin{array}{l}p \text {-value } \\
(* \text { indicates } \\
\text { statistical } \\
\text { significance } \\
\text { at the }<0.05 \\
\text { level })\end{array}$ \\
\hline Be able to identify a credible source & 72.4 & 100 & .395 \\
$\begin{array}{l}\text { Question what they (students) read on } \\
\text { the Internet }\end{array}$ & 61.6 & 100 & $.033^{*}$ \\
$\begin{array}{l}\text { Question their (students') beliefs when } \\
\text { they find new information that } \\
\text { contradicts those beliefs }\end{array}$ & 42.9 & 80 & .322 \\
$\begin{array}{l}\text { Think critically about information that } \\
\text { they (students) read in books, articles, } \\
\text { or other sources }\end{array}$ & 72.4 & 100 & $.031^{*}$ \\
$\begin{array}{l}\text { Take the context of a source into } \\
\text { account when determining its } \\
\text { credibility and appropriateness }\end{array}$ & 71.7 & 100 & .134 \\
$\begin{array}{l}\text { Be able to tell the difference between } \\
\text { popular and academic sources }\end{array}$ & 64.1 & & \\
$\begin{array}{l}\text { Be able to identify a primary source } \\
\text { and a secondary source }\end{array}$ & 54.7 & 100 & .170 \\
\hline
\end{tabular}

Use. With regard to using information, $100 \%$ of faculty members agreed that they expected their students to use facts and/or evidence to back up claims they made in their class assignments and papers, compared to $86.7 \%$ of students who agreed that they 
used facts and/or evidence to back up claims. In addition, $90 \%$ of faculty agreed that they expected their students to use scholarly, academic, and/or peer-reviewed sources for their class assignments or papers, while $70.8 \%$ of students agreed that they used scholarly, academic, and/or peer-reviewed sources. On the issue of writing a paper, $70 \%$ of faculty members agreed that they expected their students to enter into a conversation with experts in their field when writing a paper, while $18.9 \%$ of students agreed that they did so. Additionally, $90 \%$ of faculty members agreed that they expected their students to pick topics that they were interested in for their papers, compared to $57.6 \%$ of students who agreed that they picked these topics. On the subject of using sources, $100 \%$ of faculty members agreed that they expected their students to give credit to the author when using other people's work in class assignments or papers, compared to $92.5 \%$ of students who agreed that they gave credit to the author. On the topic of reference management tools, $0 \%$ of faculty members agreed that they expected their students to use a reference management tool, while $17.9 \%$ of students agreed that they used one. Regarding plagiarism, $100 \%$ of faculty members agreed that they expected their students not to plagiarize or use sources unethically, compared to $88.7 \%$ of students who agreed that they did not plagiarize or use sources unethically. In addition, $20 \%$ of faculty members agreed that they expected their students to use the language of their field, while $67 \%$ of students agreed that they did so. Regarding annotated bibliographies, $80 \%$ of faculty members agreed that they expected students to be able to write an annotated bibliography, while $49.5 \%$ of students agreed that they could write an annotated bibliography. Finally, $80 \%$ of faculty members agreed that they expected their students 
to be able to write a thesis statement, compared to $79.1 \%$ of students who agreed that they could write a thesis statement. Three of these items showed a statistically significant difference between student and faculty results: (a) use facts and/or evidence to back up claims in class assignments or papers; (b) when writing a paper, enter into a conversation with experts in the field of the topic; and (c) in class assignments and papers, use the language of [the student's] field. The results of the comparisons between student and faculty responses to the survey items about using information can be seen in Table 10 . Table 10

Percentage of Students Who Agreed Compared to Percentage of Faculty Members Who Agreed to Statements about Their Practices (Students) and Expectations (Faculty Members) Regarding Using Information

\begin{tabular}{|c|c|c|c|}
\hline $\begin{array}{l}\text { Survey Item (Student Practice/Faculty } \\
\text { Expectation) }\end{array}$ & $\begin{array}{l}\text { Student } \\
\text { Percent Agreement }\end{array}$ & $\begin{array}{l}\text { Faculty } \\
\text { Percent } \\
\text { Agreement }\end{array}$ & $\begin{array}{l}p \text {-value } \\
(* \text { indicates } \\
\text { statistical } \\
\text { significance } \\
\text { at the }<0.05 \\
\text { level })\end{array}$ \\
\hline $\begin{array}{l}\text { Use facts and/or evidence to back up } \\
\text { claims in class assignments or papers }\end{array}$ & 86.7 & 100 & $.047^{*}$ \\
\hline $\begin{array}{l}\text { Use scholarly, academic, and/or peer- } \\
\text { reviewed sources for class } \\
\text { assignments or papers }\end{array}$ & 70.8 & 90 & .335 \\
\hline $\begin{array}{l}\text { When writing a paper, enter into a } \\
\text { conversation with experts in the field } \\
\text { of the topic }\end{array}$ & 18.9 & 70 & $.018^{*}$ \\
\hline $\begin{array}{l}\text { Pick topics that they (students) are } \\
\text { interested in for their papers }\end{array}$ & 57.6 & 90 & .245 \\
\hline $\begin{array}{l}\text { When using other people's work in } \\
\text { class assignments or papers, give } \\
\text { credit to the author }\end{array}$ & 92.5 & 100 & .422 \\
\hline Use a reference management tool & 17.9 & 0 & .092 \\
\hline
\end{tabular}


(such as Zotero or EndNote)

When working on class assignments

88.7

100

.066

or papers, NOT plagiarize or use

sources unethically

In research and classwork, use the

67

20

$.007^{*}$

language of the student's field

Be able to write an annotated

49.5

80

.201

bibliography

Be able to write a thesis statement

79.1

80

Basic skills. Regarding basic skills, $100 \%$ of faculty members agreed that they expected their students to display (a) basic writing and (b) basic comprehension skills, compared to $90.5 \%$ of students who agreed that they displayed basic writing skills and $90.5 \%$ of students who agreed that they displayed basic comprehension skills. In addition, $90 \%$ of faculty members agreed that they expected their students to display basic search skills, while $90.4 \%$ of students agreed that they displayed these skills. Comparisons of student and faculty responses to survey content items regarding basic skills are shown in Table 11.

Table 11

Percentage of Students Who Agreed Compared to Percentage of Faculty Members Who Agreed to Statements about Their Practices (Students) and Expectations (Faculty Members) Regarding Basic Skills

\begin{tabular}{llll}
\hline $\begin{array}{l}\text { Survey Item (Student Practice/Faculty } \\
\text { Expectation) }\end{array}$ & $\begin{array}{l}\text { Student } \\
\text { Percent Agreement }\end{array}$ & $\begin{array}{l}\text { Faculty } \\
\text { Percent } \\
\text { Agreement }\end{array}$ & $p$-value \\
\hline Display basic writing skills & 90.5 & 100 & .621 \\
Display basic comprehension skills & 90.5 & 100 & .451 \\
Display basic search skills & 90.4 & 90 & .870 \\
\hline
\end{tabular}


Attitudes. For attitudes, $100 \%$ of faculty members agreed that they expected their students to display (a) persistence, and (b) curiosity, compared to $81.1 \%$ of students who agreed that they displayed persistence, and $84.6 \%$ of students who agreed that they displayed curiosity. Additionally, $88.9 \%$ of faculty members agreed that they expected their students to display motivation, while $67.9 \%$ of students agreed that they displayed motivation. Finally, $88.9 \%$ of faculty members agreed that they expected their students to get out of their comfort zones, while $46.6 \%$ of students agreed that they got out of their comfort zones. One of these items showed a statistically significant difference between student and faculty results: get out of [the student's] comfort zone. In Table 12, I display the comparison of student and faculty responses to survey items in the category of attitudes.

Table 12

Percentage of Students Who Agreed Compared to Percentage of Faculty Members Who Agreed to Statements about Their Practices (Students) and Expectations (Faculty Members) Regarding Attitudes

\begin{tabular}{|c|c|c|c|}
\hline $\begin{array}{l}\text { Survey Item (Student Practice/Faculty } \\
\text { Expectation) }\end{array}$ & $\begin{array}{l}\text { Student } \\
\text { Agree, Strongly } \\
\text { Agree }\end{array}$ & $\begin{array}{l}\text { Faculty } \\
\text { Agree, } \\
\text { Strongly } \\
\text { Agree }\end{array}$ & $\begin{array}{l}p \text {-value } \\
(* \text { indicates } \\
\text { statistical } \\
\text { significance } \\
\text { at the }<0.05 \\
\text { level })\end{array}$ \\
\hline Display persistence & 81.1 & 100 & .124 \\
\hline Display curiosity & 84.6 & 100 & .305 \\
\hline Display motivation & 67.9 & 88.9 & .520 \\
\hline Get out of comfort zone & 46.6 & 88.9 & $.012 *$ \\
\hline
\end{tabular}


Citation. When it came to expectations and practices regarding citation, $50 \%$ of faculty members agreed that they expected their students to use APA style in their class assignments or papers, compared to $23.6 \%$ of students who agreed that they used APA style. In addition, $50 \%$ of faculty members agreed that they expected their students to use MLA style, while $75.5 \%$ of students agreed that they used MLA style, and $20 \%$ of faculty members agreed that they expected their students to use a citation style other than APA or MLA, while $11.4 \%$ of students agree that they used another citation style.

Overall, $80 \%$ of faculty members agreed that they expected their students to use APA, MLA, or another citation style, while $85.8 \%$ of students agreed that they used APA, MLA, or another citation style. A comparison of student and faculty responses to survey items regarding citation styles is displayed in Table 13.

Table 13

Percentage of Students Who Agreed Compared to Percentage of Faculty Members Who Agreed to Statements About Their Practices (Students) and Expectations (Faculty Members) Regarding Citation

\begin{tabular}{llll}
\hline $\begin{array}{l}\text { Survey Item (Student Practice/Faculty } \\
\text { Expectation) }\end{array}$ & $\begin{array}{l}\text { Student } \\
\text { Percent Agreement }\end{array}$ & $\begin{array}{l}\text { Faculty } \\
\text { Percent } \\
\text { Agreement }\end{array}$ & $p$-value \\
\hline $\begin{array}{l}\text { Use APA citation style in class } \\
\text { assignments or papers }\end{array}$ & 23.6 & 50 & .157 \\
$\begin{array}{l}\text { Use MLA citation style in class } \\
\text { assignments or papers }\end{array}$ & 75.5 & 50 & .071 \\
$\begin{array}{l}\text { Use a citation style other than APA or } \\
\text { MLA in class assignments or papers }\end{array}$ & 11.4 & 20 & .515 \\
\hline
\end{tabular}




\section{Research Questions and Data}

In this section, I talk about each of my research questions, and how my data helps to answer each of them. I begin by explaining how I used data to answer the first and second research questions, followed by how I used data to answer the third and fourth research questions.

\section{Student Practices and Faculty Expectations}

To begin, I used data from the qualitative part of the study to answer Research Questions 1 and 2, which centered on faculty expectations of information literacy practices, and student information literacy practices. Again, my first two research questions were (a) what information literacy practices do faculty members expect freshman students to use?, and (b) What information literacy practices do freshman students use?

In the interviews, students and faculty members described a number of practices and expectations, within the context of attending a course, doing academic work, or teaching a course. One strength of the qualitative data was that it allowed me to hear students and faculty members describe their experience in their own words and bring up topics that were important to them. I found a variation in the expectations that the participants mentioned during the interview. The academic practices and topics mentioned by student participants are listed in Table 14, and the expectations and topics mentioned by faculty member participants are listed in Table 15 . 
INFORMATION LITERACY

Table 14

Freshman Student Academic Practices from Interview Data

Practices and topics identified by students in interviews

Find information in databases, magazine articles, newspapers

Go to the university library building

Use the university library website

Use databases for specific fields (i.e. sociology)

Determine credibility by looking at the type, origin or publisher of sources

Look up information about author to determine credibility

Give credit to author by using APA or MLA

See passion as being important for success

Write an outline

Go to Google Scholar for information

Ask reference librarians for help

Want more information on plagiarism and citing sources properly

Find peer-reviewed journals

Look at information critically

Are confused by university library databases

Use the Internet

Use Wikipedia

Use online newspapers

Use a reference list or works cited page

Look for authors who are experts

Frame arguments based on literature

Evaluate the experiment described in an article

Table 15

Faculty Member Expectations for Freshman Students from Interview Data

Expectations and topics identified by faculty members in interviews

Go to the university library building

Use the university library website

Show sources

In writing, have a conversation with experts in the field

Identify primary/secondary sources

Pick a topic they have interest in

Use scholarly sources

Use facts based on evidence/back up statements with evidence 
Back up claims

Do not use Wikipedia as a source

Critically evaluate information

Be able to write a thesis statement

Be able to write an annotated bibliography

Have curiosity and motivation

Go beyond the first page of search results

When entering as a freshman, have basic writing, understanding, note-taking skills

Think critically

Get out of their comfort zones

Know how to find a reliable source

Know how to cite sources

Use Google Scholar through the university library link

Question what they read

Give credit to other authors for their information

Recognize the relevant journals, books, and databases to answer their research questions

Locate books and journals

Use the language and keywords for their fields

Have a command of their online presence

Use peer-reviewed sources

Use credible newspapers

Distinguish between scholarly and academic sources

Have basic search skills

Be able to refine searches

Understand what a good source is depending on the context

Use a reference management tool

Additionally, I used data from the quantitative part of the study to explore faculty expectations and student practices. When I constructed the survey instrument, I distilled the lists from both Tables 14 and 15 into 42 content items to address the student practices and expectations, while allowing these practices and expectations to be presented in an easy to understand and parallel format. The data from the survey instrument gave me an idea of whether the practices or expectations were common to students and faculty members, by allowing me to compare the percentage of students or faculty members who agreed with each practice or expectation. Figures 1-14 show the percentages of how 
INFORMATION LITERACY

many student and faculty members agreed with statements about their practices and expectations.

\section{Alignment and Differences of Student Practices and Faculty Expectations}

To answer Research Questions 3 and 4, which examined the alignment and differences in faculty expectations and student practices, I used data from the survey. Again, the third and fourth research questions were (a) how do faculty members' information literacy expectations and students' information literacy practices align?, and (b) how do faculty members' information literacy expectations and students' information literacy practices differ?

Using survey data, I examined each of the 42 expectations/practices individually. I was able to see which of these items aligned, or in other words, which practices faculty members expected students to do and students reported doing. On the other hand, I was also able to identify differences, or which practices faculty members expected and students reported not doing, or conversely, which practices faculty members did not report expecting, and students reported doing. Of the 42 survey items, I found that 34 had a gap of more than $10 \%, 25$ had a gap of more than $20 \%, 17$ had a gap of more than $30 \%$, and eight had a gap of more than $40 \%$. Table 16 shows the difference in percentages of students and faculty members agreeing to the survey items.

Table 16

Difference in Student and Faculty Agreement to Survey Items

\begin{tabular}{llll}
\hline Survey Item & Student & Faculty & Difference in \\
& Agreement & Member & Percent \\
& & Agreement & Agreement
\end{tabular}




\begin{tabular}{|c|c|c|c|}
\hline $\begin{array}{l}\text { Go beyond the first page of web or database } \\
\text { results** }\end{array}$ & 18.9 & 80 & -61.1 \\
\hline $\begin{array}{l}\text { When writing a paper, enter into a conversation } \\
\text { with experts in the field of the topic }\end{array}$ & 18.9 & 70 & -51.1 \\
\hline $\begin{array}{l}\text { Go to the university library building to do } \\
\text { research }\end{array}$ & 31.1 & 80 & -48.9 \\
\hline $\begin{array}{l}\text { In research and classwork, use the language of the } \\
\text { student's field }\end{array}$ & 67 & 20 & +47 \\
\hline $\begin{array}{l}\text { Locate journal articles through the university } \\
\text { library website }\end{array}$ & 53.8 & 100 & -46.2 \\
\hline $\begin{array}{l}\text { Locate physical books in the university library } \\
\text { building }\end{array}$ & 46.2 & 90 & -43.8 \\
\hline Get out of comfort zone & 46.6 & 88.9 & -42.3 \\
\hline $\begin{array}{l}\text { Ask librarians at university library for assistance } \\
\text { (in person or via chat, email, text, or phone) }\end{array}$ & 48.1 & 90 & -41.9 \\
\hline Question what they (students) read on the Internet & 61.6 & 100 & -38.4 \\
\hline $\begin{array}{l}\text { Locate electronic books through the university } \\
\text { library website }\end{array}$ & 51.9 & 90 & -38.1 \\
\hline Use the university library website to do research & 52.4 & 90 & -37.6 \\
\hline $\begin{array}{l}\text { Question students' beliefs when they find new } \\
\text { information that contradicts those beliefs }\end{array}$ & 42.9 & 80 & -37.1 \\
\hline $\begin{array}{l}\text { Be able to tell the difference between popular and } \\
\text { academic sources }\end{array}$ & 64.1 & 100 & -35.9 \\
\hline $\begin{array}{l}\text { Use Google Scholar to find scholarly or academic } \\
\text { sources }\end{array}$ & 44.3 & 80 & -35.7 \\
\hline $\begin{array}{l}\text { NOT find sources for class assignments and } \\
\text { papers on websites that end with .com or .org** }\end{array}$ & 6.6 & 40 & -33.4 \\
\hline $\begin{array}{l}\text { Pick topics that they (students) are interested in } \\
\text { for their papers }\end{array}$ & 57.6 & 90 & -32.4 \\
\hline Be able to write an annotated bibliography & 49.5 & 80 & -30.5 \\
\hline $\begin{array}{l}\text { Take the context of a source into account when } \\
\text { determining its credibility and appropriateness }\end{array}$ & 71.7 & 100 & -28.3 \\
\hline $\begin{array}{l}\text { Find scholarly, academic, and/or peer-reviewed } \\
\text { sources for class assignments and papers }\end{array}$ & 62.2 & 90 & -27.8 \\
\hline Be able to identify a credible source & 72.4 & 100 & -27.6 \\
\hline $\begin{array}{l}\text { Think critically about the information they } \\
\text { (students) read in books, articles, or other sources }\end{array}$ & 72.4 & 100 & -27.6 \\
\hline Find credible sources for papers & 72.7 & 100 & -27.3 \\
\hline $\begin{array}{l}\text { Use APA citation style in class assignments or } \\
\text { papers }\end{array}$ & 23.6 & 50 & -26.4 \\
\hline $\begin{array}{l}\text { Use MLA citation style in class assignments or } \\
\text { papers }\end{array}$ & 75.5 & 50 & +25.5 \\
\hline
\end{tabular}


Display motivation

Use scholarly, academic, and/or peer-reviewed

sources for class assignments or papers

Display persistence

Locate hard-copy journals in the library building

Use the appropriate keywords for a topic when searching in an online database or search engine Use a reference management tool (such as Zotero or EndNote)

Display curiosity

Recognize the relevant journals, books, and databases to answer a research question Use facts and/or evidence to back up claims in class assignments and papers

When working on class assignments or papers, NOT plagiarize or use sources unethically

Display basic writing skills

Display basic comprehension skills

Use a citation style other than APA or MLA in class assignments or papers

When using other people's work in class

assignments or papers, give credit to the author Be able to identify a primary source and a secondary source

Be able to write a thesis statement

Display basic search skills

NOT use Wikipedia as a scholarly or academic source**
67.9

88.9

$-21$

70.8

90

$-19.2$

81.1

100

$-18.9$

21.7

40

$-18.3$

71.7

90

$-18.3$

17.9

0

$+17.9$

84.6

100

$-15.4$

55.

70

$-14.4$

86.7

100

$-13.3$

88.7

100

$-11.3$

90.5

100

$-9.5$

90.5

100

$-9.5$

11.4

20

$-8.6$

92.5

100

$-7.5$

54.7

60

79.1

80

$-0.9$

90.4

90

$+0.4$

69.8

70

$-0.2$

**student scores have been reversed for these items

In response to the alignment and differences between student practices and faculty member expectations, I found eight student practices and faculty expectations that were close to alignment, that is to say, the number of students and faculty members who agreed to these items were within $10 \%$ of each other. Another 17 student 
practices/faculty expectations differed moderately, by which I mean that the number of students and faculty members who agreed to these items were less than $30 \%$ different from each other. The remaining 17 student practices/faculty expectations differed greatly, with between $30 \%$ and $60.1 \%$ difference in agreement.

\section{Survey Reliability}

I developed the survey instrument for use in my study; therefore, it had no previous testing with regard to reliability. Litwin (1995) defined reliability as "a statistical measure of how reproducible the survey instrument's data are" (p. 6), or in other words, how often a survey instrument would produce the same results. Due to the nature of my study, which was a cross-sectional design in which I used the survey instrument one time, I decided to examine internal consistency reliability, which Litwin described as "another commonly used psychometric measure in assessing survey instruments and scales. It is applied not to single items but to groups of items that are thought to measure different aspects of the same concept" (p. 21). To assess my survey instrument for internal consistency reliability, I used Cronbach's $\alpha$ (alpha), a common measurement for reliability (Field, 2013). First, I grouped 37 of the 42 content statements into five categories: find, evaluate, use, basic skills, and attitudes. The remaining five content items, falling into the find reverse structure and citation categories, were structured differently and were analyzed separately, and were therefore not included in the reliability analysis. In each of the five thematic categories that I examined for reliability, I correlated student responses to each of the items. A Cronbach's $\alpha$ value of .7 or .8 is a generally accepted threshold for reliability (Field, 
2013). All five of the categories I examined with Cronbach's $\alpha$ had a reliability statistic of over .7. The items in the find category had a Cronbach's $\alpha$ statistic of .835. Similarly, the items in the evaluate category had a Cronbach's $\alpha$ statistic of .813. The items in the use category had a Cronbach's $\alpha$ statistic of .779. The highest Cronbach's $\alpha$ statistic was with the items in the basic skills category, which had a statistic of .910. Finally, the items in the attitudes category had a Cronbach's $\alpha$ statistic of .786. The thematic categories and their Cronbach's $\alpha$ statistics are displayed in Table 17.

Table 17

Thematic Category with Number of Items and Cronbach's a Reliability Statistic

\begin{tabular}{ll}
\hline Category (number of items) & Cronbach's $\alpha$ \\
\hline Find (13) & .835 \\
Evaluate (7) & .813 \\
Use (10) & .779 \\
Basic Skills (3) & .910 \\
Attitudes (4) & .786 \\
\hline
\end{tabular}

\section{Limitations}

Several limitations need to be taken into account when looking at the results of the study. I begin by discussing the limitations of the qualitative interviews, followed by a discussion of the limitations of the quantitative survey.

\section{Interview Limitations}

One limitation of the interviews was their format. With the intention of making interviews accessible to all participants, but not requiring them to come to campus or another location, I conducted the interviews by phone. In retrospect, I may have been able to get more information from the participants in person, because the participants may 
have felt more comfortable speaking to me in person, and they may have been more interested in extending the conversation or offering more details. On the other hand, it is possible that participants could have felt less comfortable in person. However, in person, I would have had the advantage of using nonverbal communication to encourage participants to share more information. Another limitation of the interviews was their length. Each phone interview lasted between 10 and 20 minutes, and I may have been able to obtain more information if I had planned for longer interviews, for example, of 30 to 60 minutes. Conversely, planning for interviews of a greater length may have discouraged participation. Another option to extend the interviews and get more data would have been to add additional questions to the interview protocol. In summary, there were several factors to the interview process that may have limited the data I obtained.

In addition, the perspectives of interview participants may have been biased, because participants who already had a strong interest in the topics of information literacy, student practices, faculty expectations, or education in general, may have volunteered to be interviewed. Therefore, the responses these participants gave may not have been typical of responses for the larger population. Instead, students and faculty members who were more interested in information literacy and academic practices may have been more likely to contact me and follow through with the interview, and I may not have had the perspective of students and faculty members who were not interested in information literacy and academic practices. 


\section{Survey Limitations}

One of the most important limitations of the survey was that the student sample differed in several ways from the greater student population (see Table 3), in terms of gender, race/ethnicity, age, and international student status. Due to this limitation, results from the sample population may not be generalizable to the larger population. The same is true for the faculty population (see Table 7), in which the sample differed from the greater population in terms of gender.

Another major limitation of the survey was the low number of participants, for both students and faculty members. Due to the low number of participants, it was not possible to analyze certain demographic items and their relationship to content items, which limited my understanding of possible differences in student practices or faculty expectations based on demographic characteristics.

The survey was also based on self-reported perception data, meaning that participants chose their answers based on what they believed, without any external verification (e.g., observations) of the responses. In addition, student and faculty member survey participants likely differed in their perception of agreement and disagreement, meaning that one participant's "strongly agree" was not necessarily equal to another participant's "strongly agree."

Finally, I chose to use a 6-point Likert scale. This scale asked participants to choose strongly agree, agree, somewhat agree, somewhat disagree, disagree, or strongly disagree. It did not give participants an option for neutral, or neither agree nor disagree. When analyzing the data, I decided that somewhat agree and somewhat disagree were not 
indicative of true agreement or disagreement, but in fact were closer to that neutral option that I had neglected to include. In retrospect, it might have been advantageous to use a 5point Likert scale, with strongly agree, agree, neither agree nor disagree, disagree, and strongly disagree. Another option would have been to include a 4-point Likert scale with the categories of strongly agree, agree, disagree, and strongly disagree. 


\section{Chapter 5: Discussion and Recommendations}

In this chapter, I discuss the results of the study. To review, the purpose of my study was to examine whether or not an alignment exists between information literacy faculty member expectations and information literacy student practices. Again, I used four research questions to guide my study:

1. What information literacy practices do faculty members expect freshman students to use?

2. What information literacy practices do freshman students use?

3. How do faculty members' information literacy expectations and students' information literacy practices align?

4. How do faculty members' information literacy expectations and students' information literacy practices differ?

I addressed these four research questions using an exploratory sequential mixed methods study (Creswell, 2014), in which I conducted qualitative interviews of students and faculty members, used the data from the interviews to develop a survey instrument, piloted the study, and then conducted a survey of a larger group of freshman students and faculty members.

\section{Synthesis of Findings}

Results are most meaningful when discussing the data from the student and faculty member surveys together. Therefore, I first discuss each of the categories of content items (find, evaluate, use, basic skills, attitudes, and citation). In each of these categories, I mention interview data that is relevant to the survey data. Then, I discuss 
the demographic differences in survey content item responses among students. Next, I discuss how the data answers my research questions and how it is related to my theoretical framework and research literature. Then, I make recommendations based on those findings, first in thematic categories, and then as a whole.

Find. Looking at the category of finding information (see Table 8), one pattern that stood out was that $50 \%$ or fewer of student participants agreed to three items that seem important for freshman students. Just over half, or 53.8\% of students agreed that they located journal articles through the library website, meaning that the remaining students are either locating journal articles in some other way, or are not locating journal articles at all. Similarly, only $52.4 \%$ of students agreed that they used the university library website to do research, and only $51.9 \%$ agreed that they located electronic books through the university library website. These results seem to indicate that freshman students are not taking advantage of the subscription databases and the collection of electronic books that are available through the library website. It is possible that some students are not aware of these resources, while others may not know how to use them. In fact, during the interviews, one of my student participants disclosed that she would like more training on using the university library website, which reinforces the idea that students could benefit from training in the use of these resources. This finding is particularly important when examined in conjunction with faculty responses.

In response to the parallel content items, $100 \%$ of faculty member participants agreed that they expected students to be able to locate journal articles through the library website. In addition, $90 \%$ of faculty members agreed that they expected students to use 
the university library website to do research, and $90 \%$ of faculty members agreed that they expected students to be able to locate electronic books through the university library website. To summarize, a gap exists between student practices and faculty member expectations when it comes to using the university library online resources, including the library website, and the ability to access journal articles and electronic books.

My findings also indicate that even fewer students are finding information at the physical library. Only $31.1 \%$ of students agreed that they went to the university library to do research, and only $21.7 \%$ agreed that they could locate hard-copy journals in the library. This finding may mean that students are not using the physical library. This is not necessarily negative because it may mean that students are able to find all the resources they need online, including journal articles and books. However, I also found that only around half of students are using the library's online resources. My overall results about finding information seem to indicate that many students are not accessing physical and online library resources, and this leads to concern about whether or not these students have sufficient resources to do their academic work. Regarding use of the physical library, $80 \%$ of faculty members agreed that they expected their students to go to the university library building to do research (compared to $31.1 \%$ who agreed that they went). In addition, $40 \%$ of faculty members agreed that they expected their students to be able to locate hard-copy journals in the library (compared to $21.7 \%$ who agreed that they could). Overall, survey data in this area reveals a gap in student practices and faculty expectations when it comes to use of the physical library, in addition to the library's online resources. 
When it came to reverse structure questions about finding information, survey responses regarding Wikipedia were encouraging. Among all student participants, only $8.5 \%$ agreed that they used Wikipedia as a scholarly or academic source. This is a positive finding, as it indicates that most students are not using Wikipedia as a scholarly or academic source. Again, four out of the six faculty members I interviewed reported that the use of Wikipedia as a scholarly or academic source was a concern. The interview data aligned with the survey data, in which $70 \%$ of faculty members agreed that they expected their students not to use Wikipedia as a scholarly or academic source.

Evaluate. When it came to evaluating information, more than two thirds of students agreed to several of the content items regarding evaluating sources (see Table 9), with $72.4 \%$ agreeing that they could identify a credible source, $72.4 \%$ agreeing that they thought critically about information that they read, and $71.7 \%$ agreeing that they take the context of a source into account when determining its credibility and appropriateness. In addition, $61.6 \%$ agreed that they questioned what they read on the Internet. These findings indicate that the majority of students may be already be practicing evaluation skills during their freshman year, while other students are still developing those skills. Regardless, I still identified a gap between student practices and faculty expectations, as $100 \%$ of faculty members agreed that they expected their students to (a) be able to identify a credible source, (b) think critically about information that they read, and (c) take the context of a source into account when determining its credibility and appropriateness. This indicates a gap between student practices and faculty expectations 
when it comes to identifying credible sources, looking critically at information, and taking the context of a source into account during evaluation.

On the other hand, fewer students reported that they questioned their beliefs. In total, $42.9 \%$ of students agreed that they questioned their beliefs when they found new information that contradicted those beliefs. This may indicate that students are evaluating information with their beliefs in mind, discarding information that does not support those beliefs, and retaining that information that does support those beliefs, a common practice known in psychology as the confirmation bias. Casad (2007) defined confirmation bias as "processing information by looking for, or interpreting, information that is consistent with one's existing beliefs" (para. 1). In other words, students are more likely to assimilate new information if it fits what they already believe. Casad wrote:

The confirmation bias is important because it may lead people to hold strongly to false beliefs, or to give more weight to information that supports their beliefs than is warranted by the evidence...these factors may lead to risky decision making and lead people to overlook warning signs and other important information. (para. 8) Whether students' self-reported behavior can be attributed to the confirmation bias or to other factors such as community or family influences, the percentage of student agreement contrasts with the faculty expectation, in which $80 \%$ of faculty members agreed that they expected their students to question their beliefs when they found new information that contradicted those beliefs.

Use. Overall, students reported strong skills when it came to information literacy skills regarding using information. Most students (92.5\%) agreed that they credited 
authors when they used their work, and $88.7 \%$ agreed that they did not plagiarize or use sources unethically. While these results indicate that most students report properly crediting authors, it also indicates that about one in 10 students do not, which is a concern for faculty members. Assuming that these groups of students overlap, faculty members with 30 students in their class may need to worry about three students not giving credit to authors or plagiarizing. Faculty members had high expectations when it came to giving credit to authors and not plagiarizing, with $100 \%$ of faculty members agreeing that they expected students to (a) give credit to the author when using other people's work, and (b) not plagiarize or use sources unethically. This contrast in student and faculty member results highlights a small, but potentially important, gap between student practices and faculty member expectations. However, this finding should be taken cautiously, because neither of these survey items showed a statistically significant difference.

The percentage of students agreeing that they used facts and/or evidence to back up their claims (86.7\%) was high, as was the percentage of students agreeing that they used scholarly, academic, and/or peer-reviewed sources (70.8\%). While this shows that many students may be using credible sources in their work, it also highlights the fact that the remaining students, nearly one third, may not be using scholarly, academic, and/or peer-reviewed sources. This inspires two questions: where are these students finding their information, and what types of sources are they using? When the student rate of agreement is compared to the faculty member rate of agreement, in which $100 \%$ of faculty members agreed that they expected students to use facts and/or evidence to back up their claims, and $90 \%$ of faculty members agreed that they expected their students to 
use scholarly, academic, and/or peer-reviewed sources, this highlights the finding that there is a gap between student practices and faculty member expectations with regard to using credible sources and substantiating claims. The difference between student and faculty member responses on the survey item regarding using facts/evidence to back up claims was statistically significant ( $p=.047)$, lending strength to this finding.

Another concerning finding was that only $57.6 \%$ of students agreed that they could pick topics that they were interested in for their papers. This may indicate that students could not identify a topic of interest within the scope of their class or assignment; however, it might also indicate that students could use more support in the process of identifying a topic. In contrast, $90 \%$ of faculty members agreed that they expected students to pick topics that they were interested in for their papers, demonstrating a gap between student practices and faculty member expectations when it comes to picking topics.

One surprising result was that $67 \%$ of students agreed that they used the language of their field. This result was surprising because many freshman students have not yet identified their major, and therefore may not have identified the language of their field. However, perhaps some students interpreted this question to mean the language of the field of the class in which they were enrolled. Either way, it is an encouraging result, as many students may be attempting to communicate using an academic language. This result contrasts with the $18.9 \%$ of students who agreed to entering into a conversation with experts in their field when writing a paper. Learning a language is a precursor to having a conversation in that language, and the survey findings may reflect the 
progression of these steps as applied to academic language and the academic conversation.

Basic skills. I found that student practices and faculty expectations were closely aligned in the area of basic skills (writing, comprehension, and search). Still, one in 10 students did not agree that they displayed basic writing, comprehension, and search skills, indicating that there may still be several students in each course who would benefit from continued instruction in these areas. Because the survey is based on self-perception, it is not possible to know if these students actually did not display these skills, or if their selfassessment was lower than what they demonstrated in the course. Likewise, it is not possible to know if all students who agreed that they displayed these basic skills actually displayed them in their courses.

Attitudes. I found a gap between student practices and faculty expectations in the area of attitudes, including curiosity, persistence, motivation, and students getting out of their comfort zones. The most drastic finding regarded students getting out of their comfort zones, in which $88.9 \%$ of faculty members agreed to this expectation, and only $46.6 \%$ of students agreed to the practice, with a statistically significant difference ( $p=$ $0.12)$.

\section{Student Demographic Differences}

I found few meaningful and statistically significant differences in student responses to the content items based on demographic factors. The fact that so few of the student demographic variables resulted in meaningful and statistically significant results

does not mean that there were no differences; it means that the group of participants was 
too small to be able to look at these variables, some of which had several categories. The two variables that did produce meaningful and statistically significant results (home language and first generation) only had two options. To be able to run contingency table analyses with content items and demographic variables and get a better sense of how demographic factors may be related to student experiences, I would need to have a much larger group of participants. Two hundred participants would be helpful to be able to compare groups, and even more than two hundred participants would be better.

Home language. The demographic variable of home language contributed the most to the analysis of demographic differences. The survey item associated with this variable asked students to report whether they spoke a language other than English at home. Eight content survey items showed a statistically significant difference between students who spoke a language other than English at home, and students who did not (see Table 5).

Students who speak a language other than English at home may have a wide variety of experiences. The demographic item that identified students who speak a language other than English was a yes/no question, and did not capture any additional information about students' experiences, such as their level of English fluency, how many additional languages they spoke, or their level of written and oral communication and comprehension. However, one interpretation of this data may be that these students were more likely to have less fluency in English, or to have learned it later in life than their counterparts who spoke English as a home language. My interpretation is supported by some of the contingency table results with statistical significance: students who spoke 
a language other than English at home assessed three out of their four basic skills at a lower rate than students who spoke English as a home language. While $95.1 \%$ of students who spoke English as a home language agreed that they displayed basic writing skills, only $76.9 \%$ of students who spoke a language other than English at home agreed that they did so. Similarly, $93.8 \%$ of students who spoke English at home agreed that they displayed basic comprehension skills, compared to $80.8 \%$ of students who spoke another language at home. In addition, $94.8 \%$ of students who spoke English as a home language agreed that they displayed basic search skills, while $77 \%$ of students who spoke a language other than English at home agreed to this item. Students' English proficiency may be at the root of these differences in assessment of basic skills, although there are other possible factors. For example, students who speak a language other than English at home may be more critical of their basic skills, and may assess them as lower than other students, although there may not be a real difference in the basic skills of students speaking English as a home language, and students speaking another language. It would be necessary to conduct additional research, such as objective measurements of skills or of English language proficiency, to learn more about the meaning of these differences. Another basic skill required by many instructors in the first year of college is writing a thesis statement. Of students who spoke English at home, $86.1 \%$ agreed that they could write a thesis statement, compared to $57.7 \%$ of students who spoke a language other than English at home. This may indicate that students speaking a language other than English at home could benefit from additional instruction and resources regarding writing thesis statements. 
Finally, students who spoke a language other than English at home were more likely to use Wikipedia as a scholarly or academic source, with $19.2 \%$ of these students agreeing that they did so, compared to $5.1 \%$ of students who did not speak a language other than English at home. The percentage of students who spoke a language other than English at home and reported using Wikipedia as a scholarly source was still low overall, with less than 1 in 5 students reporting this practice.

Three additional contingency tables revealed statistical significance among variables when it came to students' home language, and showed a higher percentage of agreement for students with English as a home language compared to students who spoke another language at home. To start with, $82.2 \%$ of students speaking English as a home language agreed that they could identify a credible source, compared to $42.3 \%$ of students speaking another language at home. This may indicate that students speaking a language other than English at home could benefit from extra support or resources regarding assessing credibility of sources.

With regard to students questioning their own beliefs, $51.9 \%$ of students speaking English as a home language agreed that they questioned their beliefs when they found new information that contradicted those beliefs, compared to $15.4 \%$ of students who spoke a language other than English at home. It should be noted that across all demographic groups only $42.9 \%$ of students agreed to the item about questioning their beliefs. This may indicate that students saw questioning their beliefs as an undesirable activity, perhaps going against traditional or religious beliefs, and in students speaking a home language other than English the negative view of questioning their beliefs may 
have been even stronger. If this activity is seen negatively by freshman students, perhaps faculty members could examine the way in which they are approaching this type of activity, and to see if it could be approached in a way that is not threatening to students. For example, asking students to question their religious beliefs could be seen as threatening, whereas more benign subjects such as beliefs about where food items originated (e.g. potatoes from the Americas) could be an easier way for students to begin thinking critically about their worldviews.

Overall, among the eight content items with statistically significant differences, a lower percentage of students speaking a language other than English at home agreed to the content items compared to students who spoke English as a home language. One contingency table analysis revealed an exception to this rule. When it came to using keywords, $76 \%$ of students speaking a language other than English at home agreed that they could use the appropriate keywords for their topic when searching in an online database or search engine, compared to $70 \%$ of students speaking English as a home language who said that they could do so. Although this difference is statistically significant, it is too small to be able to attribute meaning to it, except to say that as a whole these two demographic groups of students report similar skill levels when it comes to using keywords, and that using keywords may not be an area of information literacy in which students speaking a language other than English at home have a particular vulnerability.

First generation. In looking at statistically significant differences between first generation students and students who were not first generation, three content items stood 
out (see Table 6). The most interesting one was when it came to questioning beliefs. Similarly to students speaking a home language other than English, fewer first generation students agreed that they questioned their beliefs (28.3\%) when they found new information that contradicted them, compared to $55.2 \%$ of students who were not first generation. Like students who speak a home language other than English, first generation students may have taken this as a more negative practice. However, it should be noted that overall, across demographic groups, only $42.9 \%$ of students agreed to this item, and that most students did not agree that they questioned their beliefs, although $80 \%$ of faculty member participants agreed that they had this expectation. It is not necessarily negative that there is a gap between student practices and faculty expectations, as higher faculty member expectations may motivate students to raise their level of practice to meet them.

Another content item in which there was a difference for first generation students and students who were not first generation regarded librarians. When it came to asking librarians at the university library for assistance, $61.7 \%$ of first generation students agreed that they did so, compared to $38 \%$ of students who were not first generation. One possible interpretation of this finding is that first generation students require more assistance from librarians, and ask for it. Another interpretation is that first generation students are more comfortable asking for assistance from librarians than students who are not first generation. In either case, it does mean that the library and librarians are a resource that is being used by first generation students, a group that may sometimes be at 
risk academically (Ishitani, 2006). Therefore, this finding emphasizes the importance of having librarians accessible for students.

The third content item where first generation and non-first generation students had a statistically significant difference was with regard to citation styles. Around 1 in 5, or $21.2 \%$ of first generation students said that they used a citation style other than APA or MLA in their class assignments and papers, compared to $3.4 \%$ of students who were not first generation. This may indicate that first generation students are less familiar with APA and MLA, the citation styles most commonly required at the university. There may be other possible interpretations, such as first generation students being more willing to try another citation style such as Chicago.

Gap between practices and expectations. As I brought up in the introduction to this paper, a gap between practices does not necessarily indicate that there is a deficiency on the part of students. More than anything, it may indicate a lack of understanding or communication between students and faculty members. That said, there are many survey items in which the percentage of agreement in students was notably different from the percentage of agreement in faculty members. While in eight out of the 42 content questions, student and faculty member responses were within $10 \%$ of each other, which I consider to be aligned, the remaining content items demonstrated misalignment. As my data shows in the previous chapter, in 34 out of the 42 items, there was a difference of greater than $10 \%$ percent, in 25 there was a difference of greater than $20 \%$, in 17 there was a difference of greater than $30 \%$, and in eight there was a difference of greater than 40 percent. In 38 items, the percent agreement for faculty expectation was higher than 
that of student practices, while in four items, the percent agreement for student practices was higher than that of faculty expectations. Overall, these findings demonstrate a gap in which faculty expectations are generally higher than student practices.

Despite these findings, my study does not answer conclusively whether or not the gap between student practices and faculty member expectations exists. As I mentioned when I discussed the limitations of my study, the number of participants was low, and may have prevented me from gaining a good representation of student practices and faculty expectations. I also found that the differences in student responses and faculty responses were statistically significant in only 12 out of 42 of the content items. In other words, the differences between student and faculty member responses could have been caused by chance. Yet, the research literature and my findings indicate the possible existence of a gap. For this reason, I recommend that the alignment and differences between student practices and faculty member expectations needs to be studied further, with a larger group of participants.

\section{Connection to Research Literature}

My findings added an additional voice to the research literature, reinforcing some scholars' ideas, while presenting a different outlook from others. For example, McGuiness (2006) found that faculty members considered students responsible for their own development of information literacy, while my findings suggest that faculty and students share responsibility. In general, faculty members who participated in the interviews gave the impression that both faculty members and students needed to be active for information literacy development. These faculty members had high 
expectations for their freshman students; however, they also talked about the high level of support and scaffolding that they offered their students. I do not know if the faculty members that I interviewed were representative of other faculty members; it is possible that the ones I interviewed already had an interest in information literacy, and had already given some thought into how to support their students in its development. A good line of inquiry to pursue in future research would be to ask faculty members about the support that they offered their students to develop information literacy.

In addition, my findings do not strongly reinforce the conclusions of Leckie (1996), who reported a lack of understanding between faculty members and students. Although my survey found a gap between many student practices and faculty expectations, it also found areas of alignment. Furthermore, my interviews of faculty members revealed strong support for freshman students' development of information literacy.

On the other hand, my survey data did support the conclusions of Avdic and Eklund (2010), who found a gap between faculty member and student understandings when it came to the use of research databases. I found a large gap between faculty member expectations and student practices when it came to (a) using the university library website; (b) locating journal articles through the university library website (an activity which centers on the use of research databases) and of the use of the university library; and (c) recognizing the relevant online resources to use to find information. 
INFORMATION LITERACY

\section{Theoretical Framework}

In my study, I used the theoretical framework of sociocultural theory, which states that culture is central to human development and learning (Vygotsky, 1978). I used sociocultural theory as my framework because the way in which people interact with information is a part of human culture (Limberg, Sundin, \& Talja, 2013). In essence, my study focused on a very narrow aspect of culture: the interactions between freshman students, faculty members who teach freshman students, and the cultural artifacts of information sources.

I earlier referred to the zone of proximal development (Vygotsky, 1978), which according to sociocultural theory is the place in which a learner is unable to complete a task alone, but can do so with the guidance of a more experienced practitioner. I assert that the learning of many of the information literacy practices examined in my study would fall within the zone of proximal development. Ultimately, as I discuss in my recommendations, students could benefit from having support as they learn to engage with information in the ways that faculty members expect for success in their academic work.

According to sociocultural theory, learning takes place through social interactions. It may actually be encouraging that faculty member expectations are generally higher than student practices. Wass and Golding (2014) examined the ZPD using conceptual analysis, and came up with recommendations for teachers in higher education. They concluded, 
Teachers should assign tasks that students cannot do on their own, but which they can do with assistance; they should provide just enough assistance so that students learn to complete the tasks independently and, finally, teachers can increase learning gains by providing learning environments that enable students to do harder tasks than would otherwise be possible and by assigning the hardest tasks students can do with assistance. (p. 671)

In relation to my findings, the gap between student practices and faculty expectations may demonstrate that faculty members are more experienced, and in a position to guide students toward being more information literate. Faculty members' high expectations may encourage students to learn more, as long as those expectations are clearly communicated. The gap that I found in my data between student practices and faculty expectations may indicate that faculty members are operating within the zone of proximal development by encouraging students to perform at a higher level, and supporting them as they develop skills. In this way, my results support the idea that faculty members may be operating within the zone of proximal development, as their expectations for students are high. In addition, the faculty members that I interviewed were all providing support for students in developing a higher level of skills, through faculty member instruction, through work with the library, and through class materials.

\section{Implications}

My study had a limited number of participants and a narrow focus, contributing a small piece to the larger picture of information literacy in higher education. Despite the size of my study, its findings still have implications for practice for freshman students 
and faculty members. In the following section, I present recommendations by thematic category area, followed by my recommendations based on demographic groups, and finally overall recommendations.

Find recommendations. One key finding in the area of finding information is that students are not accessing sufficient physical and online library resources. To complete satisfactory academic work, and to meet faculty member expectations, more students need to access online or physical library resources to find information. Some of the interviewed faculty members discussed ways in which they support students' use of library resources, and I recommend two of these practices: (a) bringing students to the library building or requiring them to go to the library building to complete a task, such as checking out a book; and (b) working with a librarian to develop activities for students, or having a librarian speak to the class. In addition, based on survey results, and student interview data, I recommend that faculty members not assume that students already know how to access online resources for finding information. Instead, I suggest that faculty members, either on their own or working with a librarian, teach students to use online library resources such as databases. Even students who are familiar with using these resources may discover new options and possibilities during a training session, especially if they are conducted with a trainer, whether faculty member or librarian, who knows advanced features of those online resources. Faculty members may also want to consider optional training sessions for students on the use of online resources, or sessions outside class in which students can earn participation points. For students, my recommendation is to take advantage of the online resources offered by their university, and to ask for help 
from the university librarians. At the university where my study took place, librarians will set aside blocks of time to assist students with searches, and to help students understand basic and advanced features of online resources. I would imagine that this kind of assistance is possible at many universities, and recommend that students take advantage of this library service.

Regarding the finding that only $8.5 \%$ of students (or less than one in 10) are using Wikipedia as a scholarly or academic source, I believe this demonstrates the success of instructors and librarians at the university in their education about the appropriate use of Wikipedia, as well as students' success in using this source appropriately. My recommendation in this area is for faculty members to continue to include the appropriate use of Wikipedia in their instruction, and for students to continue to use this resource appropriately.

Evaluate recommendations. Based on the finding that there is a gap between student practices and faculty expectations when it comes to identifying credible sources, looking critically at information, and taking the context of a source into account during evaluation, I would recommend that faculty members focus attention on these evaluative practices. Several frameworks can help students think about and develop evaluation skills, such as the C.R.A.A.P. test (Blakeslee, 2004). One of my faculty member interview participants mentioned that they used the Curious Researcher (Ballenger, 2015) to help students with both the research and writing process. In this book, Ballenger covered many of the expectations for student practices that faculty members mentioned in the interviews. Regardless of the framework selected, faculty members should be sure to 
address and refer students to tools for information evaluation. With regard for recommendations for students, I recommend that students also find a framework that helps them evaluate information, especially information found online.

With regard to students questioning their beliefs, I think that this content item and this skill have the potential to be controversial, as either students or faculty members could see this as referring to traditional or religious beliefs. However, beliefs encompass a much wider field than just tradition or religion, and faculty members in their instruction can focus on less controversial areas of belief. For example, the belief that eggs are bad for your health can be examined with scientific studies, to evaluate whether or not there is evidence to support such a belief. In addition, faculty members may want to mention the phenomenon of confirmation bias, along with a demonstration of how it works, so that students can keep this phenomenon in mind when they are searching for information in their own research.

Use recommendations. As many instructors might agree, and as I found in my own teaching experience, plagiarism and the ethical use of sources continues to be a concern with a small number of students. Yet, even one instance of plagiarism in a class can take up a great a deal of time and energy for the instructor. Based on the finding that plagiarism may still be an issue with some students, I recommend that faculty members train students on this issue at the beginning of the term. One of the faculty members I interviewed said that they focus on plagiarism at the beginning of the year, and ask students to take a test and to sign a document saying that students understand what plagiarism is, a practice that I recommend. For students, I suggest asking questions when 
there is any doubt about the ethical use of information or proper attribution. Some types of information are difficult to use and cite properly. Students should be aware that their questions about citation or related topics might lead to instruction that will benefit all students in their course.

Another of my recommendations responds to the gap between student practices and faculty expectation in the area of using facts and/or evidence to back up claims, and using scholarly, academic, or peer-reviewed sources. These two practices/expectations are closely related because facts and evidence in student academic work are often expected to be sourced primarily from scholarly, academic, or peer-reviewed sources. Although the majority of students reported doing both of these practices, a considerable number of students did not. Faculty members should be aware that students in their courses may have different skill levels in the area of using facts and/or evidence and using credible sources, and should not assume that all students in a class are at the same level. Instead, if levels in a class seem to be disparate, faculty members may want to consider assignments to scaffold these skills—offering a more basic option for students who are at the beginning level, and having a more challenging option for students who are further along in their skills.

Basic skills recommendations. Because students and faculty members were closely aligned in their practices and expectations in this area, I do not offer any major recommendations regarding basic skills, except to suggest that faculty members continue their current instruction. Regardless, my survey data showed a small number of students who are not assessing their basic skills at a level that aligns with faculty member 
expectations. These students-and perhaps the entire class-may benefit from knowing exactly what faculty members expect in the area of basic skills. Therefore, I recommend that faculty members state their expectations for students clearly.

Attitude recommendations. Attitudes may be a difficult area of expectations for students, as they may not be overtly displayed or discussed. In this area, my only recommendation is for faculty members to be more transparent about their expectations. For example, they may want to tell students casually, "In order to be successful in this class, and throughout your university experience, you should consider whether you are displaying these attitudes." Ultimately, attitudes may be developed over the course of an entire university career, but it may be helpful for students to know faculty expectations from the beginning of their university experience.

Home language recommendations. Overall, the findings in reported differences based on home language indicate that students speaking a language other than English at home assess their display of basic skills at a lower level than students who speak English at home. This finding may not be surprising, as some students who speak another language at home may be less fluent in English, and therefore may be more challenged when attending university courses conducted in English. Faculty members may want to offer all students additional resources to support development of basic skills, such as links to grammar or research tutorials.

The finding that more students speaking a home language other than English agreed to using Wikipedia as a scholarly or academic source is concerning, although still less than one in five students agreed to this statement. However, this finding may 
demonstrate that the message that Wikipedia is not a scholarly or academic source is being communicated by instructors, academic professionals, and other students, and that the message is reaching the majority of students. My recommendation for faculty members is to continue educating all of their students about the appropriate use of Wikipedia, and perhaps to assess students' understanding of this topic to make sure that all students understand.

Finally, regarding students questioning their beliefs when they find new information that contradicts those beliefs, the finding that fewer students who speak a language other than English at home agree to this practice does not change my general recommendations for this skill that I described in a previous section. Again, faculty members should instruct students about the confirmation bias, and should provide noncontroversial examples of changing beliefs based on new information.

Demographic differences recommendations. Although the differences in content item responses based on demographics of home language and first generation status may have some possible meanings, there is far too little data to have much of a story. To understand the experiences of students with a home language other than English, or of first generation students, one good option would be to follow up on the surveys with a qualitative method, such as interviews or focus groups, and to ask these students about their experiences regarding the content items in which there was a statistically significant difference based on demographics. Students might be able to explain, for example, what motivated them to seek assistance, or not to seek assistance, from university librarians. It would be interesting to ask all students about their 
experiences when it came to questioning their beliefs when they found information that contradicted those beliefs. Such a topic could be the focus of a qualitative research project, or of a QUAN $\rightarrow$ QUAL research project, in which students take a survey, followed by interviews to understand the depth of students' experience.

\section{Overall Recommendations for Practice}

In addition to recommendations based on specific content items, I also have two overall recommendations, taking all of my study data into account. I recommend that faculty members and students collaborate with librarians, and I recommend greater transparency in expectations on the part of faculty members.

Library collaboration. All of the interviewed faculty members worked with the library in one way or another, whether it was asking students to go to the library, or having a librarian work with their class. For faculty members, I recommend scheduling some class time in which a librarian can work with students. At the university where I conducted this study, librarians will design presentations and activities that cater specifically to the topics addressed by the course, and to any assignments involving research. If this type of a session is a possibility at their university, I recommend that faculty members take advantage of librarians' time and expertise. Librarians can help students with a wide range of information literacy practices, and can instruct a wide range of skill levels.

Transparency. Four faculty members that I interviewed described the ways in which they were transparent with their students by specifically stating their expectations regarding academic research and writing (fields that overlap significantly with 
information literacy.) I recommend that all faculty members follow this practice of transparency, specifically letting students know about their expectations. On students' side, I recommend that students ask their instructors to state their expectations regarding research and writing. I also suggest that students be transparent about their current information literacy practices, so that faculty members know how students are dealing with information, and how their current practices can be enhanced or can be used as examples for other students or faculty members.

Regarding differences in responses based on home language and first generation status, faculty members need to be aware of students in their classes who speak a language other than English at home (which may not be at all apparent from the student's appearance or way of speaking) and students who are the first in their families seeking a four-year degree. However, identification of these students does not need to entail singling students out, or giving them different instruction or assignments. Knowing that students from these demographic groups are enrolled in their courses, faculty members can be transparent about expectations and provide information literacy resources to the entire class, as all students may benefit from these practices.

In the first chapter of this study, I discussed hidden curriculum or "the unwritten and unspoken rules of how to successfully navigate through the nebulous academic culture of higher education, which is essential for academic success" (Smith, 2004, p. 48). This study did not examine which faculty expectations might be a part of hidden curriculum. However, with the finding that there is a gap between faculty expectations and student practices, one possible factor for this gap is that some faculty expectations 
are hidden curriculum, of which only some students are aware. One recommended approach to remedy the problem of hidden curriculum surrounding information literacy is for faculty members to be open and explicit with students about their expectations surrounding research and writing. Several of the faculty members who I interviewed explained how they followed this practice. Another recommendation was also illustrated by several faculty member interview participants, who advocated scaffolding, or providing steps for students for searching for information, evaluating the information they found, and for using the information properly in their class assignments. I suggest that the scaffolding approach has merits, though I have no way of knowing if the approach is typical of faculty members. An inquiry into when and how faculty members scaffold skills related to information literacy was outside of the scope of my study, but I would recommend it be explored in future research.

Regarding the differences in responses for students who spoke a language other than English at home and first generation students, hidden curriculum may certainly be a concern. In both of these demographic groups, students' backgrounds may not have prepared them to know the hidden curriculum of expectations for information literacy (as well as for related expectations regarding research and writing). Although my study did not have a large enough group of participants to be able to find significant differences between specific demographic groups, other demographic groups may face challenges with hidden curriculum as well. Additional research with a larger group of student participants would be helpful in determining whether this is an issue. 
Future research should also include case studies of students and faculty members, because it is difficult to capture what students and faculty members are doing in just surveys, just interviews, or even in a study such as mine that combined these two methods. I recommend a full case study of a course, and perhaps even of a couple of students within that course. Such a study could include observations of one faculty member's interactions with students and explanations of information literacy expectations, an analysis of written materials provided by the faculty member, and observations of students as they completed the class activities both inside and outside of the classroom. Although it would be a great deal of work for the researcher and the participants, such a study would provide a much fuller look at information literacy expectations and practices, and the resulting data could potentially be developed into a more comprehensive quantitative survey.

\section{Conclusion}

Despite the need to reinforce my study with additional research, my findings may be a starting place for faculty members to think about their expectations and how those expectations are expressed to students. Are the expectations clear and expressed in a way that students can understand? Are the expectations both written and expressed orally? Is there an opportunity for students to ask questions or get more details? For students, my study is a call to find out about faculty member expectations, and if possible to ask faculty members for specific details. For both students and faculty members, my study highlights the importance of working with librarians, in whose field information literacy 
falls, and who may be able to assist both students and faculty members with developing greater information literacy.

Additional stakeholders may find this study useful as well. As a graduate student who works with students developing information literacy skills, I can follow the recommendations for faculty members (e.g., giving students information on plagiarism, or scheduling a session with a librarian). Other professionals, such as tutors or academic support staff, can recommend that students find out more from their instructors regarding expectations. Even if students do not want to, or are not able to get more information about expectations from their professors, they can still use the expectations in my study, along with the percentages of faculty members who agreed with them, to get a general idea of what some faculty members expect from their freshman students.

In the larger picture, correcting to some extent the misalignment between student practices and faculty member expectations regarding information literacy can have positive benefits for both students and faculty members, and in particular, students who know the least about the hidden curriculum of higher education may benefit the most. My study indicated that students who spoke a home language other than English and first generation students might have the most misalignment with faculty members when it comes to practices and expectations. Therefore, more transparency about expectations, and more collaboration with the library may support these demographic groups.

Along with the literature that I reviewed in the second chapter, my findings add credence to the idea that there may be a misalignment between student practices and faculty expectations when it comes to information literacy. However, I cannot emphasize 
enough how more research is needed to further examine this possible misalignment. I strongly encourage other researchers to investigate my topic further, and add to the body of literature regarding student practices and faculty expectations in information literacy. 
INFORMATION LITERACY

\section{References}

American Library Association (ALA). (1989). Presidential committee on information literacy: Final report. Retrieved from http://www.ala.org/acrl/publications/whitepapers/presidential

Asher, A. D. \& Duke, L. M. (2010, February). Information literacy and first year students: Evaluating knowledge, needs, and instruction. Paper presented at the National Resource Center Annual Conference on the First-Year Experience, Denver, CO.

Association of College \& Research Libraries (ACRL). (2000). Information literacy competency standards for higher education. Retrieved from http://www.ala.org/acrl/standards/informationliteracycompetency

Avdic, A. \& Eklund, A. (2010). Searching reference databases: What students experience and what teachers believe that students experience. Journal of Librarianship \& Information Science, 42(4), 224-235.

Ballenger, B. (2015). The curious researcher: A guide to writing research papers (8th ed.). Boston, MA: Pearson.

Barrett, R. A. (1984). Culture and conduct: An excursion in anthropology. Belmont, CA: Wadsworth.

Blakeslee, S. (2004). The CRAAP test. LOEX Quarterly, 31(3), 4.

Bowles-Terry, M. (2012). Library instruction and academic success: A mixed-methods assessment of a library instruction program. Evidence Based Library \& Information Practice, 7(1), 82-95. 
Breivik, P. S. \& Gee, E. G. (1989). Information literacy: Revolution in the library. New York, NY: Macmillan.

Britz, J. J. (2004). To know or not to know: A moral reflection on information poverty. Journal of Information Science, 30(3), 192-204.

Bruce, C. S. (2004). Information literacy as a catalyst for educational change. A background paper. In P. A. Danaher (Ed.) Proceedings of Lifelong Learning: Whose responsibility and what is your contribution?, the $3^{\text {rd }}$ International Lifelong Learning Conference. (pp. 8-19). Yeppoon: Queensland. Retrieved from http://eprints.qut.edu.au/4977/

Cameron, L., Wise, S. L., \& Lottridge, S. M. (2007). The development and validation of the information literacy test. College \& Research Libraries, 68(3), 229-237.

Casad, B. J. (2007). Confirmation bias. In R.F. Baumeister \& K. D. Vohs (Eds.). Encyclopedia of social psychology. Thousand Oaks, CA: Sage.

Creswell, J. W. (2014). Research design: Qualitative, quantitative, and mixed-method approaches $\left(4^{\text {th }}\right.$ ed.). Thousand Oaks, CA: Sage.

Deitering, A., \& Jameson, S. (2008). Step by step through the scholarly conversation: A collaborative library/writing faculty project to embed information literacy and promote critical thinking in first year composition at Oregon State University. College \& Undergraduate Libraries, 15(1-2), 57-79.

DeMars, C., Cameron, L., \& Erwin, T. D. (2003). Information literacy as foundational: Determining competence. The Journal of General Education, 52(4), 253-265. 
INFORMATION LITERACY

Donham, J. (2014). College ready: What can we learn from first-year college assignments? An examination of assignments in Iowa colleges and universities. School Library Research, 17, 1-21.

Dubicki, E. (2013). Faculty perceptions of students' information literacy skills competencies. Journal of Information Literacy, 7(2), 97-125.

Encyclopedia Britannica. (2015). University. Retrieved from http://www.britannica.com/EBchecked/topic/618194/university

Field, A. (2013). Discovering statistics using IBM SPSS Statistics (4 ${ }^{\text {th }}$ ed.). Los Angeles, CA: Sage.

Ganley, B., Gilbert, A. \& Rosario, D. (2013). Faculty and student perceptions and behaviours related to information literacy: A pilot study using triangulation. Journal of Information Literacy, 7(2), 80-96.

Gross, M. \& Latham, D. (2012). What's skill got to do with it? Information literacy skills and self-views of ability among first-year college students. Journal of the American Society for Information Science \& Technology, 63(3), 574-583.

Head, A. J. (2008). Information literacy from the trenches: How do humanities and social science majors conduct academic research? College \& Research Libraries, 69(5), 427-446.

Hillard, V. E. (2009). Information literacy as situated literacy. In K. A. Johnson \& S. R. Harris (Eds.), Teaching literary research: Challenges in a changing environment (pp. 11-21). Chicago, IL: Association of College \& Research Libraries. 
Ishitani, T. (2006). Studying attrition and degree completion behavior among firstgeneration college students in the United States. The Journal of Higher Education, 77(5), 861-885.

Karp, M. M., \& Bork, R. H. (2014). "They never told me what to expect, so I didn't know what to do": Defining and clarifying the role of a community college student. Teachers College Record, 116(5), 1-40.

Kvale, S. (2007). Doing interviews. Los Angeles, CA: Sage.

Lammers, H. B., Kiesler, T., Curren, M. T., Cours, D., \& Connett, B. (2005). How hard do I have to work? Student and faculty expectations regarding university work. Journal of Education for Business, 80(4), 210-213.

Leckie, G. J. (1996). Desperately seeking citations: Uncovering faculty assumptions about the undergraduate research process. Journal of Academic Librarianship, $22(3), 201-208$.

Limberg, L., Sundin, O., \& Talja, S. (2013). Three theoretical perspectives on information literacy. Human IT: Journal for Information Technology Studies as a Human Science, 11(2), 93-130.

Litwin, M. S. (1995) How to measure survey reliability and validity. Thousand Oaks, CA: Sage.

Maughan, P. D. (2001). Assessing information literacy among undergraduates: A discussion of the literature and the University of California-Berkeley assessment experience. College \& Research Libraries, 62(1), 71-85. 
McDonough, B. A. (2014). Critical information literacy in practice: An interpretive synthesis. (Doctoral dissertation). Retrieved from ProQuest Dissertations \& Theses Full Text. (3619056).

McGuiness, C. (2006). What faculty think-exploring the barriers to information literacy development in undergraduate education. The Journal of Academic Librarianship, $32(6), 573-582$.

Morgan, D. L. (2007). Paradigms lost and pragmatism regained: Methodological implications of combining qualitative and quantitative methods. Journal of Mixed Methods Research, 1(1), 48-76.

Rea, L. M., \& Parker, R. A. (2014). Designing and conducting survey research: A comprehensive guide (4th ed.). Hoboken, NJ: Wiley.

Samson, S. (2010). Information literacy learning outcomes and student success. Journal of Academic Librarianship, 36(3), 202-210.

Schilling, K. M., \& Schilling, K. L. (1999). Increasing expectation for student effort. About Campus, 4(2), 4-10.

Smith, B. (2004). Leave no college student behind. Multicultural Education, 11(3), 4849.

Smith, J. K. (2013). Secondary teachers and information literacy (IL): Teacher understanding and perceptions of IL in the classroom. Library \& Information Science Research, 35(3), 216-222.

Smith, J. K., Given, L. M., Julien, H. Ouellette, D., \& DeLong, K. (2013). Information literacy proficiency: Assessing the gap in high school students' readiness for 
INFORMATION LITERACY

undergraduate academic work. Library \& Information Science Research, 35(2), 88-96.

Smith, M. D., \& Dailey, A. B. (2013). Improving and assessing information literacy skills through faculty-librarian collaboration. College \& Undergraduate Libraries, 20(3-4), 314-326.

Townsend, L., Brunetti, K., \& Hofer, A. R. (2011). Threshold concepts and information literacy. Portal: Libraries and the Academy, 11(3), 853-869.

Vogt, W. P., Gardner, D. C., \& Haeffele, L. M. (2012). When to use what research design. New York, NY: Guilford Press.

Vygotsky, L. S. (1978). Mind in society: The development of higher psychological processes. Cambridge, MA: Harvard University Press.

Wass, R. \& Golding, C. (2014). Sharpening a tool for teaching: The zone of proximal development. Teaching in Higher Education, 19(6), 671-684.

Weiner, S. A. (2014). Who teaches information literacy competencies? Report of a study of faculty. College Teaching, 62(1), 5-12.

Wise, S. L., Cameron, L., Yang, S., Davis, S. L., \& Russell, J. (2009). The Information Literacy Test (ILT): Test manual. Harrisonburg, VA: Center for Assessment and Research Studies, James Madison University.

Wong, S. H. R., \& Cmor, D. (2011). Measuring association between library instruction and graduation GPA. College \& Research Libraries, 72(5), 464-473. 
Zurkowski, P. G. (1974). The information service environment relationships and priorities. Related paper no. 5. Washington, DC: National Commission on Libraries and Information Science. 


\section{Appendix A}

\section{Interview Protocol: Students}

Research question: What information literacy practices do freshman students use?

Protocol: Thank participant for coming, short introduction of interviewer. Advise participant of recording of session and of expected session length. Short introduction of study and its purpose.

Questions for participants:

1. Describe your process of writing a research paper. What is the first step? Second step? Etc.

2. Where do you usually find information on a topic?

3. If you have an unusual topic, how do you find information on it?

4. How do you know if the information you find is believable?

5. When you are using outside information for your paper, do you give credit to the author? How?

6. What else is important for me to know about how you find, evaluate, and use information?

7. Are you familiar with the term information literacy?

8. Read ALA definition

9. What information literacy practices do you need to use to be successful in your classes? 


\section{Appendix B}

\section{Interview Protocol: Faculty Members}

Research Question: What information literacy practices do faculty members expect freshman students to use?

Protocol: Thank participant for coming, short introduction of interviewer. Advise participant of recording of session and of expected session length. Short introduction of study and its purpose.

Questions for participants:

1. Are you familiar with the term information literacy?

2. Read ALA definition

3. What information literacy abilities do you think students need to have in order to be successful in your class? Do you expect students to arrive in your classes with some information literacy abilities? Which abilities?

4. Walk me through the process you expect students to follow when writing a paper. What is the first step or steps that they should take? What is the second? Etc.

5. Where do you expect students to find information to use in their assignments and papers?

6. What is important to know about how your students find, evaluate, and use information? 


\section{Appendix C}

\section{Student Survey Instrument}

Part I: Content Items

Please indicate how strongly you agree or disagree with the following statements about your academic practices [options: strongly disagree, disagree, somewhat disagree, somewhat agree, agree, strongly agree].

1. I go to the [the university] library building to do research.

2. I can locate physical books in the library building.

3. I can locate hard-copy journals in the library building.

4. I ask librarians at [the university library] for assistance (in person or via chat, email, text, or phone).

5. I use the [university] library website to do research.

6. I can locate electronic books through the [university] library website.

7. I can locate journal articles through the [university] library website.

8. I can find credible sources for my papers.

9. I find sources for my class assignments and papers on websites that end with .com or .org.

10. I use Wikipedia as a scholarly or academic source.

11. I use Google Scholar to find scholarly or academic sources.

12. I find scholarly, academic, and/or peer-reviewed sources for my class assignments and papers.

13. When I have a research question, I can recognize the relevant journals, books, and databases to answer the question.

14. When I conduct web or database searches, I generally look at just the first page of results.

15. When searching in an online database or search engine, I can use the appropriate keywords for my topic.

16. I can identify a credible source.

17. I question what I read on the Internet.

18. I question my beliefs when I find new information that contradicts those beliefs.

19 . When reading articles, books, or other sources, I think critically about the information I read.

20. I take the context of a source into account when determining its credibility and appropriateness.

21 . I can tell the difference between popular and academic sources.

22. I can identify a primary and a secondary source.

23. In my class assignments or papers, I use facts and/or evidence to back up my claims.

24. I use scholarly, academic, and/or peer-reviewed sources for my class assignments or papers.

25. When I write a paper, I enter into a conversation with experts in the field of my topic.

26. When I'm going to write a paper, I can pick a topic that I'm interested in. 
27. When I use other people's work in my class assignments or papers, I give credit to the authors.

28. I use APA citation style in my class assignments or papers.

29. I use MLA citation style in my class assignments or papers.

30. I use a citation style other than APA or MLA in my class assignments or papers.

31. I use a reference management tool (such as Zotero or EndNote).

32. When working on class assignments or papers, I do not plagiarize or use sources unethically.

33. In my research and class work, I use the language of my field (e.g., history).

34. I can write an annotated bibliography.

35. I can write a thesis statement.

36. I display basic writing skills.

37. I display basic comprehension skills.

38. I display basic search skills.

39. I display persistence.

40. I display curiosity.

41. I display motivation.

42. I get out of my comfort zone.

Short Answer:

43. Do you have any additional comments about your academic practices?

Part II: Demographic Items

Please answer the following questions about your background.

44. How old are you?

45. What is your gender?

46. Does your family use a language other than English at home?

a) Yes (please specify)

b) No

47. Are you an international student?

48. What is your racial/ethnic background?

a) Asian/Pacific Islander

b) Black/African American

c) Hispanic/Latino

d) Native American/American Indian

e) White/Caucasian

f) Multiple Ethnicities

g) Other (please specify)

49. Which of the following best describes your current primary residence?

a) In open country (not on a farm)

b) On a farm

c) In a small town (under 50,000)

d) In a medium-sized city or town $(50,000-250,000)$ 
e) In a suburb near a large city

f) In a large city (over 250,000)

g) Other (please specify)

50. Which of the following best describes your primary residence (the place where you spent the longest amount of time) when you were under 18 ?

a) In open country (not on a farm)

b) On a farm

c) In a small town (under 50,000)

d) In a medium-sized city or town $(50,000-250,000)$

e) In a suburb near a large city

f) In a large city (over 250,000)

g) Other (please specify)

51. What was your total household income before taxes in the last 12 months?

a) Less than $\$ 25,000$

b) $\$ 25,000-49,999$

c) $\$ 50,000-74,999$

d) $\$ 75,000-99,999$

e) $\$ 100,000-149,999$

f) $\$ 150,000$ or more

52. What is the highest level of education achieved by your mother (or primary female guardian)?
a) Did not graduate from high school
b) High school graduate or GED
c) Some college (including 2 year degree)
d) Bachelor's degree (B.A., B.S., etc.)
e) Master's degree (M.A., M.S., etc.)
f) Doctorate or professional degree $(\mathrm{PhD}, \mathrm{MD}$, etc.)

53. What is the highest level of education achieved by your father (or primary female guardian)?
a) Did not graduate from high school
b) High school graduate or GED
c) Some college (including 2 year degree)
d) Bachelor's degree (B.A., B.S., etc.)
e) Master's degree (M.A., M.S., etc.)
f) Doctorate or professional degree (PhD, MD, etc.)

54. What is the highest level of education that you have completed?
a) Did not graduate from high school
b) High school graduate or GED
c) Some college (including 2 year degree)
d) Bachelor's degree (B.A., B.S., etc.)
e) Master's degree (M.A., M.S., etc.)
f) Doctorate or professional degree $(\mathrm{PhD}, \mathrm{MD}$, etc.)

55. What is your current class standing at PSU?

a) Freshman (1-44 credits) 
b) Sophomore (45-89 credits)

c) Junior (90-134 credits)

d) Senior (135 or more credits)

e) Post-baccalaureate (hold a degree) 


\section{Appendix D}

\section{Faculty Survey Instrument}

Part I: Content Items

Please indicate how strongly you agree or disagree with the following statements about your expectations.

For the purposes of this survey, use this definition of expectations: what you think your students should know, or be able to do, by their second quarter as a full-time student at your institution, based on faculty instruction, [teaching assistant] instruction, and their previous educational experience.

[options: strongly disagree, disagree, somewhat disagree, somewhat agree, agree, strongly agree].

1. I expect my students to go to the [university] library building to do research.

2. I expect my students to be able to locate physical books in the library building.

3. I expect my students to be able to locate hard-copy journals in the library building.

4. I expect my students to ask librarians at [the university library] for assistance (in person or via chat, email, text, or phone.)

5. I expect my students to use the [university] library website to do research.

6. I expect my students to be able to locate electronic books through the [university] library website.

7. I expect my students to be able to locate journal articles through the [university] library website.

8. I expect my students to be able to find credible sources for their papers.

9. I expect my students to NOT find sources for their class assignments and papers on websites that end with .com or .org.

10. I expect my students to NOT use Wikipedia as a scholarly or academic source.

11. I expect my students to use Google Scholar to find scholarly or academic sources.

12. I expect my students to find scholarly, academic, and/or peer-reviewed sources for their class assignments and papers.

13. I expect my students to recognize the relevant journals, books, and database to answer a research question.

14. I expect my students to go beyond the first page of web or database search results. 15. When searching in an online database or search engine, I expect my students to be able to use the appropriate keywords for their topic.

16. I expect my students to be able to identify a credible source.

17. I expect my students to question what they read on the Internet.

18. I expect my students to question their beliefs when they find new information that contradicts those beliefs.

19. I expect my students to think critically about information that they read in books, articles, or other sources. 
20. I expect my students to take the context of a source into account when determining its credibility and appropriateness.

21. I expect my students to be able to tell the difference between popular and academic sources.

22. I expect my students to be able to identify a primary source and a secondary source.

23. I expect my students to use facts and/or evidence to back up claims that they make in their class assignments or papers.

24. I expect my students to use scholarly, academic, and/or peer-reviewed sources for their class assignments or papers.

25 . When they write a paper, I expect my students to enter into a conversation with experts in their field.

26. I expect my students to pick topics that they are interested in for their papers.

27. I expect my students to give credit to authors when they use their work.

28. I expect my students to use APA citation style in their class assignments or papers.

29. I expect my students to use MLA citation style in their class assignments or papers.

30. I expect my students to use a citation style other than APA or MLA in their class assignments or papers.

31. I expect my students to use a reference management tool (such as Zotero or EndNote.)

32. I expect my students to NOT plagiarize or use sources unethically.

33. I expect my students to use the language of their field (e.g., history.)

34. I expect my students to be able to write an annotated bibliography.

35 . I expect my students to be able to write a thesis statement.

36. I expect my students to display basic writing skills.

37. I expect my students to display basic comprehension skills.

38. I expect my students to display basic search skills.

39. I expect my students to display persistence.

40. I expect my students to display curiosity.

41. I expect my students to display motivation.

42. I expect my students to get out of their comfort zones.

Short Answer:

43. Do you have anything else to add about your expectations for students?

Part II: Demographic Items

Please answer the following questions about your background.

44. How old are you?

45. What is your gender?

46. Does your family use a language other than English at home?

a) Yes (please specify)

b) No

47. What is your racial/ethnic background?

a) Asian/Pacific Islander 
b) Black/African American

c) Hispanic/Latino

d) Native American/American Indian

e) White/Caucasian

f) Multiple Ethnicities

g) Other (please specify)

48. Which of the following best describes your current primary residence?

a) In open country (not on a farm)

b) On a farm

c) In a small town (under 50,000)

d) In a medium-sized city or town (50,000-250,000)

e) In a suburb near a large city

f) In a large city (over 250,000)

g) Other (please specify)

49. Which of the following best describes your primary residence (the place where you spent the longest amount of time) when you were under 18 ?
a) In open country (not on a farm)
b) On a farm
c) In a small town (under 50,000)
d) In a medium-sized city or town (50,000-250,000)
e) In a suburb near a large city
f) In a large city (over 250,000)
g) Other (please specify)

50. What was your total household income before taxes in the last 12 months?
a) Less than $\$ 25,000$
b) $\$ 25,000-49,999$
c) $\$ 50,000-74,999$
d) $\$ 75,000-99,999$
e) $\$ 100,000-149,999$
f) $\$ 150,000$ or more

51. What is the highest level of education that you have completed?
a) Did not graduate from high school
b) High school graduate or GED
c) Some college (including 2 year degree)
d) Bachelor's degree (B.A., B.S., etc.)
e) Master's degree (M.A., M.S., etc.)
f) Doctorate or professional degree $(\mathrm{PhD}, \mathrm{MD}$, etc.)

52. What is your position at PSU?

a) Adjunct faculty member

b) Fixed-term faculty member

c) Tenure-track faculty member

d) Tenured faculty member (specify department)

53. How many courses are you teaching at PSU this term?

54. How many courses are you teaching at other institutions this term? 


\section{Appendix E}

\section{Student Percentage Agreement to Content Questions Including Somewhat Agree,}

\section{Agree, and Strongly Agree}

\section{Find}

Find credible sources for papers

Use the appropriate keywords for a topic when searching in an online database or search engine

Recognize the relevant journals, books, and databases to answer a research question

Find scholarly, academic, and/or peer-reviewed sources for class assignments and papers

Locate journal articles through the university library website

Locate physical books in the university library building

Use Google Scholar to find scholarly or academic sources

Locate electronic books through the university library website

Use the university library website to do research

Ask librarians at the university library for assistance

Go to the university library building to do research

Locate hard-copy journals in the university library building

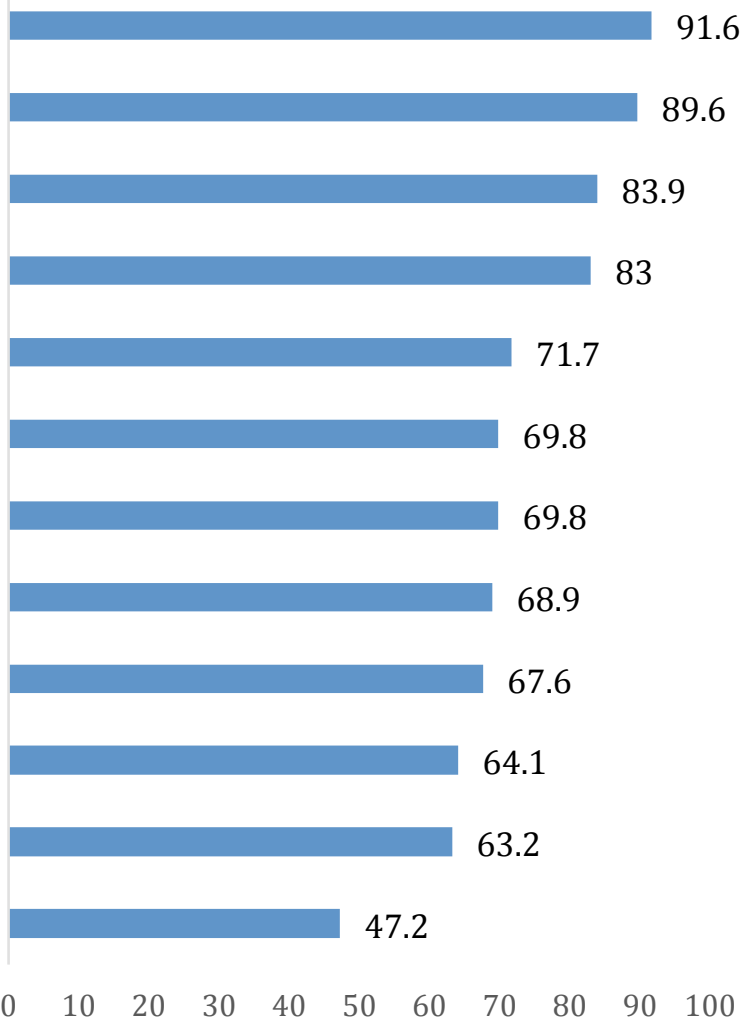

Figure 15. Percentage of students who agreed with statements about their academic practices regarding finding information (with level of agreement including somewhat agree, agree, and strongly agree). 


\section{Find reverse structure}

Find sources for class assignments and papers on websites that end with .com or .org When conducting web or database searches, just look at the first page of results

Use Wikipedia as a scholarly or academic source

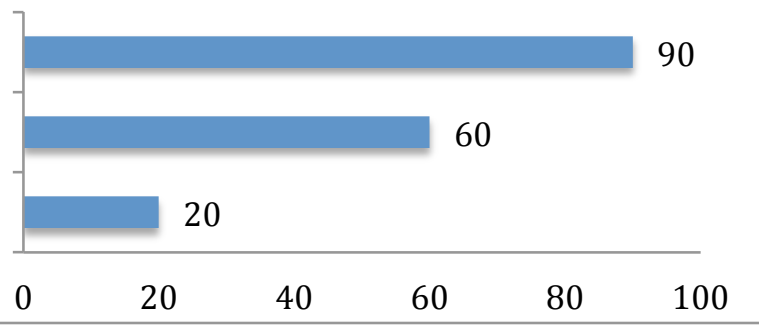

Figure 16. Percentage of students who agreed with statements about their academic practices regarding finding information (with level of agreement including somewhat agree, agree, and strongly agree).

\section{Evaluate}

Question what they (students) read on the

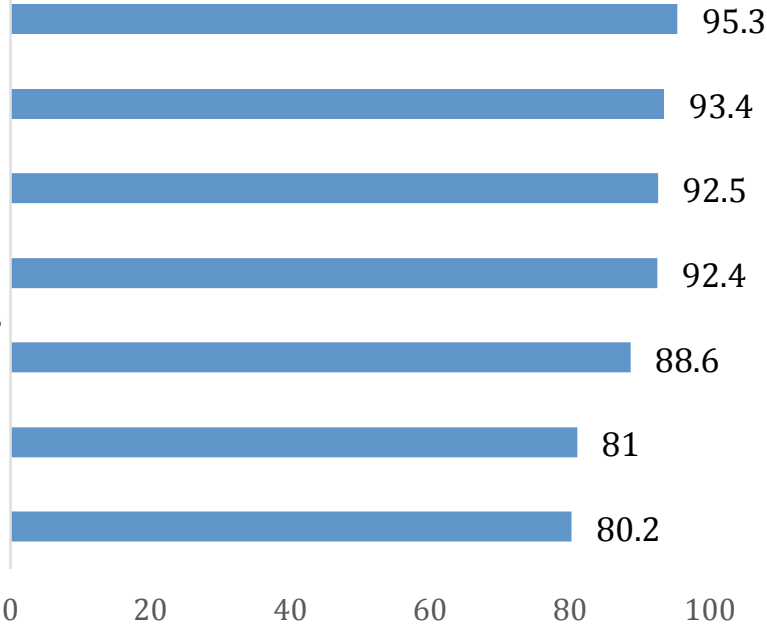

Internet

Be able to identify a credible source

Take the context of a source into account when determining its credibility and appropriateness Think critically about information that they (students) read in books, articles, or other sources Be able to tell the difference between popular and academic sources

Question their (students') beliefs when they find new information that contradicts those beliefs Be able to identify a primary source and a secondary source

$\begin{array}{llllll}0 & 20 & 40 & 60 & 80 & 100\end{array}$

Figure 17. Percentage of students who agreed with statements about their academic practices regarding evaluating information (with level of agreement including somewhat agree, agree, and strongly agree). 


\section{Use}

When working on class assignments or papers, NOT plagiarize or use sources unethically When using other people's work in class assignments or papers, give credit to the author.

Use facts and/or evidence to back up claims in class assignments or papers

In research and classwork, use the language of the student's field

Be able to write a thesis statement

Use scholarly, academic, and/or peer-reviewed sources for class assignments or papers

Pick topics that they (students) are interested in for their papers

Be able to write an annotated bibliography

When writing a paper, enter into a conversation with experts in the field of the topic

Use a reference management tool

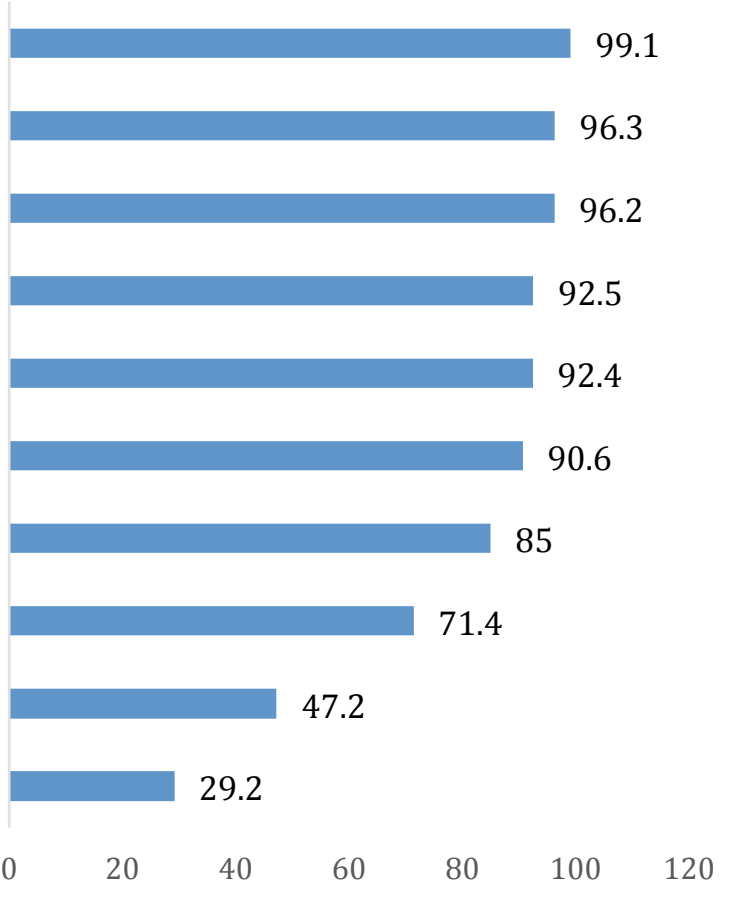

Figure 18. Percentage of students who agreed with statements about their academic practices regarding using information, followed by the mean response (with level of agreement including somewhat agree, agree, and strongly agree).

\section{Basic skills}

Display basic search skills

Display basic comprehension skills

Display basic writing skills

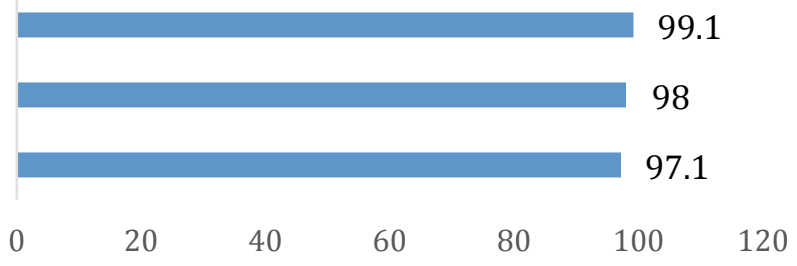

$\begin{array}{lllllll}0 & 20 & 40 & 60 & 80 & 100 & 120\end{array}$

Figure 19. Percentage of students who agreed with statements about their academic practices regarding basic skills (with level of agreement including somewhat agree, agree, and strongly agree). 


\section{Attitudes}

Display persistence

Display curiosity

Display motivation

Get out of comfort zone

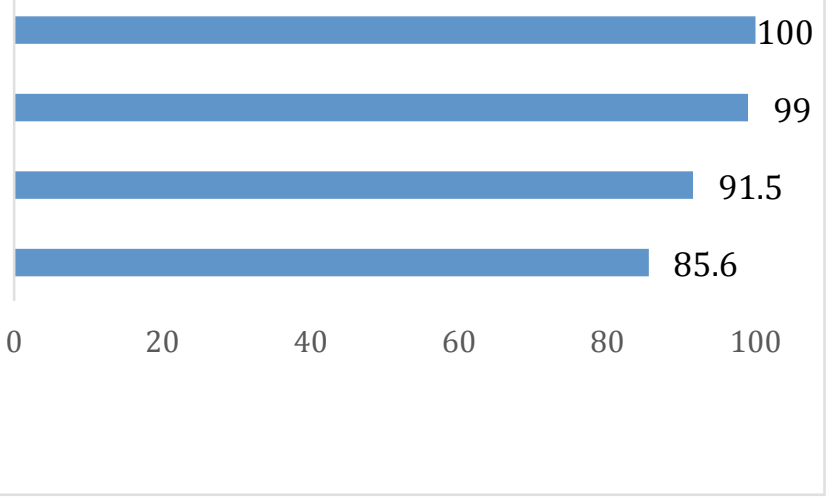

Figure 20. Percentage of students who agreed with statements about their academic practices regarding attitudes (with level of agreement including somewhat agree, agree, and strongly agree).

\section{Citation}

Use MLA citation style in class assignments or papers

Use APA citation style in class assignments or papers

Use a citation style other than APA or MLA

Use APA, MLA, or another citation style

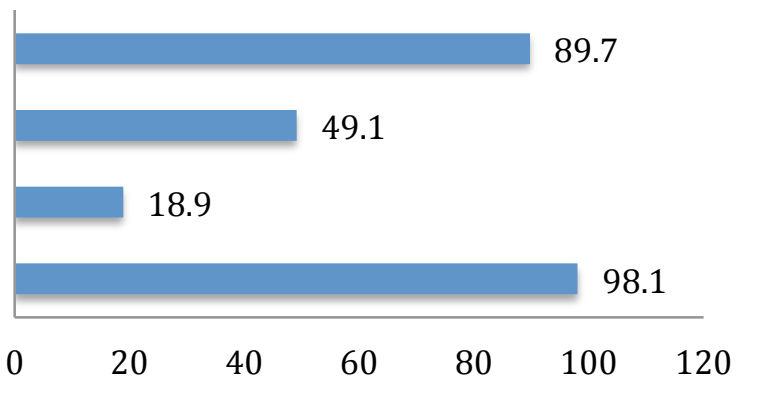

Figure 21. Percentage of students who agreed that they used APA, MLA, or another citation style, and percentage of students who agreed to any of these three content items (with level of agreement including somewhat agree, agree, and strongly agree). 


\section{Appendix F}

\section{Faculty Member Percentage Agreement to Content Questions Including Somewhat}

\section{Agree, Agree, and Strongly Agree}

\section{Find}

Find credible sources for papers

Locate journal articles through the university library website

Locate physical books in the university library building

Use the appropriate keywords for a topic when searching in an online database or search engine Ask librarians at the university library for assistance

Find scholarly, academic, and/or peer-reviewed sources for class assignments and papers Go to the university library building to do research

Use the university library website to do research

Recognize the relevant journals, books, and databases to answer a research question Locate electronic books through the university library website

Use Google Scholar to find scholarly or academic sources

Locate hard-copy journals in the university library building

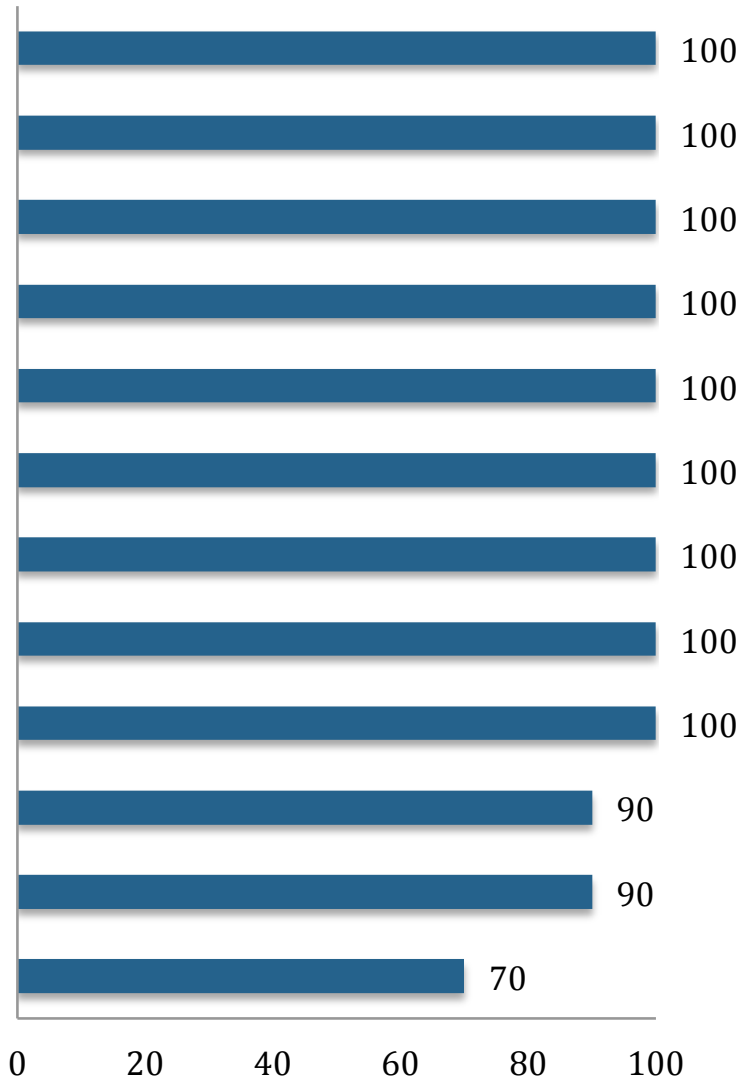

Figure 22. Percentage of faculty members who agreed with statements about their expectations for students regarding finding information (with levels of agreement including somewhat agree, agree, and strongly agree.) 


\section{Find reverse structure}

Go beyond the first page of web or database search results

NOT use Wikipedia as a scholarly or academic source

NOT find sources for class assignments and papers on websites that end with .com or .org

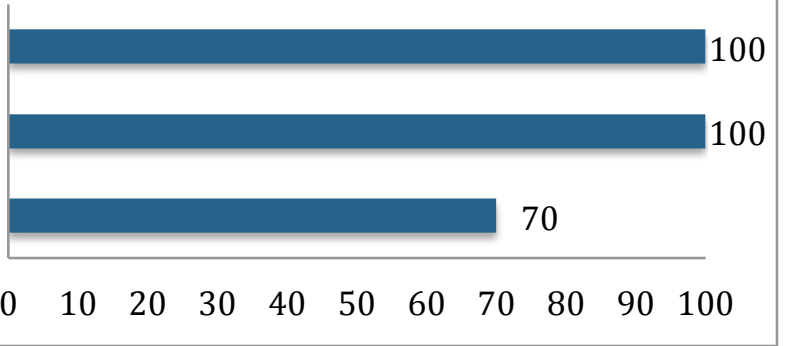

Figure 23. Percentage of faculty members who agreed with statements about their expectations for students regarding finding information (with levels of agreement including somewhat agree, agree, and strongly agree.)

\section{Evaluate}

Be able to identify a credible source

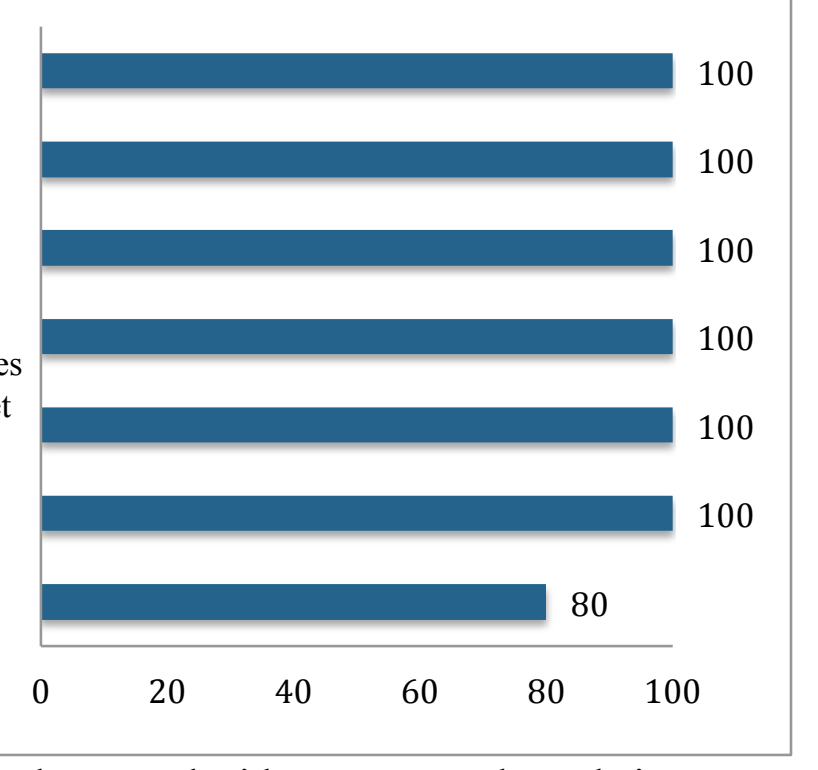

Be able to tell the difference between popular sources and academic sources

Take the context of a source into account when evaluating its credibility and appropriateness Think critically about information that they (students) read in books, articles, or other sources Question what they (students) read on the Internet

Question their (students') beliefs when they find new information that contradicts those beliefs Be able to identify a primary source and a secondary source

Figure 24. Percentage of faculty members who agreed with statements about their expectations for students regarding evaluating information (with levels of agreement including somewhat agree, agree, and strongly agree.) 


\section{Use}

Use facts and/or evidence to back up claims in class assignments or papers

When using other people's work in class assignments or papers, give credit to the author When working on class assignments or papers, NOT plagiarize or use sources unethically Pick topics that they (students) are interested in for their papers

Be able to write a thesis statement

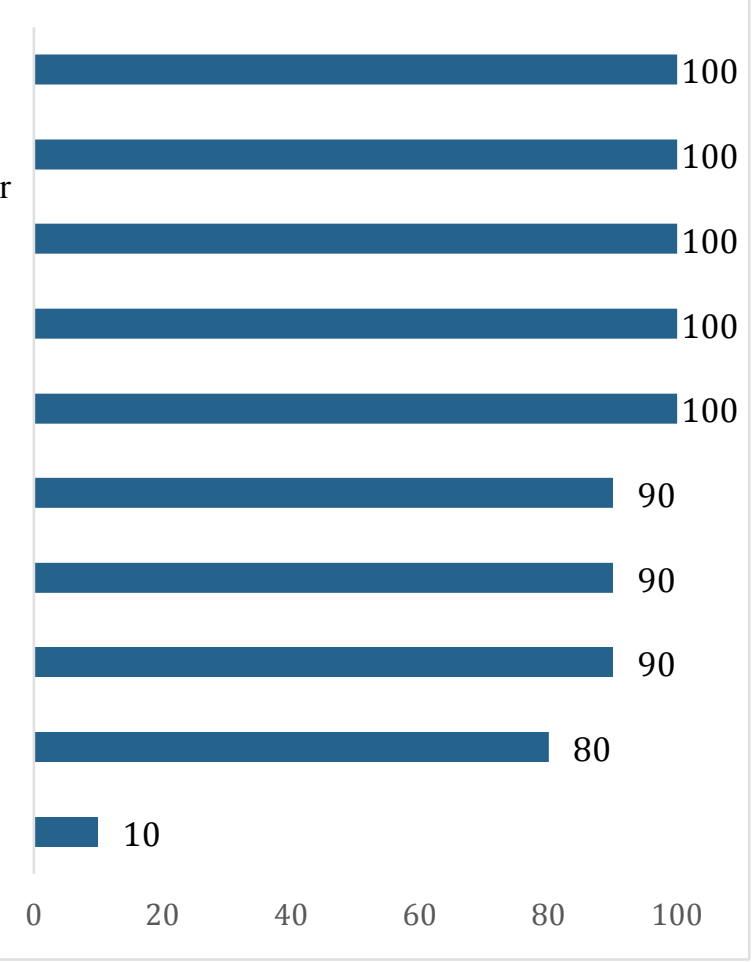

Use scholarly, academic, and/or peer-reviewed sources for class assignments or papers

Be able to write an annotated bibliography

In research and classwork, use the language of the student's field

When writing a paper, enter into a conversation with experts in the field of the topic

Use a reference management tool

Figure 25. Percentage of faculty members who agreed with statements about their expectations for students regarding using information (with levels of agreement including somewhat agree, agree, and strongly agree.)

\section{Basic skills}

Display basic writing skills

Display basic comprehension skills

Display basic search skills

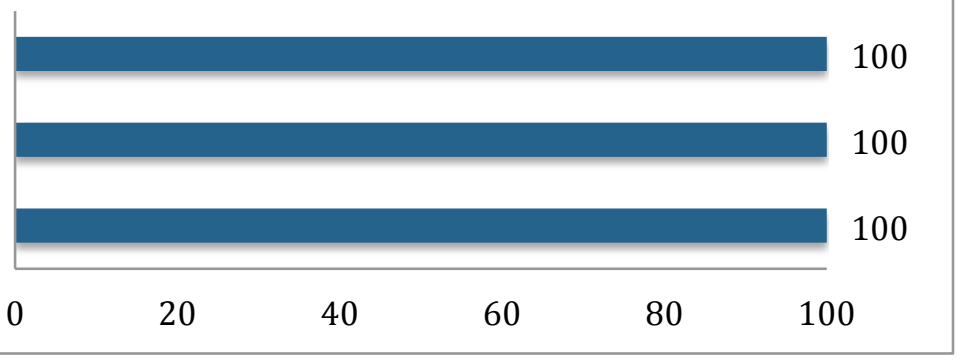

Figure 26. Percentage of faculty members who agreed with statements about their expectations for students regarding basic skills (with level of agreement including somewhat agree, agree, and strongly agree.) 


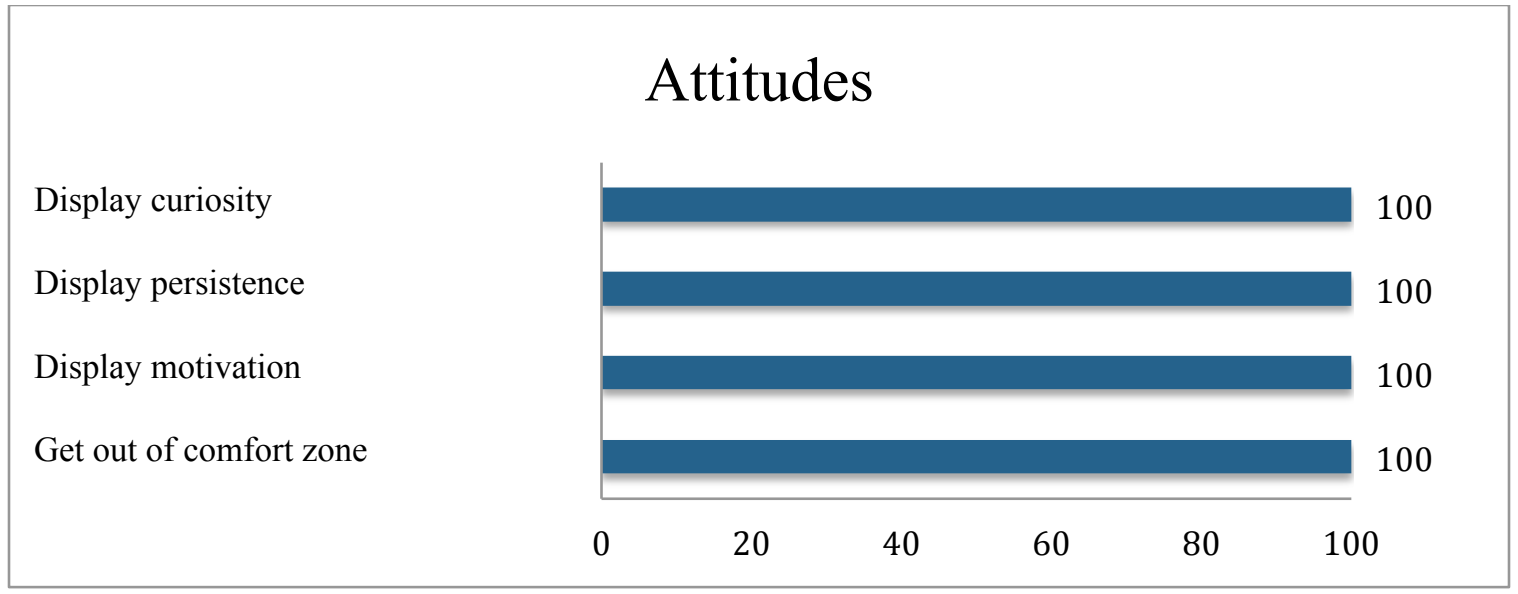

Figure 27. Percentage of faculty members who agreed with statements about their expectations for students regarding attitudes (with level of agreement including somewhat agree, agree, and strongly agree.)

\section{Citation}

Use MLA citation style in class assignments or papers

Use APA citation style in class assignments or papers

Use a citation style other than APA or MLA

Use APA, MLA, or another citation style

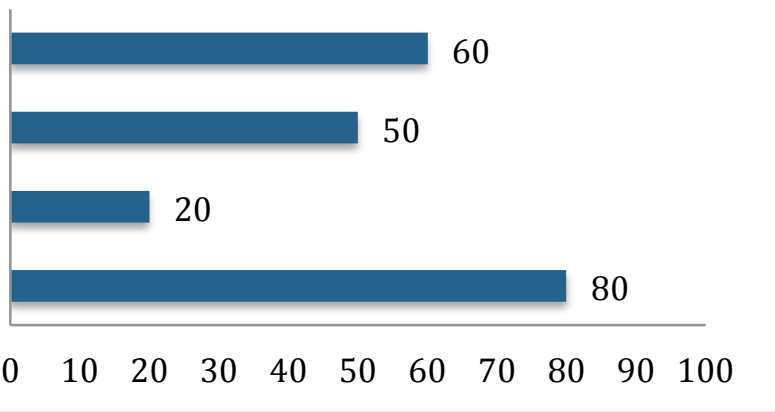

Figure 28. Percentage of faculty members who agreed that they expected their students to use APA, MLA, or another citation style, and percentage of faculty members who agreed to any one of these three content items (with level of agreement including somewhat agree, agree, and strongly agree.) 


\section{Appendix G}

\section{Comparisons of Student and Faculty Member Responses with Levels of Agreement Calculated with Somewhat Agree, Agree, and Strongly Agree}

Table 18

Percentage of Students Who Agreed Compared to Percentage of Faculty Members Who Agreed to Statements about Their Practices (Students) and Expectations (Faculty Members) Regarding Finding Information (Levels of Agreement Including Somewhat Agree, Agree, and Strongly Agree)

\begin{tabular}{llll}
\hline Survey Item (Student Practice/Faculty & Student & Faculty & $p$-value \\
Expectation) & Percent & Percent & (*indicates \\
& Agreement & Agreement & statistical \\
& & & significance \\
at the $>0.05$ \\
level).
\end{tabular}

Go to the university library building to

63.2

100

$.008^{*}$

do research

Locate physical books in the university

69.8

100

$.022 *$

library building

Locate hard-copy journals in the

47.2

70

.582

university library building

Ask librarians at the university library for assistance (in person or via chat,

64.1

100

$>.001^{*}$

email, text, or phone)

Use the university library website to do

67.6

100

$.037 *$

research

Locate electronic books through the

68.9

90

.288

university library website

71.7

100

.055

university library website

Find credible sources for papers

91.6

100

.295

NOT find sources for class assignments

15.1

70

$.002 *$

.com or .org** 
NOT use Wikipedia as a scholarly or academic source**

Use Google Scholar to find scholarly or academic sources

Find scholarly, academic, and/or peerreviewed sources for class assignments and papers

Recognize the relevant journals, books, and databases to answer a research question

Go beyond the first page of web or database results**

Use the appropriate keywords for a topic when searching in an online database or search engine $\begin{array}{lll}81.1 & 100 & .360\end{array}$

$69.8 \quad 90$

.354

$83 \quad 100$

100

100

$.001 *$

89.6

100

.718

Table 19

Percentage of Students Who Agreed Compared to Percentage of Faculty Members Who Agreed to Statements about Their Practices (Students) and Expectations (Faculty Members) Regarding Evaluating Information (Levels of Agreement Including Somewhat Agree, Agree, and Strongly Agree)

\begin{tabular}{|c|c|c|c|}
\hline $\begin{array}{l}\text { Survey Item (Student Practice/Faculty } \\
\text { Expectation) }\end{array}$ & $\begin{array}{l}\text { Student } \\
\text { Percent Agreement }\end{array}$ & $\begin{array}{l}\text { Faculty } \\
\text { Percent } \\
\text { Agreement }\end{array}$ & $\begin{array}{l}p \text {-value } \\
(* \text { indicates } \\
\text { statistical } \\
\text { significance } \\
\text { at the }<0.05 \\
\text { level })\end{array}$ \\
\hline Be able to identify a credible source & 93.4 & 100 & .395 \\
\hline $\begin{array}{l}\text { Question what they (students) read on } \\
\text { the Internet }\end{array}$ & 95.3 & 100 & $.033 *$ \\
\hline $\begin{array}{l}\text { Question their (students') beliefs when } \\
\text { they find new information that } \\
\text { contradicts those beliefs }\end{array}$ & 81 & 100 & .322 \\
\hline
\end{tabular}


Think critically about information that

92.4

100

$.031 *$

they (students) read in books, articles,

or other sources

Take the context of a source into

92.5

100

.134

account when determining its

credibility and appropriateness

Be able to tell the difference between

88.6

100

.170

popular and academic sources

80.2

80

.436

Be able to identify a primary source

and a secondary source

Table 20

Percentage of Students Who Agreed Compared to Percentage of Faculty Members Who Agreed to Statements about Their Practices (Students) and Expectations (Faculty Members) Regarding Using Information (Levels of Agreement Including Somewhat Agree, Agree, and Strongly Agree)

\begin{tabular}{llll}
\hline $\begin{array}{l}\text { Survey Item (Student Practice/Faculty } \\
\text { Expectation) }\end{array}$ & $\begin{array}{l}\text { Student } \\
\text { Percent Agreement }\end{array}$ & $\begin{array}{l}\text { Faculty } \\
\text { Percent } \\
\text { Agreement }\end{array}$ & $\begin{array}{l}p \text {-value } \\
(* \text { indicates } \\
\text { statistical } \\
\text { significance } \\
\text { at the }<0.05\end{array}$ \\
& & & level $)$
\end{tabular}

Use facts and/or evidence to back up

96.2

100

$.047^{*}$

claims in class assignments or papers

Use scholarly, academic, and/or peer- $\quad 90.6$

90

.335

reviewed sources for class

assignments or papers

When writing a paper, enter into a

80

$.018^{*}$

conversation with experts in the field

of the topic

Pick topics that they (students) are

When using other people's work in

96.3

100

class assignments or papers, give

credit to the author 
Use a reference management tool

.092

(such as Zotero or EndNote)

When working on class assignments

99.1

100

.066

or papers, NOT plagiarize or use

sources unethically

In research and classwork, use the

92.5

90

$.007^{*}$

language of the student's field

Be able to write an annotated

71.4

90

.201

bibliography

Be able to write a thesis statement

92.4

100

.467

Table 21

Percentage of Students Who Agreed Compared to Percentage of Faculty Members Who Agreed to Statements about Their Practices (Students) and Expectations (Faculty Members) Regarding Basic Skills (Levels of Agreement Including Somewhat Agree, Agree, and Strongly Agree)

\begin{tabular}{llll}
\hline $\begin{array}{l}\text { Survey Item (Student Practice/Faculty } \\
\text { Expectation) }\end{array}$ & $\begin{array}{l}\text { Student } \\
\text { Percent Agreement }\end{array}$ & $\begin{array}{l}\text { Faculty } \\
\text { Percent } \\
\text { Agreement }\end{array}$ & $p$-value \\
\hline Display basic writing skills & 97.1 & 100 & .621 \\
Display basic comprehension skills & 98 & 100 & .451 \\
Display basic search skills & 99.1 & 100 & .870
\end{tabular}

Table 22

Percentage of Students Who Agreed Compared to Percentage of Faculty Members Who Agreed to Statements about Their Practices (Students) and Expectations (Faculty Members) Regarding Attitudes (Levels of Agreement Including Somewhat Agree, Agree, and Strongly Agree)

\begin{tabular}{llll}
\hline Survey Item (Student Practice/Faculty & Student & Faculty & $p$-value \\
Expectation) & Agree, Strongly & Agree, & $($ indicates \\
& Agree & Strongly & statistical \\
\hline
\end{tabular}




\begin{tabular}{lccc}
\hline & Agree & $\begin{array}{l}\text { significance } \\
\text { at the }<0.05 \\
\text { level })\end{array}$ \\
\hline Display persistence & 100 & 100 & .124 \\
Display curiosity & 99 & 100 & .305 \\
Display motivation & 91.5 & 100 & .520 \\
Get out of comfort zone & 85.6 & 100 & $.012^{*}$ \\
\hline
\end{tabular}

Table 23

Percentage of Students Who Agreed Compared to Percentage of Faculty Members Who Agreed to Statements about Their Practices (Students) and Expectations (Faculty Members) Regarding Citation (Levels of Agreement Including Somewhat Agree, Agree, and Strongly Agree)

\begin{tabular}{llll}
\hline $\begin{array}{l}\text { Survey Item (Student Practice/Faculty } \\
\text { Expectation) }\end{array}$ & $\begin{array}{l}\text { Student } \\
\text { Percent Agreement }\end{array}$ & $\begin{array}{l}\text { Faculty } \\
\text { Percent } \\
\text { Agreement }\end{array}$ & $p$-value \\
\hline $\begin{array}{l}\text { Use APA citation style in class } \\
\text { assignments or papers }\end{array}$ & 49.1 & 50 & .157 \\
$\begin{array}{l}\text { Use MLA citation style in class } \\
\text { assignments or papers }\end{array}$ & 89.7 & 60 & .071 \\
$\begin{array}{l}\text { Use a citation style other than APA or } \\
\text { MLA in class assignments or papers }\end{array}$ & 18.9 & 20 & .515 \\
\hline
\end{tabular}

